\title{
Pyrolysis Gas Composition for a Phenolic Impregnated Carbon Ablator Heatshield
}

\author{
J. Rabinovitch, ${ }^{*}$ V. M. Marx,$^{\dagger}$ and G. Blanquart ${ }^{\ddagger}$ \\ California Institute of Technology, Pasadena, California, 91125, USA
}

\begin{abstract}
Published physical properties of phenolic impregnated carbon ablator (PICA) are compiled, and the composition of the pyrolysis gases that form at high temperatures internal to a heatshield is investigated. A link between the composition of the solid resin, and the composition of the pyrolysis gases created is provided. This link, combined with a detailed investigation into a reacting pyrolysis gas mixture, allows a consistent, and thorough description of many of the physical phenomena occurring in a PICA heatshield, and their implications, to be presented.
\end{abstract}

\section{Nomenclature}

EDL Entry, Descent, and Landing

F Formaldehyde

FIAT Fully Implicit Ablation and Thermal Response

$\lambda \quad$ Mean Free Path (m)

LCA Lightweight Ceramic Ablator

LMS Low Molecular Weight Substances

MEADS Mars Entry Atmospheric Data System

MISP MEDLI Integrated Sensor Plug

MSL Mars Science Laboratory

P Phenol

PAH Polycyclic-Aromatic Hydrocarbon

PICA Phenolic Impregnated Carbon Ablator

$\sigma \quad$ Collision Diameter (m)

VKI von Karman Institute for Fluid Dynamics

Ablative heatshields, like the one recently used on the successful Mars Science Laboratory (MSL) mission, are designed to dissipate the high heat fluxes experienced during atmospheric entry through material degradation. The heatshield is designed to undergo a phase change such that the thermal energy is dissipated by the ablation of specific components in the heatshield. This translates into a heatshield that is designed to recess upon entry into an atmosphere at hypervelocity speeds. A variety of lightweight ceramic ablators (LCAs) were invented at the NASA Ames Research Center in the 1990s specifically designed for this purpose. These materials are made of a carbon fiber pre-form impregnated with a phenolic resin. Some examples of these materials designed for high speed atmospheric entry include phenolic impregnated carbon ablator (PICA, developed at AMES in the 1990s and first used as the material for the Stardust forebody heat shield, launched in 1999) [1-3], ASTERM (a PICA like material under development by Astrium through ESA, starting in the early 2000s) [4,5], and PICA-X ${ }^{a}$ (a PICA like material developed by SpaceX in con-

\footnotetext{
*PhD Candidate, Graduate Aerospace Laboratories, 1200 E. California Blvd. MC 205-45, AIAA Student Member.

${ }^{\dagger}$ Postdoctoral Scholar, Division of Chemistry and Chemical Engineering, 1200 E. California Blvd. MC 164-30, AIAA NonMember.

$¥$ Assistant Professor, Mechanical Engineering, 1200 E. California Blvd. MC 104-44, AIAA Member.

aSpaceX Manufactured Heat Shield Material Passes High Temperature Tests Simulating, http://www.spacex.com/ press/2012/12/19/spacex-manufactured-heat-shield-material-passes-high-temperature-tests-simulating, accessed $02 / 03 / 2014$.
} 
junction with NASA). Sharpe and Wright [6] provide a review of materials used for applications in extreme environments from the 1960s until the present.

Being able to accurately characterize and model these materials in simulations is necessary to safely design a heatshield for a mission. Although this has been an active field of research since the 1960s [7-16], the state of the art modeling tools used for high-enthalpy aerothermodynamic predictions leave room for improvement. Prediction uncertainty is as high as $60 \%$ for laminar convective heating [17-20]. This in turn necessitates the heatshield to be over-designed and more massive than needed, which takes away mass that could be used towards other mission components, such as additional science payloads.

The goal of this paper is to perform a detailed investigation into the pyrolysis gases produced by a PICA heatshield. Improving our understanding of the pyrolysis gas composition and the evolution of the pyrolysis gases will aid in accurately modeling the performance of a PICA heatshield. The endothermic phase change from solid to gas is designed to dissipate the high heat loads; modeling this effect is critical. In the ablation community, there is currently a large disconnect between the physical properties of solid PICA, and the pyrolysis gases that are created when PICA starts to undergo a thermal decomposition. For example, there is little discussion in the published literature pertaining to the choice of elemental composition for the pyrolysis gas mixture in numerical simulations, and why the elemental composition of the pyrolysis gas mixture is assumed to be constant $[1,21-25]$. This is in direct contrast to experimental data that shows that the elemental composition of the pyrolysis gas mixture varies with temperature $[16,26]$. It should be noted that much of the numerical work performed by NASA (for example, see $[18,21,23,24,27,28]$ ) for modeling the thermal response of PICA uses the fully implicit ablation and thermal response code (FIATv3) [29]. Material properties of high-performance ablators are subject to export-control restrictions, and therefore the ablation and thermal property model used in FIATv3 is only available in the appropriate NASA technical report, available to qualified U.S. persons. ${ }^{b}$ No information from NASA/TM-2009-215377 is used in this paper. Unfortunately, because of these restrictions, it is unclear as to which physical phenomena are included in FIATv3, and why certain values are used (for example, the elemental composition of the pyrolysis gas mixture, and why it is assumed to be constant).

Only recently have the numerical capabilities been developed to incorporate a reacting, non-constant elemental pyrolysis gas mixture, with a full thermal response code [30]. To the author's best knowledge, the work performed by Lachaud and Mansour [30] is the only published study that accounts for non-constant elemental composition of the pyrolysis gas mixture, while also accounting for the complicated porous flow field internal to the heatshield. Despite these advances, a simplified chemistry model is used in [30] for the computation to be feasible. On the contrary, this paper focuses on the thermodynamic and kinetic processes related to the pyrolysis gas mixture, and simplifying assumptions are made for the fluid mechanics relating to the flow of the pyrolysis gases. The focus is placed on better understanding the complicated chemical processes occurring in the reacting pyrolysis gas mixture.

This work links solid PICA to the pyrolysis gases that form at high temperatures by compiling published physical properties of PICA, and by explaining the fundamental processes that are involved with phenolic resin synthesis and the thermal decomposition of the resin. This provides a necessary link between the composition of the resin as a solid, the composition of the pyrolysis gases, and their evolution through the pyrolysis layer. When modeling the pyrolysis gas mixture computationally, certain species must be chosen to create a gas model. The inclusion or emission of species has a large effect on the pyrolysis gas composition, yet there is a lack of literature explaining why certain species are chosen, and why others are neglected in previous studies. The effects of choosing a specific gas species composition are quantitatively shown in this paper, emphasizing the importance of choosing an accurate model for the pyrolysis gas mixture. Specifically, the need to include large aromatic species in the gas mixture is emphasized, and physical phenomena associated with aromatic species, such as solid carbon deposition, are investigated. The kinetic evolution of the pyrolysis gas mixture is also investigated, and the assumption of thermodynamic equilibrium vs. finite-rate kinetics is evaluated. This investigation into a reacting pyrolysis gas mixture allows a much needed consistent and detailed description, of many of the physical phenomena occurring in a PICA heatshield, and their implications, to be formulated. To begin, the following section outlines the many physical processes that occur during ablation.

\footnotetext{
${ }^{\mathrm{b}}$ Milos, F.S., and Chen, Y.-K., "Ablation and Thermal Property Model for Phenolic Impregnated Carbon Ablator (PICA)," NASA/TM-2009-215377, Jan. 2009.
} 


\section{Ablation Overview}

The multi-component nature of ablation has been described previously in great detail, and many of the modeling issues and uncertainties that are associated with it have been reviewed in previous works [23-25, 29-33]. Figure 1 shows a schematic overview of the physical phenomena occurring for an ablating heatshield. While the scope of this work is limited to a detailed investigation of the pyrolysis gases formed through the thermal decomposition of a phenolic resin (the type of resin used in PICA heatshields), it is still necessary to be aware of all of the processes occurring during ablation. For example, certain species radiate more than others at high temperatures, influencing the heat transfer to the heatshield. As a result, even though making an error in the amount of strong radiators $\left(\mathrm{C}, \mathrm{CO}, \mathrm{C}_{2}, \mathrm{C}_{3}, \mathrm{C}_{5}, \mathrm{C}_{2} \mathrm{H}, \mathrm{H}, \mathrm{CN}\right)^{\mathrm{c}}$ may not affect the global properties of the gas mixture, the radiative heat flux would no longer be correct.

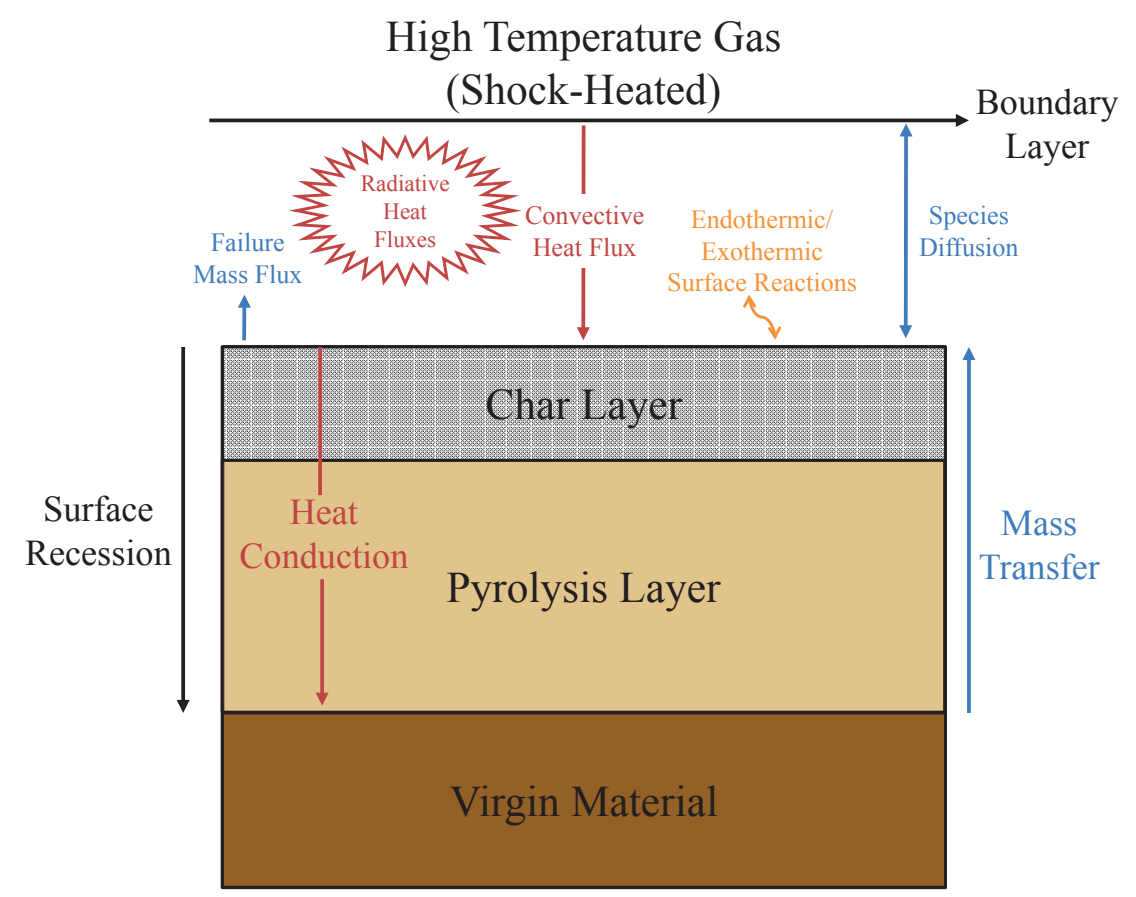

Figure 1: Schematic diagram (not to scale) outlining the many physical phenomena occurring for an ablative heatshield. Red arrows refer to heat fluxes, while blue arrows refer to mass fluxes. Surface reactions can involve both heat and mass fluxes, and are shown in orange.

The virgin material of the heatshield consists of temperature resistant carbon fibers impregnated with a phenolic resin. The resin is composed primarily of carbon, hydrogen, and oxygen, and potentially small amounts of nitrogen and other contaminants (based on the resin type and manufacturing process). As the material is heated, the resin begins to decompose and vaporize. Many small gas bubbles are formed in the material, and once the bubbles become connected, porous flow ensues. The gases produced are referred to as pyrolysis gases, and are generated throughout the entire pyrolysis layer. As the temperature rises, the pressure in the heatshield continues to rise, and the pyrolysis gases flow into the boundary layer. Some of the thermal energy of the external flow is dissipated through this endothermic phase change. A "blowing" phenomenon at the heatshield surface also adds a cooling effect to the flow, as the boundary layer is at a higher temperature than the pyrolysis gases. Furthermore, the addition of the pyrolysis gases into the flow affects many properties of the flowfield, including radiative properties, heat conductivity, flow field dynamics, etc.

Another reason why phenolic resins have been found to be effective for these applications is due to the carbonaceous residue that results from the thermal decomposition of the resin. This solid residue is generally referred to as char. The solid char either adheres to the fibers inside of the heatshield (as shown in Fig. 1), or is advected away through the boundary layer. The char layer (Fig. 1) refers to the area where all pyrolysis reactions have come to completion, and the carbon fibers closest to the heat shield have been covered (to

${ }^{\mathrm{c}}$ Private communications with Professor Alexandre Martin, University of Kentucky. 
some degree) with solid char. This highly emissive char can help radiate heat outwards, thermally insulate the interior of the vehicle, and add to the structural stability of the heatshield itself [34]. Reinforcing the original carbon fibers with this char material can also aid in reducing the amount of spallation that occurs during atmospheric entry. It is possible for the fibers/char to ablate and enter the boundary layer in a gaseous form, and it is also possible for spallation to occur, which adds solid carbon to the boundary layer. The spallation effect is generally referred to as a failure flux, and is labeled in Fig. 1. A more detailed description of PICA itself will be presented in the next section.

\section{PICA Composition}

Phenolic impregnated carbon ablators, as previously described, are a composite material that consist of rigid, lightweight carbon fibers infused with a phenolic resin. A wide range of physical properties are reported for PICA, and it is the goal of this section to compile previously reported values, in order to understand the range of possible properties for this material. In addition, there is often a large disconnect between the physical properties of PICA, and the pyrolysis gases produced from PICA at high temperatures. Without a proper understanding of the composition of solid PICA, it is not possible to explain the composition of the pyrolysis gases which are produced when PICA starts to undergo a thermal decomposition.

Phenolic resins are not limited to the aerospace industry, and are used for a wide variety of applications: from coatings, to adhesives, to carbon-less copy paper. In the year 2000, worldwide consumption of phenolic resins exceeded $4 \cdot 10^{6} \mathrm{t}$ [35]. Due to this demand, there is a large quantity of literature available concerning phenolic resins, and phenolic composite materials (like PICA), from a pure chemistry or industrial background. This work combines publicly available data from the aerospace community on PICA, as well as knowledge from the chemistry community on resin synthesis/decomposition and reacting mixtures. Combining knowledge from both of these fields allows a full picture of the thermal decomposition of PICA, and the subsequent generation and evolution of pyrolysis gases to be formed.

Shifting back to aerospace, Tran et al. [3] report densities for PICA ranging from 14 to $17 \mathrm{lbm} / \mathrm{ft}^{3}$ $\left(224 \mathrm{~kg} / \mathrm{m}^{3}-272 \mathrm{~kg} / \mathrm{m}^{3}\right)$. If surface densification is performed on the material, then the density can be increased to $18-23 \mathrm{lbm} / \mathrm{ft}^{3}\left(288 \mathrm{~kg} / \mathrm{m}^{3}-368 \mathrm{~kg} / \mathrm{m}^{3}\right)$. In comparison, Avcoat-5026, the material used for the ablative heat shields in the Apollo capsules, is a heavier material with a density of $32 \mathrm{lbm} / \mathrm{ft}^{3}\left(513 \mathrm{~kg} / \mathrm{m}^{3}\right)$. Finally, Helber et al. [36] report that densities of ASTERM, an ESA material similar to PICA, range from 240 to $550 \mathrm{~kg} / \mathrm{m}^{3}$. Figure 2, reproduced from Stackpoole et al. [37], shows micro-graphs of samples taken from the Stardust heatshield. These images show the complicated microscopic structure of PICA, and how the amount of resin still bonded to the fibers decreases from the virgin material (Slice 30) to the char layer (Slice 1). Slice 6 and Slice 9 are taken from inside the pyrolysis layer.

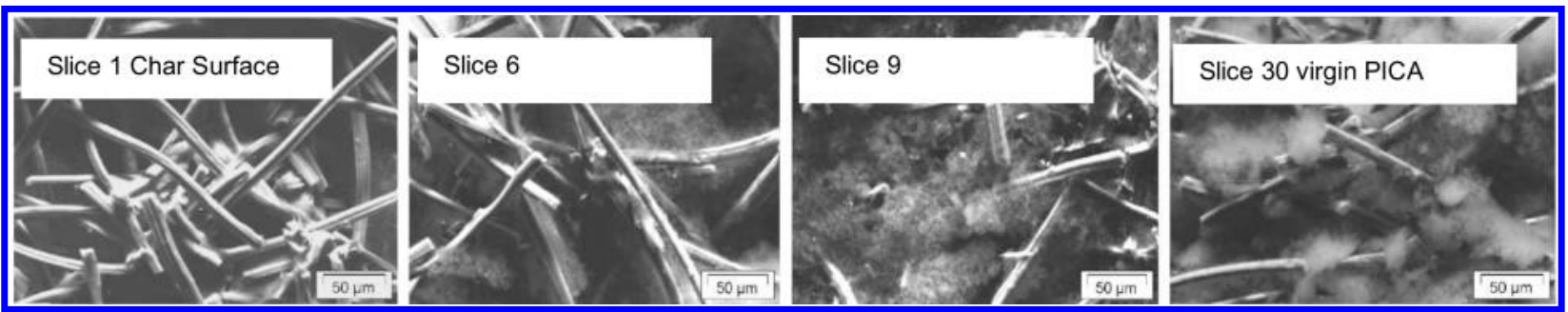

Figure 2: Micro-graphs taken at different depths for the Stardust PICA heatshield. Depth increases from left to right, where Slice 1 is close to the heatshield surface, Slice 6 is located $\sim 5 \mathrm{~mm}$ below the surface, Slice 9 is located $\sim 9 \mathrm{~mm}$ below the surface, and Slice 30 shows the virgin PICA material. Image reproduced from [37].

The following sections outline the expected physical properties for each individual component of PICA: the carbon fibers, the phenolic resin, and the carbonaceous char that is created when the resin is heated to high enough temperatures.

\section{II.A. Expected Fiber Properties}

PICA, as outlined by NASA, uses a fibrous ceramic substrate called Fiberform $\AA$ (manufactured by Fibermaterials Inc.), which consists of rigid, lightweight carbon fibers, designed to be resistant to high temperatures 
in vacuum [3]. This material is then impregnated with a phenolic resin. Tran et al. [3] report that the fibers used have a diameter of $14-16 \mu \mathrm{m}$, and that the material (Fiberform $\AA$, fibers only) has a density ranging from 8.5 to $11 \mathrm{lbm} / \mathrm{ft}^{3}\left(136-176 \mathrm{~kg} / \mathrm{m}^{3}\right)$. Information listed about Fiberform $\AA$ Rigid Insulation is publicly available, ${ }^{\mathrm{d}}$ and a density range of $150 \mathrm{~kg} / \mathrm{m}^{3}$ to $230 \mathrm{~kg} / \mathrm{m}^{3}$ is noted, which is similar to what Tran et al. report in [3]. A room temperature porosity range of $80.2 \%-94.2 \%$ is also given. ${ }^{\mathrm{d}}$

Helber et al. [36] have recently reported results on material response from ablation studies performed in the von Karman Institute for Fluid Dynamics (VKI) Plasmatron [38]. A detailed study was performed on ASTERM and other similar materials used by ESA. Properties for a material (carbon fiber pre-form manufactured by Mersen Scotland Ltd.) similar to the pre-form used in ASTERM are given in the report [36]. The fiber diameter is reported to be $d \sim 6.5 \mu \mathrm{m}$, the fiber length is $l \sim 650 \mu \mathrm{m}$, density of the virgin material is $\rho \sim 180 \mathrm{~kg} / \mathrm{m}^{3}$, porosity is $\sim 90 \%$, and the specific surface area is $\sim 3.24 \cdot 10^{6} \mathrm{~m}^{3} / \mathrm{m}^{2}$, or $18000 \mathrm{~m}^{2} / \mathrm{kg}$. Visual images presented taken with a scanning electron microscope show the same random nature of the fiber alignments, and the potential for non-uniformity inside of the carbon pre-form as for PICA (Fig. 2).

Tran et al. [3] also report on the mechanical and thermal performance of the carbon fibers. The fibers themselves are an anisotropic material, with different properties along the fiber length direction (strong direction) than along the fiber diameter (weak direction). In a heatshield, it is useful for the ablative surface to be perpendicular to the weak direction of the fibers as the thermal conductivity in the strong direction is 2.4 times that of the weak direction. In addition, the thermal conductivity is reported by the manufacturer to be $0.21 \mathrm{~W} / \mathrm{mK}$ at $530 \mathrm{~K}$ and $1.24 \mathrm{~W} / \mathrm{mK}$ at $2500 \mathrm{~K}$ in the strong direction. ${ }^{\mathrm{d}}$ Tran et al. [3] measured the thermal conductivity yielding similar results, and also observed that the thermal conductivity is strongly dependent on the temperature of the fibers.

\section{II.B. Expected Resin Properties}

The phenolic resin used in PICA is a product of a polycondensation reaction between phenol $\left(\mathrm{C}_{6} \mathrm{H}_{5} \mathrm{OH}\right)$ and formaldehyde $\left(\mathrm{CH}_{2} \mathrm{O}\right)$ in the presence of a catalyst [6]. The method used to make the resin depends on the original ratio of formaldehyde to phenol $(\mathrm{F} / \mathrm{P})$. This process is outlined in other sources $[3,6,35,39]$, and is elaborated on in Appendix A. The chemical processes outlined in Appendix A show how these phenolic resins are synthesized, and how the manufacturing process can affect the final resin composition and its mechanical and thermal properties. The SC-1008 (made by Momentive ${ }^{\mathrm{TM}}$ ) phenolic infiltrant is specifically mentioned in NASA reports [3], but other commercial phenolic resins are available (for example, Plenco Phenolic Resins ${ }^{\mathrm{e}}$ ).

\section{II.B.1. Types and Production}

Table 1: Summary of starting reagent and reaction conditions for novolac and resole resins. Specific ratios are taken from [35].

\begin{tabular}{cccc} 
Type of Resin & F:P & Catalyst Used & Crosslinking Agent Required? \\
\hline Resole & $1.2: 1.0-3.0: 1.0$ & Basic (Alkaline) & No \\
Novolac & $0.5: 1.0-0.8: 1.0$ & Acidic & Yes
\end{tabular}

Phenolic resins can be broadly classified into two groups: novolac resins and resole resins. With an initial molar excess of formaldehyde to phenol $(\mathrm{F} / \mathrm{P}>1)$, a resole resin is produced. The formaldehyde and phenol are mixed, heated, and begin to cross-link (link one polymer chain to another) on their own. The procedure is performed in the presence of a basic (alkaline) catalyst. With an initial molar excess of phenol to formaldehyde $(\mathrm{F} / \mathrm{P}<1)$, a novolac resin is produced. Once again, the formaldehyde and phenol are mixed and heated, but do not begin to cross-link until a cross-linking agent is added to the mixture. This procedure is performed in the presence of an acidic catalyst. By changing the original ratio of phenol to formaldehyde, $\mathrm{pH}$, catalyst, reaction temperature, reaction time, and distillation amount, it is possible to generate a variety of resin structures, which in turn have a range of physical properties. The initial conditions for these two types of resins are summarized in Table 1.

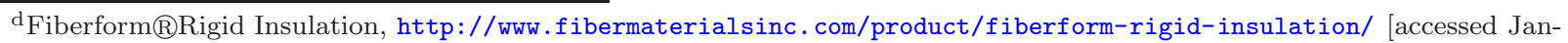
uary 24,2014$]$.

${ }^{e}$ Plenco - Plastics Engineering Company, http://www.plenco.com/phenolic-novolac-resol-resins.htm [accessed October 21, 2013].
} 
As an example, let us consider the Durite SC-1008 phenolic resin (data taken from the Momentive website $^{\mathrm{f}}$ ). It is a resole type phenolic resin, and is listed as having a specific gravity of 1.07-1.10 (pre-cure). This is equivalent to a pre-cure density of $1.07-1.10 \mathrm{~g} / \mathrm{cm}^{3}$. A post-cure density of $1.25 \mathrm{~g} / \mathrm{cm}^{3}$ is often used as the density for the resin in many molecular dynamics studies performed [34,40-43].

Given the manufacturing process described above and in Appendix A, most resins are composed of carbon, hydrogen and oxygen elements, and potentially leftover components from the manufacturing process. These are the same elements that will be present in the pyrolysis gases. An idealized linear polymer (no cross-linking) is shown in Fig. 3, and the composition used for the resin in this thesis will be taken to be the repeating unit, $n$, in this figure $(\mathrm{C}: \mathrm{H}: \mathrm{O}=0.500: 0.429: 0.071$ by mole). The repeating unit, which corresponds to $\mathrm{C}_{7} \mathrm{H}_{6} \mathrm{O}$, has a molecular composition close to that of a single phenol molecule, $\mathrm{C}_{6} \mathrm{H}_{6} \mathrm{O}$. Due to this similarity, pure phenol may be used as a representative "surrogate" for the initial composition of the pyrolysis gases or resin, when a simplified model is required. As an aside, if an idealized, fully crosslinked phenol molecule (3 cross-links per molecule, similar to Fig. 28) is used to calculate the composition of the resin, then a value of C:H:O = 0.517:0.414:0.069 is obtained. This composition and the composition of the repeating unit in Fig. 3 will act as limiting idealized cases for the elemental compositions of the resin. Actual phenolic resins are not expected to be $100 \%$ cross-linked, but are also not expected to be linear polymers; some finite amount of cross-linking is expected depending on the resin type and synthesis process (see Appendix A). Only minor discrepancies are noted when either of these compositions are used in calculations, as the elemental compositions are extremely similar between the limiting cases.

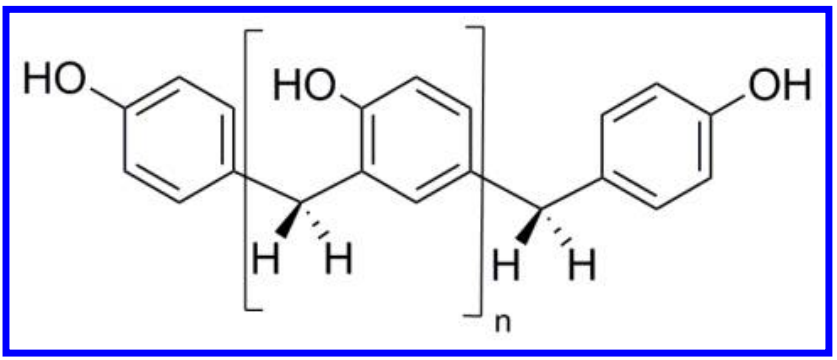

Figure 3: Linear polymer representing an idealized cured resin structure for a phenolic resin.

\section{II.B.2. Curing and Thermal Decomposition}

The composition of a resin can also be modified post-polymerization by the application of a subsequent curing step. A more detailed explanation of this process and the expected thermal decomposition of the resin is found in Sec. A.B. The present summary is based on results and explanations presented in $[16,26,35,39]$, and more recently in [33].

In the curing step, excess formaldehyde (or a formaldehyde source), sufficient heat (typically $\sim 150^{\circ} \mathrm{C}$ ), and/or an acid or base catalyst is applied in order to promote the cross-linking of any remaining unjoined or open sites in the polymer. This promotes the formation of methylene bridges, potentially eliminating other types of linkages that may have formed previously (Fig. 27). This was explicitly noted by Sykes [16], where it was found that the amount of water produced during pyrolysis at relatively low temperatures was greatly affected by the cure time of the sample.

The decomposition of the resin, and pyrolysis gases produced, can generally be broken down into three different temperature ranges. At approximately $300^{\circ} \mathrm{C}$, any remaining ether and nitrogen linkages begin to break, forming aldehydes, cresols, and azomethines. Furthermore, at this stage, any small molecules that were trapped from the manufacturing process are released, such as excess phenol, water, formaldehyde, ammonia etc. A large percentage of the pyrolysis gases are found to be $\mathrm{H}_{2} \mathrm{O}$ in this temperature range [16, 33]. At approximately $600^{\circ} \mathrm{C}$, substantial shrinkage of the polymer occurs as a result of the formation of carbon-carbon bonds between aromatic rings, resulting in the formation of a polyaromatic char. Substantial quantities of pyrolysis gases are liberated, composed mainly of hydrogen, but also methane, volatile aromatic compounds (such as phenol or benzene), water, carbon monoxide, and carbon dioxide. At temperatures above this, $\left(\sim 900^{\circ} \mathrm{C}\right)$ any non-carbon species continue to be evolved, and the pyrolysis gas consists mainly of $\mathrm{H}_{2}[16,33]$.

\footnotetext{
${ }^{\mathrm{f}}$ Momentive, http://www.momentive.com/Products/TechnicalDataSheet. aspx?id=5652, accessed December 17, 2013.
} 
The expected pyrolysis gas products are a strong function of the temperature at which pyrolysis is occurring. Knowing this, it follows that the elemental composition of the pyrolysis gas products is not expected to be constant, and will also be a strong function of temperature. The fact that the elemental composition of the pyrolysis gases is not constant over a temperature range is very important, and will be discussed in more detail in later sections.

\section{II.B.3. Presence of Impurities}

Due to the complicated synthesis and curing process that is required to create phenolic resins, it is possible for a phenolic resin to contain small amounts of impurities, which will affect the overall properties of the resin.

The Apollo capsules used Avcoat 5026-39 HC/G as the resin in their ablative heatshields, which is a novolac resin [44]. Hexamethylenetetramine, $\left(\mathrm{CH}_{2}\right)_{6} \mathrm{~N}_{4}$, is typically used as the cross-linking agent during the production of this resin. As a result, a small amount of leftover nitrogen is often assumed to be present when calculating the composition of the pyrolysis gas from Avcoat, as done by Park et. al. [25]. More recent carbon phenolic heatshields use a resole resin where no catalyst is needed in the cross-linking process. In some studies, nitrogen is not included when calculating the composition of the pyrolysis gas [25], whereas in other studies [24], small amounts of nitrogen are included for PICA heat shields. Other contaminants, such as $\mathrm{Si}$, can be included in the pyrolysis gas composition as well [24].

Experimental measurements performed in [16] on a novolac resin (Union Carbide Corporation BRP 5549) showed the post-cure content of the resin to be $75.6 \% \mathrm{C}, 6.12 \% \mathrm{H}, 2.35 \% \mathrm{~N}$, and $15.93 \% \mathrm{O}$ by mass (C:H:N:O $=0.465: 0.449: 0.012: 0.074$ by mole), extremely close to the expected value of $\mathrm{C}: \mathrm{H}: \mathrm{O}=0.500: 0.429: 0.071$, if a phenol linked with $\mathrm{CH}_{2}$ ( $n$ in Fig. 3), is assumed to be the primary component of the resin. The novolac resin used in [16] was premixed with hexamethylenetetramine, and then cured by the authors. The experiments were performed on a neat resin sample, not the composite material.

It is important to note than any nitrogen present in the final resin is generally leftover from the synthesis process, and can be found in two general forms. It is possible that the nitrogen is physically trapped in the resin, not chemically bound to other molecules. It is also possible that the nitrogen is chemically bound in the resin structure (see $o$ in Fig. 26). Sykes [16] attributes the relatively high nitrogen content in the resin to trapped ammonia $\left(\mathrm{NH}_{3}\right)$, as ammonia is a product of the decomposition of hexamethylenetetramine. If it is assumed that all of nitrogen content observed by Sykes [16] is trapped ammonia, removing this ammonia from the resin results in a new elemental ratio of $\mathrm{C}: \mathrm{H}: \mathrm{O}=0.488: 0.434: 0.078$. This is even closer to the expected composition previously described, further validating the use of the idealized resin structure shown in Fig. 3.

\section{II.C. Expected Char Composition}

Char refers to the solid carbonaceous residue that is created when the resin is heated to high enough temperatures. This is the solid that is left behind as the resin undergoes a thermal decomposition. Some of the initial resin is converted into pyrolysis gases, while some of the resin stays in the solid phase, and evolves into char. The chemical pathways and timescales associated with the solid char formation are still subjects that are under investigation $[26,45,46]$.

In general, the amount of polyaromatic char that is expected to form from a virgin resin is approximately $60 \%$ by mass of the original virgin resin [35]. This assumes that after a full thermal decomposition of the resin has occurred, $40 \%$ of the original mass present was converted into pyrolysis gases, and $60 \%$ of the original mass present remained as a solid, and evolved into char. This is close to the value of $54 \%$ observed experimentally by Sykes [16].

Sykes [16] analyzed the char composition of a neat, cured novalac resin, through elemental analysis. It was observed that the char present at $850^{\circ} \mathrm{C}$ contained $92.6 \% \mathrm{C}, 0.9 \% \mathrm{H}$, and $6.5 \% \mathrm{O}$ by mass (C:H:O $=$ 0.856:0.099:0.045 by mole). Tran et al. [3] tested a composite material (cured resole resin and fibers) sample in an arc-jet at $1065 \mathrm{Btu} / \mathrm{ft}^{2}-\mathrm{s}\left(1210 \mathrm{~W} / \mathrm{cm}^{2}\right), 0.34 \mathrm{~atm}$ stagnation pressure, for a total heat load of $26,625 \mathrm{Btu} / \mathrm{ft}^{2}\left(30,235 \mathrm{~J} / \mathrm{cm}^{2}\right)$. The composition of the char was then measured using X-ray photoelectron spectroscopy. The elemental composition (by mole) of the char was found to be $98 \% \mathrm{C}, 1.7 \% \mathrm{O}, 0.3 \% \mathrm{Si}$ ( $\mathrm{Si}$ noted as an error due to the sample processing technique). This discrepancy in char composition between different experimental studies should be addressed in more detail in future works. 
The char, which has been observed to be primarily composed of carbon, may also have other elements bound inside of it. For example, Syke's [16] hypothesized that through oxidation reactions it would be possible for oxygen to be present in the solid char. These elements could also be evidence of incomplete pyrolysis, or contamination of the experimental samples.

It is also believed that some parallels can be drawn between soot that traditionally forms in flames, and char. Both char and soot are solids consisting primarily of carbon atoms that are formed at high temperatures, through reactions involving aromatic hydrocarbons. A dehydrogenation process has been observed in combustion with soot formation. As time progresses, or as the soot matures, the $\mathrm{H} / \mathrm{C}$ ratio of soot decreases $[47,48]$. This type of phenomena should affect the carbon char as well, and may help explain the discrepancies observed in experimentally measured char compositions.

In addition, the char composition reported by Tran et. al [3] was taken from an actual PICA sample after arc-jet testing. The PICA sample was subjected to a very high heat load, and was heated for a longer time than the samples in Sykes' [16] work. It is likely that the sample tested by Tran et. al [3] was fully pyrolyzed, which could explain the very high carbon content measured in the char. Based on the above discussion, for the rest of this thesis, when an idealized char material is needed, it will be assumed to be composed uniquely of carbon. A similar assumption is made in other works [30].

This section has provided an overview of the physical components of PICA, and a basic explanation of the synthesis of phenolic resins and the expected decomposition products of a phenolic resin at high temperatures. With this understanding of the components that make up PICA, and investigation into the pyrolysis gas composition can now be performed.

\section{Pyrolysis Gas Composition}

Due to the formation of a solid carbonaceous residue (char), it is clear that the elemental composition of the pyrolysis gases injected into the boundary layer is not that of the original resin. Experiments performed on a phenolic resin have confirmed that the pyrolysis gases differ in composition significantly from the original resin [49]. This has large implications for modeling efforts, as the elemental composition of the pyrolysis gas is an additional unknown. Not only is it desired to have an accurate description of the gas that is injected into the boundary layer, but the gas flowing internally in the heat shield must also be modeled correctly in order to accurately predict the full thermal response of the heatshield.

Many experimental works (for example, Sykes [16], Wong et al. [33]) show that the elemental composition of the pyrolysis gas mixture produced is not constant over a large temperature range. Very recently, Lachaud and Mansour [30], and Wong et al. [33] reported a decomposition model for the solid resin based on experimental results. In this model, the gas mixture does not have a constant elemental composition. The work by Lachaud and Mansour [30] is the first computational work, to the author's knowledge, to report results using a non-constant elemental composition for the pyrolysis gas mixture. This differs significantly from all previous computational works that use an average composition for the pyrolysis gas mixture (for example, see Milos and Chen [24]). A review of existing thermal response codes is provided by Lachaud et al. [50], and a summary of the varying degree of complexity that is included in these codes, i.e., frozen chemistry, equilibrium chemistry, or fine-rate kinetics, is provided by Lachaud and Mansour [30].

In order to understand how these different composition assumptions affect the pyrolysis gas, the following sections investigate the effects of various gas models used, the chosen elemental composition of the pyrolysis gas, and the equilibrium vs. non-equilibrium assumption on the mixture enthalpy of the pyrolysis gases.

\section{III.A. Equilibrium Pyrolysis Gas Composition}

Internal to the heatshield, the pyrolysis gas flows at relatively low speeds. The complicated nature of this porous flow is outside the scope of this work, but has received attention in the literature elsewhere [30,51]. It has previously been proposed that as the pyrolysis gases flow through the porous medium internal to the heatshield, the gas speed is on the order of $10 \mathrm{~m} / \mathrm{s}$ [51]. Based on the rather slow motion of the gases inside of the heatshield, previous works have assumed that the pyrolysis gases are in thermodynamic equilibrium at the local temperature and pressure. The current work begins with this assumption.

As described previously, when the phenolic resin starts to degrade, many small gas bubbles are formed in the material, and a porous flow begins once the bubbles become connected. As the flow gets closer to the surface of the heatshield, the temperature increases. A range of temperatures for when the resin 
starts to decompose can be found in the literature. In [3], $150^{\circ} \mathrm{C}$ is given (fibers impregnated with resole resin), $250^{\circ} \mathrm{C}$ is given in [46] (fibers impregnated with resole resin), $300^{\circ} \mathrm{C}$ is given in [35] (neat resole resin), and $350^{\circ} \mathrm{C}$ is given in [16] (neat novolac resin), for example. It is expected that different phenolic resins have different physical properties, which helps explain this range of temperatures found in the literature. Given these uncertainties, an average temperature of $230^{\circ} \mathrm{C}$ is used in this work as a starting point for resin decomposition. This temperature should be understood as the temperature at the edge between the virgin material and the pyrolysis layer (Fig. 1), and is similar to what is used in other works [33].

\section{III.A.1. Gas Model}

Through a collaborative effort with the von Karman Institute (VKI), a reduced 55 species thermodynamic model has been developed to represent the pyrolysis gases produced from a typical PICA heatshield. This model only includes thermodynamic properties for the different species chosen, and no information pertaining to chemical reactions. Therefore, this model can only be used for thermodynamic equilibrium calculations, and not for calculations that would require a set of chemical reactions and reaction rates (finite-rate chemistry).

To create the model, 193 species were taken from the Chemical Equilibrium with Applications (CEA) database [52. Species characteristic of a typical carbon phenolic decomposition (species with $\mathrm{C} / \mathrm{H} / \mathrm{O}$ ) were originally chosen, and then species containing $\mathrm{N}$ were also added. This accounts for mixing between an atmosphere that may be partially composed of nitrogen, and the ablation products from a heatshield. In addition, thermodynamic properties for 8 additional species $\left(\mathrm{C}_{24} \mathrm{H}_{12}, \mathrm{C}_{16} \mathrm{H}_{10}\right], \mathrm{C}_{3} \mathrm{H},{ }^{1} \mathrm{C}_{3} \mathrm{H}_{2},{ }^{3} \mathrm{C}_{3} \mathrm{H}_{2}, \mathrm{C}_{4} \mathrm{H}$, $\mathrm{C}_{5} \mathrm{H}$, and $\mathrm{C}_{5} \mathrm{H}_{5}$ ) were recomputed, and added to the 193 species set, creating a full model with 201 species.

Next, a model reduction was performed by calculating different thermodynamic equilibrium compositions at constant temperature, and pressure, for the full 201 species model. The temperature was varied from $25^{\circ} \mathrm{C}$ to $5800^{\circ} \mathrm{C}$, and pressure was varied from $1 \mathrm{kPa}$ to $10 \mathrm{MPa}$. At each respective temperature and pressure condition, 1000 different elemental compositions were chosen (uniformly varying in the ratio of C:H:N:O), and thermodynamic equilibrium calculations were performed. If a mole fraction of a specific species was consistently (for all $P, T$, and $\mathrm{C}: \mathrm{H}: \mathrm{N}: \mathrm{O}$ values tested) below $10^{-4}$, the species was removed from the gas model. It was found that trying more than 1000 different elemental compositions at every temperature and pressure did not change the final reduced species model.

This reduced the original 201 species model to a 55 species model. A comparison was then made between the 55 species model, and the 201 species model, to calculate relative errors made by the reduced species model on the bulk properties of the mixture. Comparisons were performed at all values of $T, P$, and $\mathrm{C}: \mathrm{H}: \mathrm{N}: \mathrm{O}$ ratios considered for the model reduction. It was found that for $c_{p}, h, s$ (entropy), and $X_{\text {radiators }}$ (see Sec. I), the errors between the 55 species model and the full 201 species model were always less than 1\%. The maximum percentage error made on mole fractions of strong radiators present is approximately $0.1 \%$.

The 55 species model was deemed acceptable for this paper due to the relatively small discrepancies with the full model. Detailed information about the gas species model reduction will be the subject of a forthcoming publication [53. The full list of species used can be found in Appendix C, along with the sources used for thermodynamic properties. Thermodynamic data is also provided for individual species that were recomputed for this gas model. This 55 species gas model is used for the rest of this work.

\section{III.A.2. Elemental Composition of Pyrolysis Gases}

In order to perform thermodynamic equilibrium calculations, an elemental composition must be specified. Three different elemental compositions are chosen, in order to understand the effect that elemental composition has on the pyrolysis gases. The first composition has a C:H:O ratio of 0.500:0.429:0.071 by mole, which is the expected composition of the pure resin (see Sec. II.B). It is understood that this is more carbon-rich than the expected pyrolysis gas composition, as this gas composition assumes that no char is formed from the resin, but it serves as a limiting test case. The second composition has a C:H:O ratio of 0.358:0.550:0.092 by mole, which is calculated by taking the original resin composition and then assuming that $35 \%$ of the mixture, by mass, will turn into a solid char comprised purely of carbon (see Sec. II.A). This mass of carbon is then removed from the mixture (35\% char yield). This composition is more characteristic of the pyrolysis gas products for mid-range temperatures during the decomposition process. The $35 \%$ char yield assumption yields an elemental composition for the pyrolysis gases that is very close to the experimentally 
measured composition of the pyrolysis gases at $500^{\circ} \mathrm{C}$ [16]. The third composition has a C:H:O ratio of 0.195:0.690:0.115 by mole, which corresponds to a $60 \%$ char yield by mass (Sec. II.C). These three chosen compositions are summarized by the first three lines of Table 2 .

In a recently published work, the species blowing rates for the pyrolysis gas were calculated for a PICA material using the FIATv3 [29] thermal response code for a chosen trajectory [24]. During heating, the surface temperature varies from $\sim 200^{\circ} \mathrm{C}$ to $\sim 3000^{\circ} \mathrm{C}$ (not monotonically) as a function of time. Milos and Chen [24] show results where the C:H:O ratio of the injected pyrolysis gas remains essentially constant at 0.18:0.68:0.12. The missing $2 \%$ from the gas mixture is attributed to $1.4 \% \mathrm{~N}$, and then trace amounts of Si. The elemental composition used in the numerical simulations by Milos and Chen [24] was taken from experiments, and the nitrogen content can be attributed to impurities in the resin (potentially from synthesis), and it is unclear as to why $\mathrm{Si}$ is observed experimentally. ${ }^{\mathrm{g}}$

Finally, in an earlier work by Park et al. [25], the elemental composition of the pyrolysis gases entering the boundary layer was $\mathrm{C}: \mathrm{H}: \mathrm{O}=0.229: 0.661: 0.110$ by mole. Using the simplified resin composition discussed (see Sec. II.B.1), the values used by Park et al. [25] correspond to approximately a $56 \%$ char yield, and the values used by Milos and Chen [24] correspond to a char yield of roughly 65\% (neglecting impurities). All pyrolysis gas compositions are summarized in Table. 2.

Table 2: Summary of different pyrolysis gas compositions.

\begin{tabular}{ccc} 
Mixture Description & Elements Included & Composition (by mole) \\
\hline Pure Resin & C:H:O & $0.500: 0.429: 0.071$ \\
35\% Char Yield & C:H:O & $0.358: 0.550: 0.092$ \\
60\% Char Yield & C:H:O & $0.195: 0.690: 0.115$ \\
Park et al. $[25]$ & C:H:O & $0.229: 0.661: 0.110$ \\
Milos and Chen [24] & C:H:N:O:Si & $0.18: 0.68: 0.014: 0.12: 0.006$
\end{tabular}

\section{III.A.3. Equilibrium Results-Polycyclic-Aromatic Hydrocarbon (PAH) Species}

This section shows results for the previously discussed elemental compositions assuming thermodynamic equilibrium. All thermodynamic equilibrium calculations are performed using Cantera [54], and are performed holding temperature and pressure constant. First, the elemental composition of the virgin resin is used, and calculations are performed at different temperatures while keeping the pressure constant at $50 \mathrm{kPa}$ (see Sec. IV.A). Fig. 4a shows the major species present using the reduced 55 species model. The most pertinent observation is that large quantities of coronene $\left(\mathrm{C}_{24} \mathrm{H}_{12}\right.$, Fig. 5), are predicted for all temperatures below $\sim 1700^{\circ} \mathrm{C}$. At $1180^{\circ} \mathrm{C}$, the mixture is predicted to be $70 \%$ coronene by mass, which shows the importance of including this molecule if thermodynamic equilibrium calculations are going to be performed in this temperature range.

In Fig. $4 \mathrm{~b}$, coronene $\left(\mathrm{C}_{24} \mathrm{H}_{12}\right)$ is removed from the list of species included and is replaced by naphthalene $\left(\mathrm{C}_{10} \mathrm{H}_{8}\right)$. Once again, significant quantities of naphthalene are observed at temperatures below $\sim 1700 \mathrm{~K}$. In fact, if both coronene $\left(\mathrm{C}_{24} \mathrm{H}_{12}\right)$ and naphthalene $\left(\mathrm{C}_{10} \mathrm{H}_{8}\right)$ are included in the species model, the predicted yield of naphthalene is essentially zero, and the results shown in Fig. 4a are obtained again. All of the mass goes into the $\mathrm{PAH}$ species with the smallest $\mathrm{H} / \mathrm{C}$ ratio. For naphthalene, $\mathrm{H} / \mathrm{C}=0.8$, and for coronene, $\mathrm{H} / \mathrm{C}=0.5$. High concentrations of these polycyclic-aromatic hydrocarbon $(\mathrm{PAH})$ molecules can also have a large effect on the global properties of the gas mixture, such as the value of the specific heat for the mixture, and the mixture enthalpy. It should be noted that at the conditions considered in this section, while the formation of $\mathrm{C}_{24} \mathrm{H}_{12}$ is favored from a thermodynamic standpoint, the validity of this assumption from a kinetic standpoint has not been addressed yet, and will be considered in the next section. Above roughly $2000^{\circ} \mathrm{C}$, both Fig. $4 \mathrm{a}$ and Fig. $4 \mathrm{~b}$ show the same mixture compositions. At these high temperatures, $\mathrm{PAH}$ species are no longer favored from a thermodynamic stand point, and the inclusion of $\mathrm{C}_{24} \mathrm{H}_{12}$ or $\mathrm{C}_{10} \mathrm{H}_{8}$ has no effect on the mixture composition.

\footnotetext{
gPrivate communication with Dr. Frank Milos, NASA-Ames.
} 


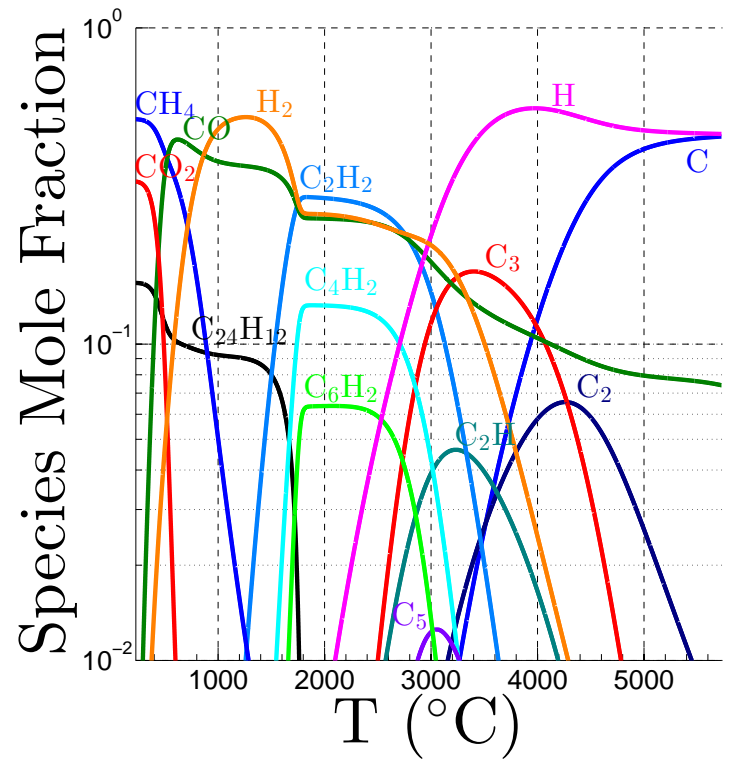

(a) Coronene Included

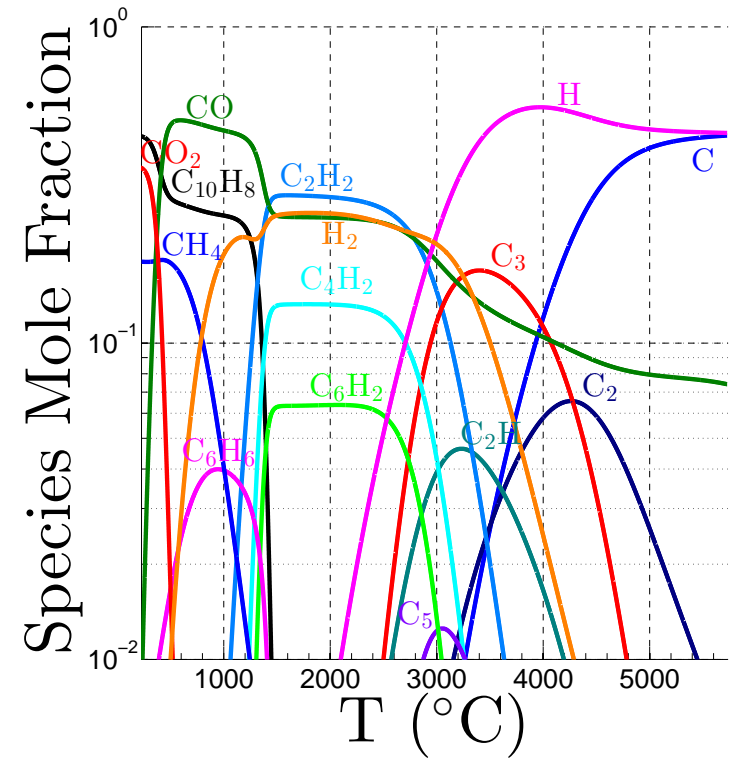

(b) Naphthalene Substituted for Coronene

Figure 4: Thermodynamic equilibrium composition of the pyrolysis gas mixture assuming an initial resin composition of $\mathrm{C}: \mathrm{H}: \mathrm{O}=0.500: 0.429: 0.071$ by mole, at $50 \mathrm{kPa}$. Species with mole fractions $>10^{-2}$ are shown in both plots. (a) includes coronene in the gas model, while (b) substitutes naphthalene for coronene.

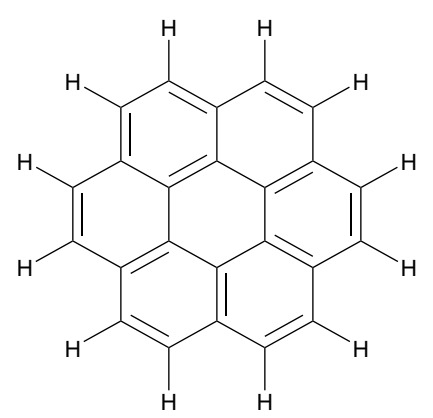

Figure 5: Coronene molecule, $\mathrm{C}_{24} \mathrm{H}_{12}$.

\section{III.A.4. Equilibrium Results - Varying Mixture Composition}

Figure 6 shows the mixture composition assuming different elemental pyrolysis gas compositions resulting from different assumed char yields, namely; 35\% char yield in Fig. 6a and 60\% char yield in Fig. 6b]. Assuming a $35 \%$ char yield results in a maximum value of $50 \% \mathrm{C}_{24} \mathrm{H}_{12}$ by mass at $1190^{\circ} \mathrm{C}$, and assuming a $60 \%$ char yield results in a maximum of $17 \% \mathrm{C}_{24} \mathrm{H}_{12}$ by mass at $1210^{\circ} \mathrm{C}$. Obviously, as the overall carbon content in the pyrolysis gas mixture decreases, the amount of $\mathrm{C}_{24} \mathrm{H}_{12}$ that forms from a thermodynamic equilibrium calculation decreases.

It is difficult to notice meaningful differences between complicated gas mixtures by looking solely at species concentrations. From an engineering stand point, the question can be raised as to whether or not it is necessary to know the concentration of every single species in such a complicated mixture.

In this study, the mass specific mixture enthalpy is chosen as a relevant property to compare between different mixtures. The mass specific mixture enthalpy gives a measure of the amount of energy contained in the gas mixture. For an ablative heatshield to be effective, the endothermic decomposition of the resin and creation of pyrolysis gases should absorb as much of the thermal energy of the external flow as possible. The enthalpy of the mixture relates to the efficiency of the pyrolysis gases in creating a cooling effect. Other quantities, such as $c_{p}$, could also be compared, but generally show similar trends as enthalpy, and changes in $c_{p}$ will also be reflected in the mixture enthalpy. If one were to consider the injection of the pyrolysis 


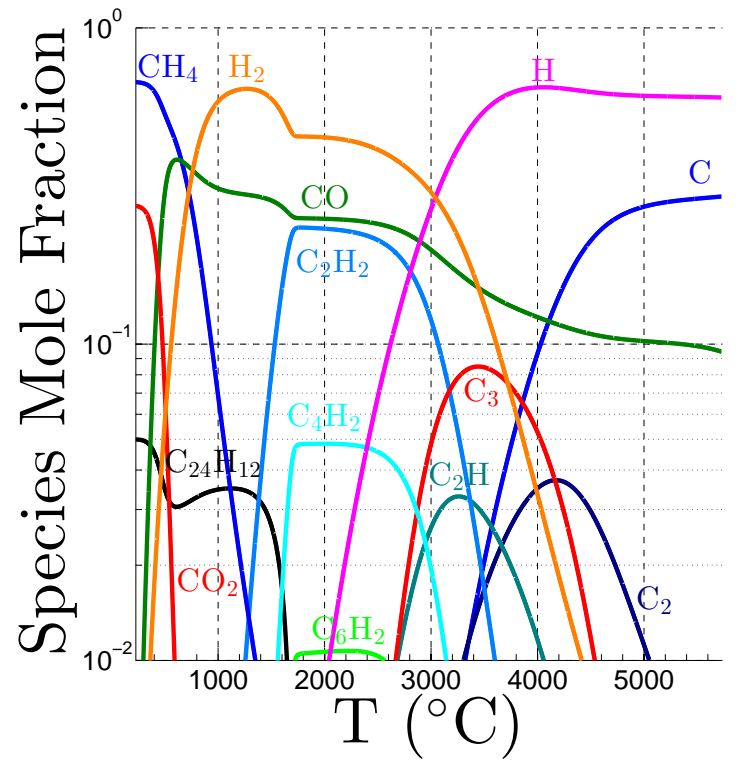

(a) $35 \%$ Char Yield

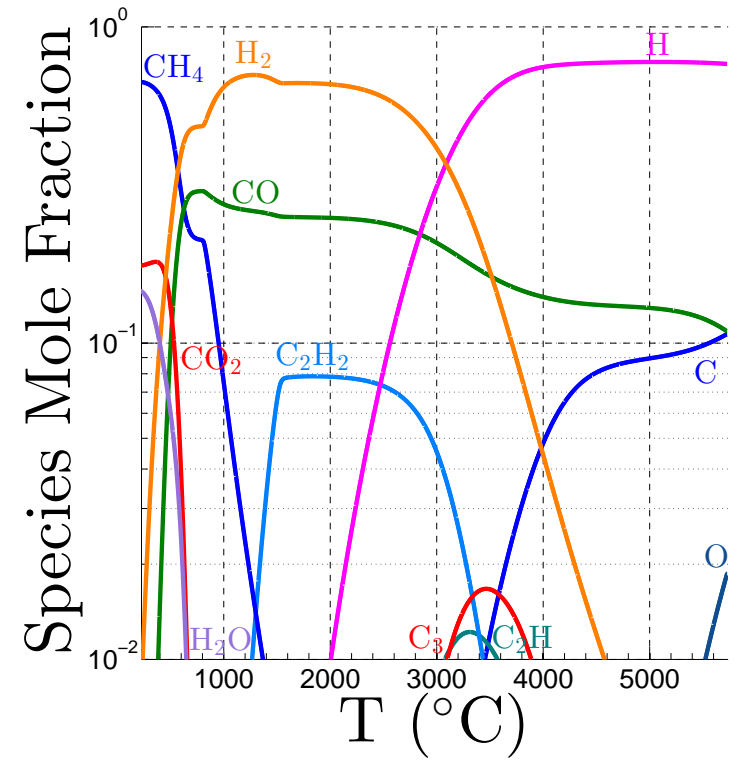

(b) $60 \%$ Char Yield

Figure 6: Thermodynamic equilibrium composition of the pyrolysis gas mixture assuming two different char yields at $50 \mathrm{kPa}$. Species with mole fractions $>10^{-2}$ are shown in both plots.(a) corresponds to a $35 \%$ char yield $(\mathrm{C}: \mathrm{H}: \mathrm{O}=0.358: 0.550: 0.092)$ and $(\mathrm{b})$ corresponds to a $60 \%$ char yield $(\mathrm{C}: \mathrm{H}: \mathrm{O}=0.195: 0.690: 0.11)$.

gas mixture into the boundary layer of the heatshield, then other properties should be chosen to compare as well, as the injection of the pyrolysis gases into the boundary layer will affect the properties of the flow external to the heatshield. Although the boundary layer flow is not the focus of this work, if this part of the flow were to be considered, one relevant choice would be to compare $\gamma$ between the different mixtures.

Figure 7 shows the quantitative effect of changing the elemental composition of the mixture by plotting the mass specific enthalpy of the mixture over a temperature range characteristic of what would be experienced inside of the heatshield. Figure 7 shows that the mixture enthalpy decreases as the char yield increases. Once again, the lower the char yield, the higher the carbon content in the pyrolysis gas mixture, which means that there is more $\mathrm{C}_{24} \mathrm{H}_{12}$ present in the mixture (Figs. 4 and 6). Figure 7 quantitatively shows that changing the elemental composition of the gas mixture, while keeping the species model constant, has a large effect on the overall mass specific mixture enthalpy especially at lower temperatures $\left(T<600^{\circ} \mathrm{C}\right)$. Interestingly, the specific enthalpy at higher temperatures $\left(T \sim 1500^{\circ} \mathrm{C}\right)$ is virtually independent from the char yield, when the reduced 55 species model is used. These two observations are important as the difference in enthalpies is related to how much heat is extracted by gaseous mixture.

In addition to showing the effect of elemental composition on mixture enthalpy, Fig. 7 shows the effect that the chosen gas model can have. In a recent study, Milos and Chen [24] used a 23 species gas mixture (including $\mathrm{C}, \mathrm{H}, \mathrm{N}, \mathrm{O}$, and $\mathrm{Si}$ ) for the pyrolysis gases injected into the boundary layer, where the largest species included is $\mathrm{C}_{6} \mathrm{H}_{6}$. The gas mixture was calculated using FIATv3 [29].

Elemental compositions corresponding to a $0 \%, 35 \%$, and $60 \%$ char yield are again used, and the current 55 species gas model is replaced by Milos and Chen's 23 species model [24]. Figure 7 shows differences in mixture enthalpy between the two different gas models. Figure 7 isolates two important phenomena: 1) the effect of elemental composition on the mixture enthalpy and 2) the effect of the chosen gas species model on mixture enthalpy. When performing thermodynamic equilibrium calculations to calculate the composition of the pyrolysis gas mixture, the species model and the elemental composition of the mixture must be chosen with care.

\section{III.A.5. Equilibrium Results-Discussion}

To emphasize the effect that the elemental composition has on the overall composition of the pyrolysis gas mixture, it is necessary to know how carbon rich a gas mixture must be in order to form $\mathrm{C}_{24} \mathrm{H}_{12}$ from a 


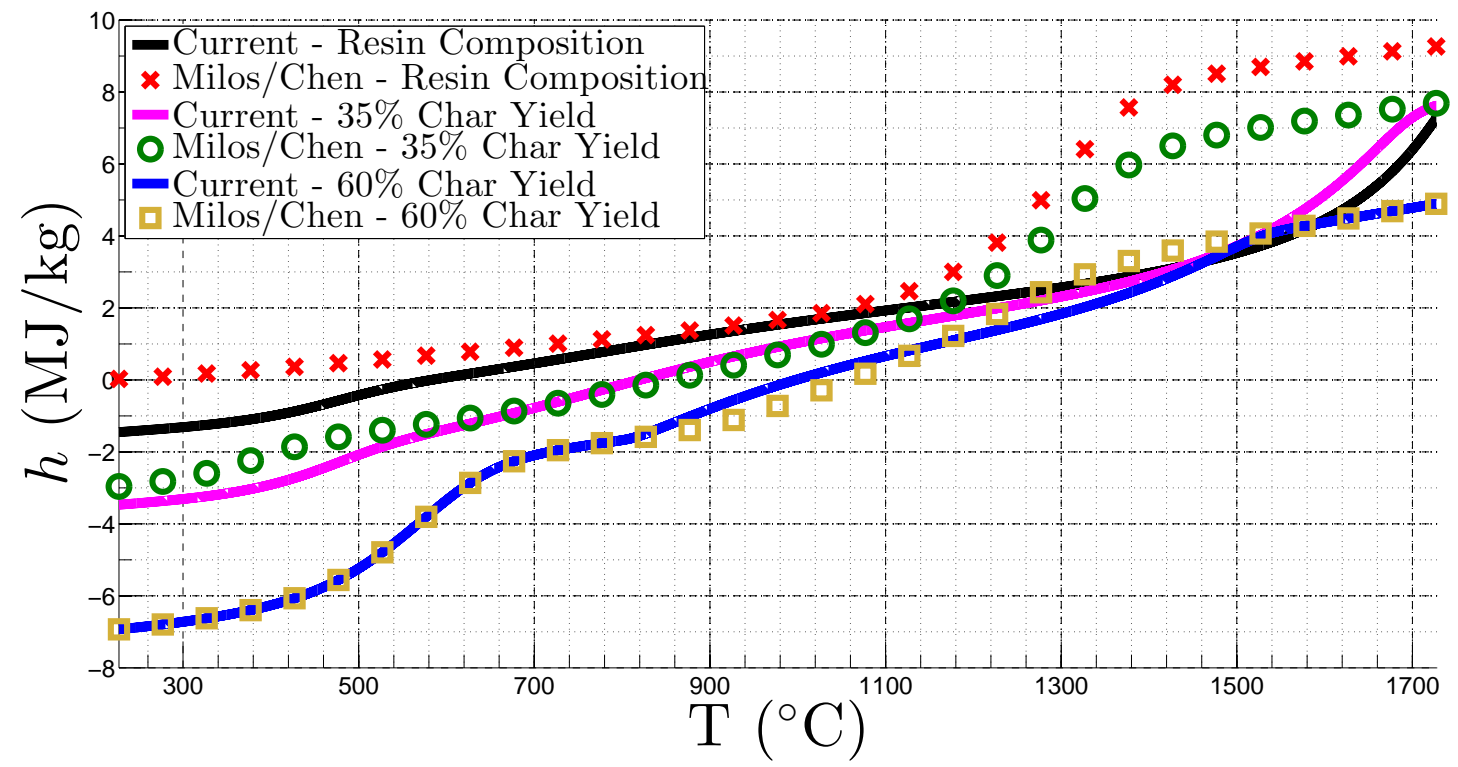

Figure 7: Enthalpy comparison for different gas models and elemental compositions. All mixtures are in thermodynamic equilibrium over a range of temperatures and at a pressure of $50 \mathrm{kPa}$.

thermodynamic standpoint. This is done by varying the char yield from $0 \%$ (carbon rich gas mixture) to $70 \%$ (carbon lean gas mixture). For a given char yield, the maximum value of mass fraction of $\mathrm{C}_{24} \mathrm{H}_{12}$ is calculated for equilibrium mixtures spanning a temperature range from $230^{\circ} \mathrm{C}$ to $1800^{\circ} \mathrm{C}$.

Figure 8 shows that for carbon rich gas mixtures, the maximum mass fraction of $\mathrm{C}_{24} \mathrm{H}_{12}$ is very high (up to $\sim 70 \%$ ). A smooth decrease in the maximum mass fraction of $\mathrm{C}_{24} \mathrm{H}_{12}$ is observed as the $\%$ char yield is increased. At a char yield of $\sim 65 \%$, no significant amount of $\mathrm{C}_{24} \mathrm{H}_{12}$ is predicted to form. This corresponds to a C:H:O elemental composition of 0.152:0.727:0.121 by mole. Figure 8 also shows that the decrease in $\max \left(Y_{C_{24} H_{12}}\right)$ is almost entirely pressure independent. It is found that the temperature associated with the maximum mass fraction of $\mathrm{C}_{24} \mathrm{H}_{12}$ occurs for $T>1150^{\circ} \mathrm{C}$ (with $P=50 \mathrm{kPa}$ ) for the range of elemental compositions considered when there is a significant amount of $\mathrm{C}_{24} \mathrm{H}_{12}$ present. However, as seen in Fig. $4 \mathrm{a}$, there is a large quantity of $\mathrm{C}_{24} \mathrm{H}_{12}$ (mole fraction) that is predicted to form at temperatures near $230^{\circ} \mathrm{C}$. At these relatively low temperatures, the prediction that gaseous coronene will form is most likely not valid. The melting point and boiling point of coronene are $438^{\circ} \mathrm{C}$ and $525^{\circ} \mathrm{C}$ respectively, at standard conditions. Even though the pressure considered in the calculations performed in this section is lower than atmospheric conditions (50 kPa vs. $101 \mathrm{kPa}$ ), at low temperatures, the effect of possible phase changes (condensation or solidification) should be considered. More investigation needs to be performed into this low temperature regime, and this could help explain the point of inflection in mole fraction of $\mathrm{C}_{24} \mathrm{H}_{12}$ in Fig. 6a. It is possible that temperatures lower than the point of inflection seen in the mole fraction of $\mathrm{C}_{24} \mathrm{H}_{12}$ in Fig. 6a correspond to unphysical predictions of $\mathrm{C}_{24} \mathrm{H}_{12}$, and temperatures higher than this point of inflection are physically accurate, but more work is needed to verify this hypothesis.

The $\%$ char yield range shown in Fig. 8 covers a wide range of elemental compositions, and shows that the presence of $\mathrm{C}_{24} \mathrm{H}_{12}$ is significant over a wide range of mixture compositions. If Park et al.'s [25] elemental composition is used (Table 2), up to $\sim 25 \%$ by mass of the equilibrium mixture is predicted to be $\mathrm{C}_{24} \mathrm{H}_{12}$ at $\sim 1200^{\circ} \mathrm{C}$, and if a composition similar to the one used by Milos and Chen (neglecting $\mathrm{Si}$ ) [24] is used (Table 2), then up to $\sim 10 \%$ by mass of the equilibrium mixture is predicted to be $\mathrm{C}_{24} \mathrm{H}_{12}$ by mass at $\sim 1200^{\circ} \mathrm{C}$; neither of the species models in these two studies included any large PAH molecules. To the author's best knowledge, no previous published works have included PAH species in pyrolysis gas mixture when modeling PICA heatshields. In order to understand the overall effect of including PAH species in the pyrolysis gas mixture on the performance of a PICA heatshield, full simulations incorporating PAH species into a thermal response code would have to be performed. 


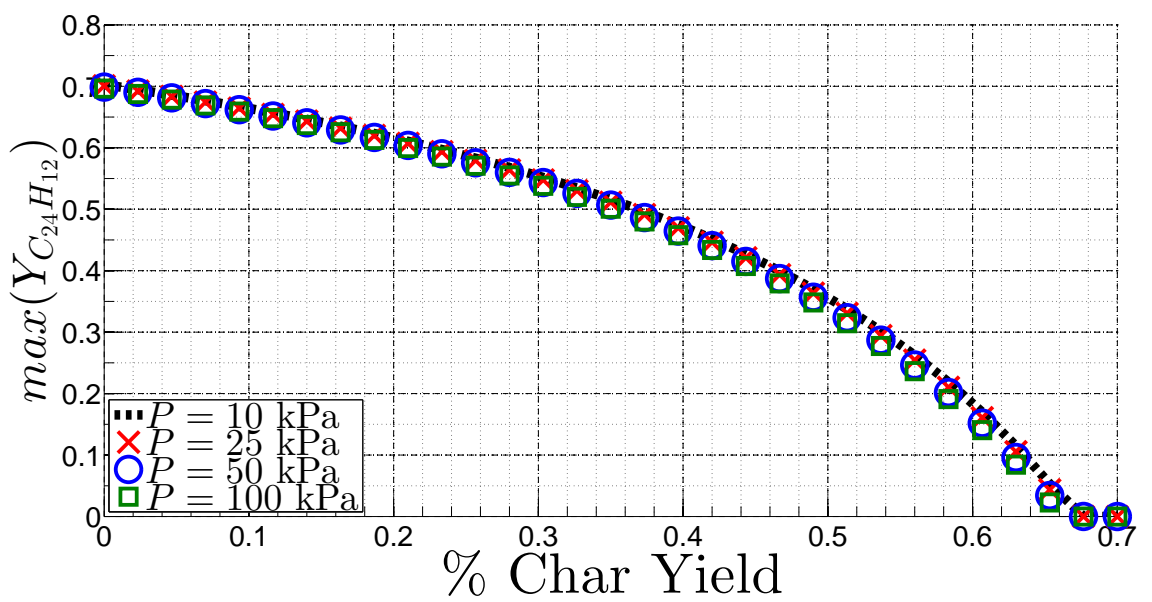

Figure 8: Maximum mass fraction observed of $\mathrm{C}_{24} \mathrm{H}_{12}$ over a temperature range from $230^{\circ} \mathrm{C}$ to $1800^{\circ} \mathrm{C}$, varying the elemental composition. The calculation is performed for four different pressures to show the pressure independence of the plotted values.

\section{III.B. Kinetic Evolution of Pyrolysis Gas Composition}

The previous section did not take into account the finite amount of time it takes to form the large PAH molecules. Although the formation of molecules such as $\mathrm{C}_{24} \mathrm{H}_{12}$ and other large aromatic species is favorable from a thermodynamic standpoint, the residence time of the pyrolysis gas inside of the heatshield might be too short for these molecules to actually form. In order to understand the characteristic timescales involved in this process, several simplifying assumptions are made.

Based on results from MSL [18,27], a characteristic length of $1 \mathrm{~cm}$ is chosen for the distance that the pyrolysis gas will flow before leaving the heatshield. This represents the thickness of the pyrolysis and char layers shown in Fig. 1. A speed of $10 \mathrm{~m} / \mathrm{s}$ is chosen to be characteristic of the speed of the gases traveling internal to the heatshield, based on the analysis performed by Ahn et al. [51]. Once again, the temperature at the bottom of the pyrolysis layer is assumed to be $230^{\circ} \mathrm{C}$, and the temperature at the surface of the heatshield is assumed to be $1800^{\circ} \mathrm{C}$. To isolate the effect of finite-rate kinetics, a simple Lagrangian approach is adopted. It is assumed that a packet of gas travels at a constant speed of $10 \mathrm{~m} / \mathrm{s}$ from the bottom of the pyrolysis layer to the surface of the heatshield, at a constant pressure of $50 \mathrm{kPa}$. This ignores the complicated flow features associated with porous flow, and the effect that the changing density, temperature, and pressure of the fluid would have on the velocity profile of the pyrolysis gases in an actual heat shield. Simulations accounting for these effects, but using simplified chemistry models, can be found in [30]. As the packet of fluid travels from the bottom of the pyrolysis layer to the surface of the heatshield, the temperature of the gas increases. Therefore, the temperature $\left({ }^{\circ} \mathrm{C}\right)$, can be written as a function of time, and for the rest of this work, a linear temperature profile of

$$
T=230^{\circ} \mathrm{C}+1.57^{\circ} \mathrm{C} \cdot t,
$$

is used, where $t$ is given in $\mu \mathrm{s}$. Prescribing a temperature rise also assumes that the heat release from the individual reactions occurring does not affect the temperature gradient imposed by the high temperature gas external to a heatshield. An initial composition of $100 \%$ gaseous phenol $\left(\mathrm{A}_{1} \mathrm{OH}\right)$ is chosen in order to represent the initial composition of the pyrolysis gases. This acts as a "surrogate" for the phenolic solid resin (Sec. II.B.1). Species diffusion is also neglected for these calculations. All of the previous assumptions are made in order to simplify the complicated reacting flow occurring inside of a heatshield, keeping in mind that the goal of these calculations is to find characteristic times associated with $\mathrm{PAH}$ formation.

The combustion database of Blanquart [55-58] is used for the homogeneous reactions involved with the pyrolysis gas mixture (this mechanism is available for public use ${ }^{\mathrm{h}}$ ). This mechanism contains 172 species and 1878 reactions (forwards and reverse reactions counted separately). While this mechanism is geared towards combustion applications, it contains all major pathways for PAH formation, and is useful for understanding timescales associated with PAH formation in the pyrolysis gas mixture. The largest hydrocarbon species

\footnotetext{
${ }^{\mathrm{h}}$ Mechanism available at http://www.theforce. caltech. edu/resources/
} 
included is $\mathrm{C}_{18} \mathrm{H}_{10}$, as the pathways and rates for the formation of larger species, such as $\mathrm{C}_{24} \mathrm{H}_{12}$, are largely unknown at this time. Chemical abbreviations used in this mechanism include: $\mathrm{A}_{1}$ (benzene, $\mathrm{C}_{6} \mathrm{H}_{6}$ ), $\mathrm{A}_{1} \mathrm{OH}$ (phenol, $\mathrm{C}_{6} \mathrm{H}_{6} \mathrm{O}$ ), $\mathrm{A}_{1} \mathrm{C}_{2} \mathrm{H}$ (ethynylbenzene, $\mathrm{C}_{8} \mathrm{H}_{6}$ ), $\mathrm{A}_{2}$ (naphthalene, $\mathrm{C}_{10} \mathrm{H}_{8}$ ), $\mathrm{A}_{2} \mathrm{R} 5$ (acenaphthylene, $\mathrm{C}_{12} \mathrm{H}_{8}$ ), $\mathrm{A}_{2} \mathrm{C}_{2} \mathrm{HB}$ (2-ethynylnapthalene, $\mathrm{C}_{12} \mathrm{H}_{8}$ ), $\mathrm{A}_{2} \mathrm{R} 5 \mathrm{C}_{2} \mathrm{H}$ (1-ethynylacenapthylene, $\mathrm{C}_{14} \mathrm{H}_{8}$ ) and FLTN (fluoranthene, $\mathrm{C}_{16} \mathrm{H}_{10}$ ).

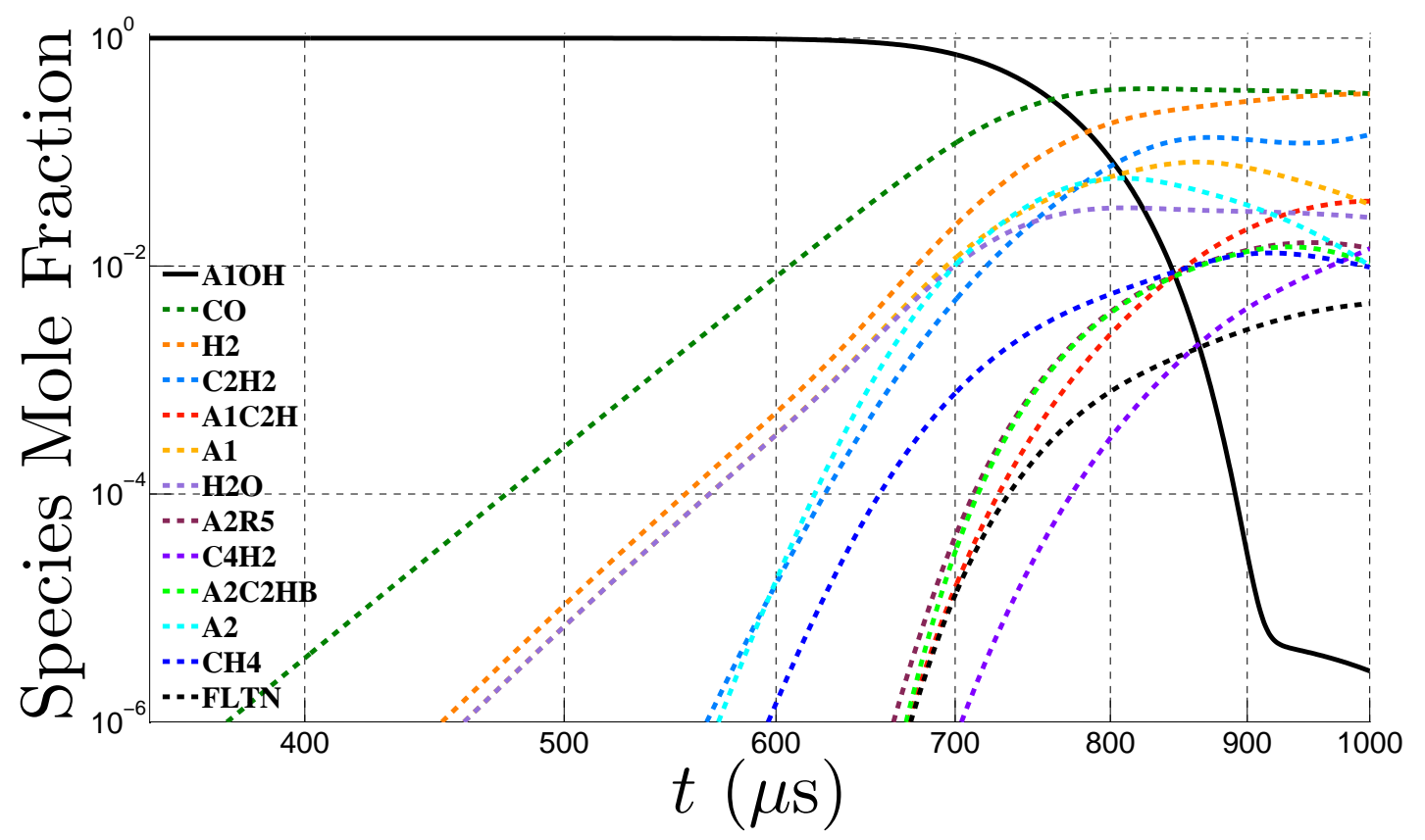

Figure 9: Kinetic evolution of pyrolysis gases with an imposed temperature and pressure profile. A time of $1000 \mu \mathrm{s}$ corresponds to the gas traveling a distance of $1 \mathrm{~cm}$ at a speed of $10 \mathrm{~m} / \mathrm{s} . T=230^{\circ} \mathrm{C}+1.57^{\circ} \mathrm{C} \cdot t$, where $T$ is in ${ }^{\circ} \mathrm{C}$, and $t$ is in $\mu \mathrm{s} . P=50 \mathrm{kPa}$.

Simulations are performed using packages from the CHEMKIN 2 library [59]. A constant pressure homogeneous reactor is used with a prescribed temperature rise as a function of time (Eq. 1), that corresponds to $\sim 1500^{\circ} \mathrm{C} / \mathrm{cm}$ for a fluid moving with a constant speed of $10 \mathrm{~m} / \mathrm{s}$. Figure 9 shows the decomposition of phenol and the kinetic evolution of the gases produced under constant pressure and a prescribed temperature profile. It is clear that significant concentrations of varying PAH molecules are formed by the end of the simulation $(1000 \mu \mathrm{s})$. To contrast this, Fig. 10 shows the composition of the gas mixture if a thermodynamic equilibrium is assumed, with the same C:H:O elemental composition as pure phenol. It is clear that there is a large discrepancy between the two mixtures, as the PAH molecules take time to form in Fig. 9. A maximum amount of $\mathrm{C}_{18} \mathrm{H}_{10}$ is found at $1300^{\circ} \mathrm{C}(8 \%$ by mole, $55 \%$ by mass) when a thermodynamic equilibrium is assumed. A quantitative comparison between the two mixtures is shown in Fig. 11, comparing the mixture enthalpies by mass between the two cases. Extremely large discrepancies are noted, showing that the bulk properties of the mixture are greatly affected by a thermodynamic equilibrium assumption.

Figures 9-11 isolate the effect of assuming that the pyrolysis gas mixture is in thermodynamic equilibrium vs. allowing the pyrolysis gas mixture to evolve kinetically. The same elemental composition (that of phenol) was used for both the equilibrium and finite-rate kinetics calculations, and the same species model was used for both of these calculations. Not only is the enthalpy of a mixture in thermodynamic equilibrium largely effected by the largest hydrocarbon molecule included, but the finite amount of time it takes the PAH species to form based on kinetics also has a great effect on the mixture enthalpy. It should be noted that the chemical mechanism used in this section was not directly designed for these conditions. Nevertheless, the results show that significant quantities of PAH species will form in a relatively small amount of time and this will have significant effects on modeling efforts for these composite ablative materials.

To summarize this entire section, three different effects have been isolated: 1) the effect of elemental composition on the pyrolysis gas mixture; 2) the effect of the gas species model chosen on the pyrolysis gas mixture; and 3) the effect of assuming thermodynamic equilibrium vs. finite-rate kinetics on the pyrolysis 
gas mixture. The large discrepancies shown between all of these assumptions must be known and accounted for when determining what models to use in a thermal response code.

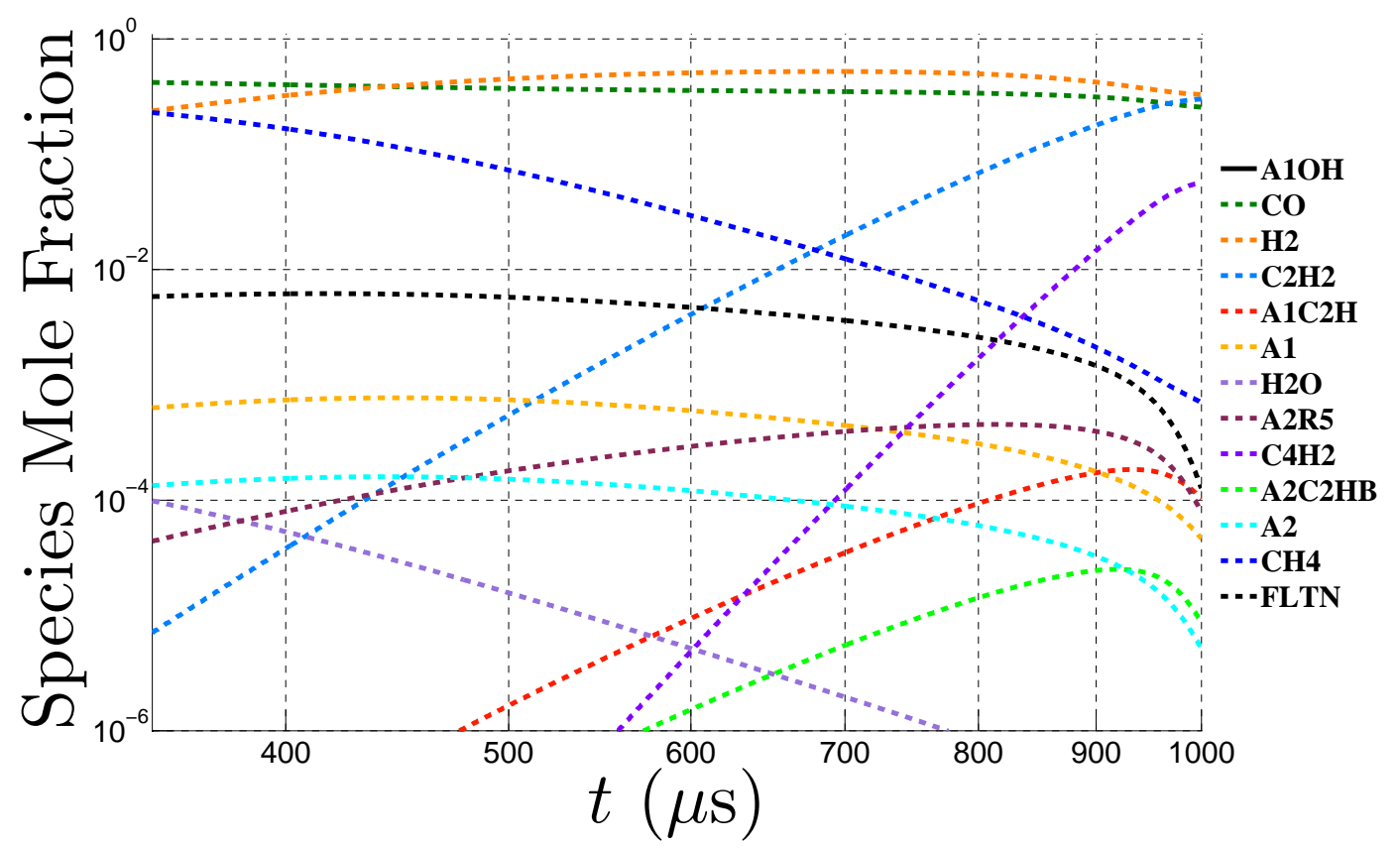

Figure 10: Equilibrium composition of pyrolysis gases with the same imposed temperature and pressure profile. $T=230^{\circ} \mathrm{C}+1.57^{\circ} \mathrm{C} \cdot t$, where $T$ is in ${ }^{\circ} \mathrm{C}$, and $t$ is in $\mu \mathrm{s} . P=50 \mathrm{kPa}$. 


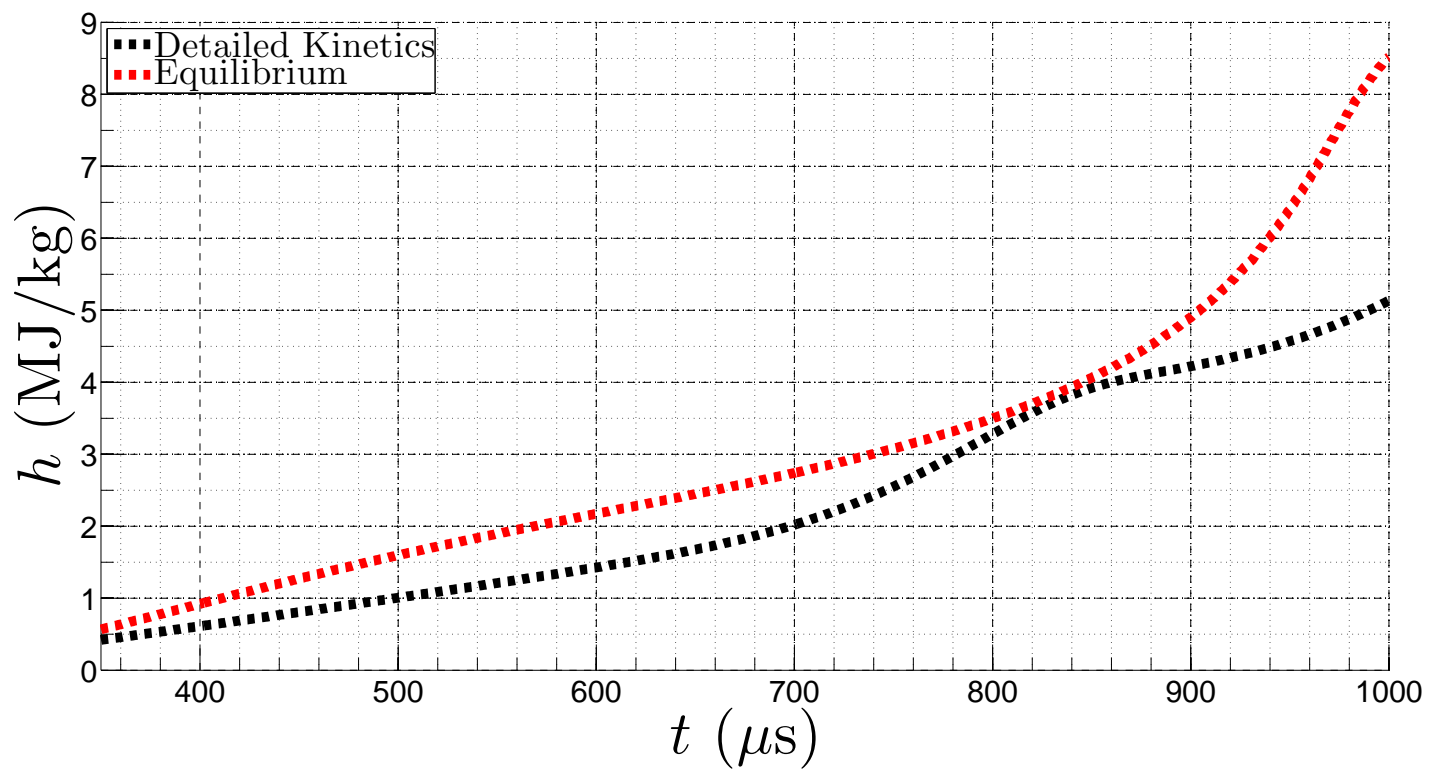

Figure 11: Enthalpy comparison between the gas mixtures assuming detailed kinetics (black) and thermodynamic equilibrium (red). $T=230^{\circ} \mathrm{C}+1.57^{\circ} \mathrm{C} \cdot t$, where $T$ is in ${ }^{\circ} \mathrm{C}$, and $t$ is in $\mu$ s. $P=50 \mathrm{kPa}$. 


\section{Pyrolysis Gas Flow Regime}

The previous analysis was performed assuming a standard continuum flow regime. In order to validate this assumption for the flow of the pyrolysis gases internal to a heatshield, relevant length scales must be compared. In this section, conditions characteristic of what MSL experienced on entry into the Martian atmosphere are used to estimate the flow regime of the pyrolysis gas inside of an ablative heatshield. By using flight data reported by Bose et al. [18] and Mahzari et al. [27], a mean free path of the pyrolysis gas can be estimated, and this can be compared to the relevant length scales in the heatshield itself (size of the pyrolysis layer, diameter of the fibers in the virgin PICA material, and the average fiber separation).

\section{IV.A. Continuum Flow Assumption}

The mean free path $(\lambda)$ can be calculated from

$$
\lambda=\frac{k_{B} T}{\sqrt{2} \pi \sigma^{2} P},
$$

where $k_{B}$ is the Boltzmann constant $(\mathrm{J} / \mathrm{K}), T$ is the temperature $(\mathrm{K}), \sigma$ is the collision diameter of the gas molecules $(\mathrm{m})$, and $P$ is the pressure of the gas $(\mathrm{Pa})$. The MISP reconstructed temperature data shows that the thermocouples installed in the MSL heatshield experienced a wide range of temperatures, depending on the location of the thermocouple in the heatshield, the time during flight, and how deep below the heatshield surface the thermocouple was installed. $1000 \mathrm{~K}$ is taken as a characteristic temperature for these calculations, which is based on the temperature range that the thermocouple closest to the heatshield surface $(\sim 0.25 \mathrm{~cm})$ experienced.

Surface pressure CFD predictions were made by Bose et al. [18], and over the time that corresponds to a heatshield temperature close to $1000 \mathrm{~K}$, surface pressure predictions range from $\sim 15 \mathrm{kPa}$ to $\sim 30 \mathrm{kPa}$. These measurements were confirmed by flight data taken by the Mars Entry Atmospheric Data System (MEADS) [60]. Calculations performed by Ahn et al. [51] for the Pioneer Venus Small Probe (Day) showed that the pressure of the pyrolysis gas inside the heatshield can be a factor of two or higher than the surface pressure. Taking these facts into consideration, a value of $50 \mathrm{kPa}$ is chosen to be a characteristic pressure inside of the heatshield for this calculation. The same pressure was used for the results presented in the previous section.

To evaluate the collision diameter, the gas mixture is assumed to have the same elemental composition as a cured phenolic resin. Assuming thermal equilibrium, the main constituents of the mixture by volume are $\mathrm{CO}(43 \%), \mathrm{H}_{2}(25 \%), \mathrm{CH}_{4}(22 \%)$, and $\mathrm{C}_{24} \mathrm{H}_{12}(10 \%)$ at $1000 \mathrm{~K}$ and $50 \mathrm{kPa}$. For simplicity, as this is an order of magnitude calculation, the diameter of $\mathrm{CO}\left(3.65 \cdot 10^{-10} \mathrm{~m}\right)$ is used in this calculation.

The Knudsen number, which is the ratio of the mean free path to a characteristic length scale $(K n=\lambda / l)$, allows one to determine if the flow is in a continuum regime. From Eq. 2, the mean free path is evaluated to be approximately $\lambda \approx 6 \cdot 10^{-7} \mathrm{~m}$. If this is compared to a characteristic length of $1 \mathrm{~cm}$ associated with the pyrolysis layer, then $K n \ll 1$, and the pyrolysis gas is in a continuum regime. While this Knudsen number shows that on a global scale the flow is in a continuum regime, the potential for collisions between the gas molecules and the carbon fibers must also be taken into account in order to estimate the importance of heterogeneous interactions [30,33].

A Knudsen number calculation based on a fiber diameter of $10 \mu \mathrm{m}$ (Sec. II.A) yields $K n \sim 0.05$. Alternatively, the mean free path can be compared to an estimation of the average separation distance between the fibers in the char layer. The mean distance is calculated by making the simplifying assumption that the cylinders are arranged into a triangular unit cell, and are infinitely long. Assuming a porosity of $90 \%$ (Sec. II.A) allows a mean separation to be estimated. A schematic of this arrangement is shown in Fig. 12, where $r$ is the fiber radius, and $s$ is a calculated distance to give the desired porosity. Using the properties of ASTERM given in Sec. II.A, a mean distance between the fibers can be estimated to be $10 \mu \mathrm{m}$, which results again in $K n \sim 0.05$. Similar values for $K n$ were calculated for the PICA heatshield used on the Stardust mission, when different conditions along the Stardust re-entry trajectory were used [61].

A $K n \sim 0.05$ is low enough that the flow can be considered to be in a continuum regime, but it is also large enough to imply that heterogeneous reactions between the pyrolysis gas and the solid carbon fibers cannot be ignored. This is the "coking zone" proposed by Lachaud and Mansour [30], and Wong et al. [33], where it is possible for the gaseous carbon to form a solid residue on the fibers, and other heterogeneous reactions to occur. In addition, it is possible for solid carbon molecules to be formed through gaseous collisions, similar to 


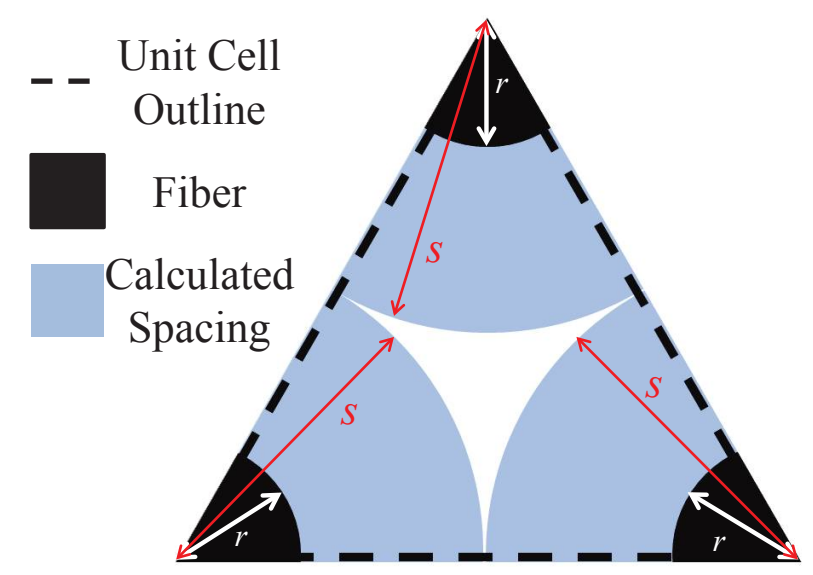

Figure 12: Schematic showing the simplified packing assumption for the carbon fibers. $r$ is the fiber radius, and $s$ is a calculated length to give the measured porosity.

soot being formed in a flame. These phenomena remove additional carbon concentration from the pyrolysis gas mixture, and effect the elemental composition of the gas. More details on these phenomena are provided in the following two sections.

\section{IV.B. PAH Collisions}

In previous studies, soot formation is primarily discussed with respect to flames, and a summary of the formation of condensed-phased materials in flames was recently written by Wang [62]. While there are competing theories on soot nucleation and growth, in general, models start from vapor-phase nucleation. Particle growth then occurs through coalescence, coagulation, surface reactions, and condensation of vapor species $[62,63]$. Nevertheless, a common trend among these theories is that collisions between PAH species are believed to form pre-cursors species for larger soot particles [62]. Early models used PAH-PAH sticking coefficients on the order of 0.2-0.4 [64], while more recent work looks into great detail of the interactions between two PAH species [65].

The frequency of PAH-PAH collisions can be calculated in order to determine whether or not "sooting" is expected to occur internal to the heatshield. Following the derivation by Vincenti and Kruger [66] for collision rates, the number of free paths terminated for a molecule of type $A$, by a molecule of type $Y$, per unit time is

$$
\Theta_{A Y}=n_{Y} \sigma_{A Y}^{2}\left(\frac{8 \pi k T}{m_{A Y}^{*}}\right)^{1 / 2}
$$

where $\Theta_{A Y}$ is the number of paths terminated per unit time, $n_{Y}$ is the number of $Y$ molecules per unit volume, $\sigma_{A Y}$ is the collision diameter of $A$ and $Y$, and $m_{A Y}^{*}$ is the reduced mass for $A$ and $Y$. As collisions between two of the same molecules, for instance $\mathrm{C}_{24} \mathrm{H}_{12}$, are being considered for soot nucleation, the reduced mass is $m_{\mathrm{C}_{24}} \mathrm{H}_{12} / 2$, and the collision diameter is the diameter of a coronene molecule. The collision diameter of $\mathrm{C}_{24} \mathrm{H}_{12}$ is approximated to be $9.2 \cdot 10^{-10} \mathrm{~m}$ through a simple MM2 [67 energy minimization calculation. $n_{Y}$ is a function of both $T$ and the partial pressure of $\mathrm{C}_{24} \mathrm{H}_{12} \cdot \Theta_{A Y}$ represents a collision frequency, and in order to estimate the number of collisions expected, this value is multiplied by a characteristic time. Once again, a speed of $10 \mathrm{~m} / \mathrm{s}$ is assumed over a length of $1 \mathrm{~cm}$ which results in a time of $1 \mathrm{~ms}$. Writing Eq. 3 in terms of $P_{\mathrm{C}_{24} \mathrm{H}_{12}}, T$ and multiplying by $1 \mathrm{~ms}$ yields

$$
\kappa \approx \frac{2300\left[\kappa \frac{\mathrm{K}^{1 / 2} \mathrm{~m} \mathrm{~s}^{2}}{\mathrm{~kg}}\right] P_{\mathrm{C}_{24} \mathrm{H}_{12}}}{T^{1 / 2}},
$$

where $\kappa$ is the number of collisions one coronene molecule is expected to undergo with another coronene molecule before it is injected into the boundary layer. From Fig. 9, mole fractions for PAH species are observed to be on the order of $1 \%$. Equilibrium mixture calculations previously shown show a range in concentrations of $\mathrm{C}_{24} \mathrm{H}_{12}$, with maximum values corresponding to approximately a $10 \%$ mole fraction of 
coronene. Assuming a mixture pressure of $50 \mathrm{kPa}$, and a temperature of $1000 \mathrm{~K}$ results in a range of approximately $36,000\left(X_{C_{24} H_{12}}=0.01\right)$ collisions to $360,000\left(X_{C_{24} H_{12}}=0.1\right)$ collisions expected.

If every collision between two PAH molecules were to lead to soot pre-cursors, and the removal of the two $\mathrm{PAH}$ molecules from the flow, then $\frac{\mathrm{d} n_{P A H}}{\mathrm{~d} t}=-2 k n_{P A H}^{2}$, where $\mathrm{k}$ is a rate constant. Relating this expression to Eq. 3 yields $\Theta_{P A H, P A H}=k n_{P A H}$. In addition, sooting models generally include a sticking efficiency, which takes into account that for every collision between two molecules, most molecules may not stick to each other, but instead "bounce off" of each other. A value of 0.3 is used for this sticking efficiency [64]. Considering $\mathrm{C}_{24} \mathrm{H}_{12}$ as the $\mathrm{PAH}$ molecule results in

$$
\frac{\mathrm{d} n_{C_{24} H_{12}}}{\mathrm{~d} t}=-2 \cdot 0.3 \cdot \sigma_{C_{24} H_{12}, C_{24} H_{12}}^{2}\left(\frac{8 \pi k T}{m_{C_{24} H_{12}, C_{24} H_{12}}^{*}}\right)^{1 / 2} n_{C_{24} H_{12}}^{2} .
$$

The solution to this ODE is

$$
n_{C_{24} H_{12}}(t)=\frac{n_{C_{24} H_{12}}^{\circ}}{1+2 \cdot 0.3 \sigma_{C_{24} H_{12}, C_{24} H_{12}}^{2} n_{C_{24} H_{12}}^{\circ} t\left(\frac{8 \pi k T}{m_{C_{24} H_{12}, C_{24} H_{12}}^{*}}\right)^{1 / 2}},
$$

where $n_{C_{24} H_{12}}^{\circ}=n_{C_{24} H_{12}}(t=0)$, the initial number of $\mathrm{C}_{24} \mathrm{H}_{12}$ molecules per unit volume.

Evaluating Eq. 6 at $t=0.001 \mathrm{~s}$ (corresponding to the surface of the heatshield), $T=1000 \mathrm{~K}, P=50 \mathrm{kPa}$, and $X_{C_{24} H_{12}}=0.01$ or $X_{C_{24} H_{12}}=0.1$, results in $99.5 \%$ and $99.95 \%$, respectively, of the $\mathrm{C}_{24} \mathrm{H}_{12}$ being removed from the flow. Even if the sticking coefficient is decreased by a factor of 1000 , and $X_{C_{24} H_{12}}=0.01,95.6 \%$ of the $\mathrm{C}_{24} \mathrm{H}_{12}$ is predicted to be removed from the flow, showing that this sooting prediction is relatively insensitive to the chosen sticking efficiency. These calculations imply that it is likely that soot will be formed from any PAH molecules. Once "soot" particles are formed, it would also be possible for these particles to collide with and deposit on the fibers. These calculations, while estimates, show that the removal of PAH species from the flow due to soot formation needs to be taken into account when considering the evolution of the pyrolysis gases.

\section{IV.C. PAH and Fiber Collisions}

Not only must collisions between PAH molecules be considered, but collisions between PAH molecules and the carbon fibers will also occur in a heatshield. Originally, when deriving Eq. 2 for the mean free path in a gas mixture, it is standard to assume that one molecule is in motion, and all other molecules are stationary. Following this derivation, once again performed by Vincenti and Kruger [66], the number of collisions per unit time for a single molecule with another molecule of the same type is found to be

$$
\Theta=\pi \sigma^{2} \bar{C} n \text {. }
$$

$\bar{C}$ is the mean molecular speed, $\sigma$ is a collision diameter (based on a sphere of influence calculation), and $n$ is the number of molecules per unit volume of the gas. This expression must now be altered in order to estimate how many times a single PAH molecule will collide with a stationary carbon fiber, as Eq. 7 is only valid for spherical particles impacting other spherical particles. Internal to a heatshield, it is assumed that spherical coronene particles are colliding with infinitely long cylindrical carbon fibers (Fig. 12). To simplify this calculation, it is assumed that coronene molecules are traveling perpendicular to the length of fibers, and all of the fibers are parallel to one another, as shown by the infinitely repeating unit cell shown in Fig. 12. The $\pi \sigma^{2} \bar{C}$ product from Eq. 7 represents a cylindrical volume carved out by a moving particle. Due to the assumption that cylindrical fibers are all parallel, and that the coronene particles move perpendicular to the fiber length, this term is now modified so that only an in plane area is considered, and becomes $\sigma \bar{C}$. However, a new area of influence must be calculated. The diameter of this "circle" of influence is given by $\sigma_{\mathrm{C}_{24} \mathrm{H}_{12}}+d_{f}$, where $d_{f}$ is the fiber diameter. A $2 \mathrm{D}$ schematic of this arrangement is shown in Fig. 13. As $d_{f} \gg \sigma_{\mathrm{C}_{24}} \mathrm{H}_{12}$, this can be approximated by $d_{f}$. A modified $n$ is now calculated such that it refers to a number density (per unit area) of carbon fiber centers.

Combining this information results in

$$
\Theta=d_{f} \bar{C} n^{*},
$$

where $n^{*}$ is the number of fiber centers per given area. Assuming a Boltzmann distribution, $\bar{C}=\left(\frac{8 k T}{\pi m_{\mathrm{C}_{24}} \mathrm{H}_{12}}\right)^{1 / 2}$. Multiplying the collision frequency by the same characteristic time as before, results in $\kappa \approx 160\left[\kappa T^{-0.5}\right] T^{0.5}$. 


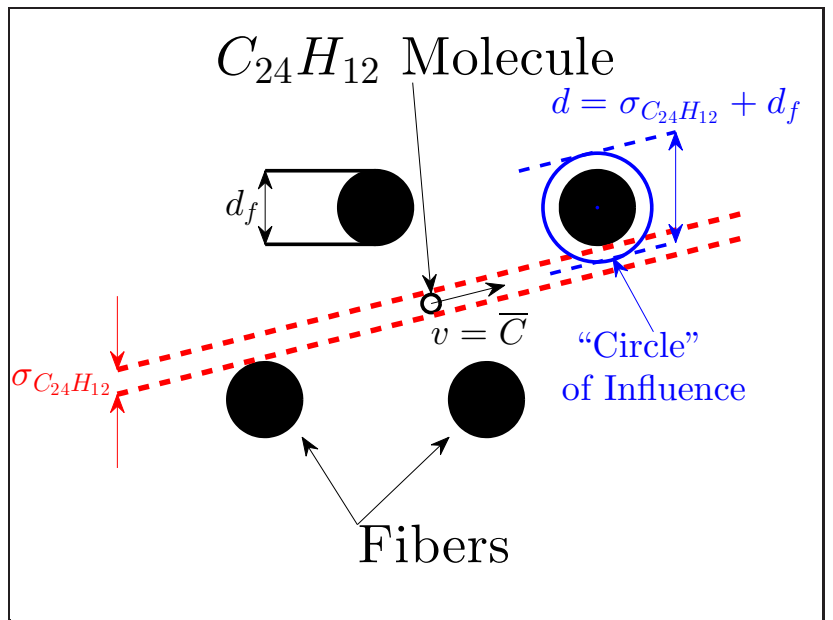

Figure 13: 2D schematic outlining the geometrical assumptions for $\mathrm{C}_{24} \mathrm{H}_{12}$ colliding with a carbon fiber. This figure represents a top-down view of a plane intersected by the fibers (fibers are assumed to be infinitely long in/out of the page). The "circle" of influence outlines an area that needs need to be considered for collisions between $\mathrm{C}_{24} \mathrm{H}_{12}$ molecules and the stationary carbon fibers.

Assuming a reference temperature of $1000 \mathrm{~K}$, this calculation shows that a single coronene molecule will collide with a carbon fiber approximately 5200 times before leaving the heatshield.

This corresponds to an estimate for an upper bound on the number collisions between PAH molecules and fibers in a heatshield. In the opposite extreme, no collisions would occur if the particles were all traveling parallel to the carbon fibers. This is an unrealistic assumption, as the length of the carbon fibers is expected to be on the order of $650 \mu \mathrm{m}$ (Sec. II.A), which is much smaller than the expected size of the pyrolysis layer $(\sim 1 \mathrm{~cm})$. Furthermore, the mean free path of the molecules was estimated to be less than $1 \mu \mathrm{m}$. Under these conditions, the molecules are not expected to remain parallel to the fibers. As was previously shown in Fig. 2, the fibers are expected to be aligned in a random manner. Because of this random structure, and the random motion of the molecules (due to Brownian collisions), a more advanced model would be required to more accurately estimate for the number of collisions between PAH molecules and fibers. Some work has been done investigating the microscopic structure of PICA through the use of numerical simulations [61], though this is outside the scope of this work.

It is interesting to note that the collision rate, $\Theta$, is no longer a function of $n_{C_{24} H_{12}}$, but is constant because $n^{*}$ is constant. If every collision between a PAH molecule and a carbon fiber were to result with the PAH molecule being deposited on the carbon fiber, then

$$
\frac{\mathrm{d} n_{P A H}}{\mathrm{~d} t}=-k n_{P A H},
$$

where $k$ is once again a rate constant. Unlike Eq. 5, Eq. 9 is linear in $n_{C_{24} H_{12}}$, since only collisions between $\mathrm{PAH}$ molecules and fibers, and not collisions between PAH molecules and other PAH molecules are being considered. Combing Eq. 8 and Eq. 9 gives

$$
\frac{\mathrm{d} n_{C_{24} H_{12}}}{\mathrm{~d} t}=-d_{f} \bar{C} n^{*} n_{C_{24} H_{12}} .
$$

The solution to this ODE is

$$
n_{C_{24} H_{12}}(t)=n_{C_{24} H_{12}}^{\circ} e^{-d_{f} \bar{C} n^{*} t},
$$

where $n_{C_{24} H_{12}}^{\circ}=n_{C_{24} H_{12}}(t=0)$, the initial number of $\mathrm{C}_{24} \mathrm{H}_{12}$ molecules per unit volume. Evaluating Eq. 11 with $T=1000 \mathrm{~K}, P=50 \mathrm{kPa}$, and $X_{C_{24} H_{12}}=0.01$ or $X_{C_{24} H_{12}}=0.1$, at $t=0.001 \mathrm{~s}$, results in essentially none of the original PAH molecules remaining. Even if the right hand side of Eq. 9 is divided by 1000 , and assuming $X_{C_{24} H_{12}}=0.01$, Eq. 11 predicts that $99 \%$ of the PAH species will be removed at $t=0.001 \mathrm{~s}$. This results is very similar to the PAH-PAH collision results; the carbon deposition prediction is relatively insensitive to the assumptions that went into the collision model. These calculations once again imply that it is likely that carbon deposition on the fibers will occur. 
Primarily, it is challenging to estimate a sticking efficiency for what percentage of collisions between a coronene molecule and a fiber will remove a $\mathrm{C}_{24} \mathrm{H}_{12}$ molecule from the gas mixture. More work needs to be put into quantifying how much mass deposition will occur on the solid fibers due to heterogeneous reactions. In the future, it might be possible to experimentally measure a sticking efficiency for the PAH molecules and fibers, similar to what is done for soot formation. Even though it is hard to draw quantitative conclusions from this analysis, the results suggest that heterogeneous collisions will affect the overall evolution of the pyrolysis gas mixture.

\section{Effect of Carbon Deposition}

When the pyrolysis gas flows through a porous medium consisting of carbon fibers, the previous sections showed that a large number of PAH-PAH and PAH-fiber collisions are expected. Preliminary calculations also showed that soot formation, and surface deposition reactions are highly probable. Surface reactions will also likely be encouraged due to the relatively large size of the carbon fibers $(\mu \mathrm{m})$, compared to the PAH molecules $(\AA)$, and soot nuclei $(\mathrm{nm})$. Heterogeneous reaction rates are still widely unknown, and previous works have only focused on oxidation reactions with respect to the fibers [68]. The potential for solid carbon deposition, through "soot" or PAH/fiber collisions, and the effect that this has on the pyrolysis gas mixture is a topic that has not received much attention previously. In order to determine whether or not solid carbon deposition on the fibers will affect the bulk properties of the pyrolysis gas, the following models are proposed.

\section{V.A. Model \#1}

To mimic the porous flow of increasing temperature towards the surface of the heat shield, we propose the following model, based on thermodynamic equilibrium calculations. At every temperature considered, any coronene present in the gaseous mixture is removed (due to the high number of collisions predicted in Sec. IV.C), and then the enthalpy of the remaining mixture is re-evaluated. The calculations are performed over a temperature range between $230^{\circ} \mathrm{C}$ and $1800^{\circ} \mathrm{C} .1800^{\circ} \mathrm{C}$ is a good approximation of the temperature that the surface of a heat shield would experience during atmospheric entry.

This simple model assumes that any carbon predicted to be in a large PAH molecule is likely to form a solid carbon substance. This assumption accounts for gas-phase nucleation of soot particles, which are then deposited inside of the heatshield, as well as heterogeneous reactions between a PAH molecule and a carbon fiber that result in a PAH molecule "sticking" to a carbon fiber. A slight variant of this model is also proposed such that any hydrogen content from coronene is added back into the overall gaseous species composition. This accounts for the dehydrogenation effect previously mentioned [47, 48]. This method is referred to as Model \#1, and is outlined by the following equations:

$$
\begin{aligned}
\mathbf{Y}^{*}(T, P) & =\mathbf{Y}^{\mathbf{E Q}}\left(T, P, \mathbf{Y}^{\circ}\right) \\
Y_{i \neq \mathrm{C}_{24} \mathrm{H}_{12}}^{M 1}(T, P) & =Y_{i}^{*}(T, P) \\
Y_{\mathrm{C}_{24} \mathrm{H}_{12}}^{M 1}(T, P) & =0 \\
h^{M 1}(T, P) & =\sum_{i=1}^{n s} h_{i}(T) Y_{i}^{M 1 *}(T, P)
\end{aligned}
$$

where the superscript $M 1$ refers to Model \#1, and Eq. 12 is a thermodynamic equilibrium calculation holding $T$ and $P$ constant, for a chosen constant initial elemental composition $\left(\mathbf{Y}^{\circ}\right)$ of the pyrolysis gas mixture. The mass fractions, $\mathbf{Y}^{\mathbf{M} 1}$, are normalized before Eq. 15 so that $\sum_{i=1}^{n s} Y_{i}^{M 1 *}(T, P)=1$. $P$ is held constant at $50 \mathrm{kPa}$, and $T$ is varied. A slight variation to this model where $\mathrm{H}$ is added back into the mixture is outlined 
by:

$$
\begin{aligned}
\mathbf{Y}^{*}(T, P) & =\mathbf{Y}^{\mathbf{E Q}}\left(T, P, \mathbf{Y}^{\circ}\right) \\
Y_{i \neq \mathrm{C}_{24} \mathrm{H}_{12}, i \neq \mathrm{H}_{2}}^{M 1 H}(T, P) & =Y_{i}^{*}(T, P) \\
Y_{\mathrm{H}_{2}}^{M 1 H}(T, P) & =Y_{\mathrm{H}_{2}}^{*}(T, P)+6 \frac{W_{\mathrm{H}_{2}}}{W_{\mathrm{C}_{24} \mathrm{H}_{12}}} Y_{\mathrm{C}_{24} \mathrm{H}_{12}}^{*}(T, P) \\
Y_{\mathrm{C}_{24} \mathrm{H}_{12}}^{M 1 H}(T, P) & =0 \\
h^{M 1 H}(T, P) & =\sum_{i=1}^{n s} h_{i}(T) Y_{i}^{M 1 H *}(T, P)
\end{aligned}
$$

where the superscript $M 1 H$ refers to Model \#1 - Add H, and Eq. 16 is once again a thermodynamic equilibrium calculation holding $T$ and $P$ constant, for a chosen initial elemental composition $\left(\mathbf{Y}^{\circ}\right)$ of the pyrolysis gas mixture. The mass fractions, $\mathbf{Y}^{\mathbf{M} 1 \mathbf{H}}$, are again normalized before Eq. 20, so that $\sum_{i=1}^{n s} Y_{i}^{M 1 H *}(T, P)=1$.

For both variants of Model \#1, no changes in $h^{M 1}$ or $h^{M 1 H}$ are observed if another thermodynamic equilibrium calculation is performed on the modified mixtures ( $\mathbf{Y}^{\mathbf{M} 1 *}$ and $\left.\mathbf{Y}^{\mathbf{M} 1 \mathbf{H}^{*}}\right)$.

\section{V.B. Model \#2}

Model \#2 accounts for the fact that Model \#1 does not consider the time history of the pyrolysis gas flowing through the porous layer. As the pyrolysis gas travels towards the surface of the heat shield, the local temperature increases, and carbon may be deposited at various locations in the heatshield. In order to take the flow history into account, a simple integration through the pyrolysis/char layer is performed using temperature as the integration variable. This approach once again assumes that the time scale associated with removing the carbon char from the flow is small compared to the time scale associated with the convection of the pyrolysis gases through the heatshield. This method is referred to as Model \#2 (M2), and it is outlined by the following equations:

$$
\begin{aligned}
\mathbf{Y}^{*}(j) & =\mathbf{Y}^{\mathbf{E Q}}\left(T(j), P, \mathbf{Y}^{\mathbf{M} 2 *}(j-1)\right) \\
Y_{i \neq \mathrm{C}_{24} \mathrm{H}_{12}}^{M 2}(j) & =Y_{i}^{*}(j) \\
Y_{\mathrm{C}_{24} \mathrm{H}_{12}}^{M 2}(j) & =0 \\
h^{M 2}(j) & =\sum_{i=1}^{n s} h_{i}(T(j)) Y_{i}^{M 2 *}(j)
\end{aligned}
$$

where Eq. 21 corresponds to a thermodynamic equilibrium calculation at the specified temperature and pressure, based on the elemental composition from the previous iteration. The mass fractions, $\mathbf{Y}^{\mathbf{M} 2}(j)$, are normalized before Eq. 24 so that $\sum_{i=1}^{n s} Y_{i}^{M 2 *}(j)=1 . \quad j$ corresponds to the index of an array, where $j=1,2, \ldots, 1000 . \mathbf{Y}^{\mathbf{M} 2 *}(0)$, the initial condition, is defined to be the thermodynamic equilibrium composition at $230^{\circ} \mathrm{C}, 50 \mathrm{kPa}$, and a chosen composition of $\mathbf{Y}^{\circ}$. As $\mathbf{Y}^{\mathbf{M} 2}(j)$ is now a function of $\mathbf{Y}^{\mathbf{M} 2}(j-1)$, any carbon that is removed from the mixture at lower temperatures is no longer present in the mixture at higher temperatures. A temperature array is defined to be $T(j)=230^{\circ} \mathrm{C}+j \cdot 1.57^{\circ} \mathrm{C}$, in order to use 1000 points through the desired temperature range. A large number of temperature iterations are used in order to mimic thermodynamic quasi-equilibrium throughout the heat shield. Increasing the number of points used had no effect on the resulting enthalpy calculations.

Again, a slight variant of this model is also proposed $(M 2 H)$ such that any hydrogen content from 
coronene is added back into the overall gaseous species composition, and is outlined by:

$$
\begin{aligned}
\mathbf{Y}^{*}(j) & =\mathbf{Y}^{\mathbf{E Q}}\left(T(j), P, \mathbf{Y}^{\mathbf{M} 2 \mathbf{H} *}(j-1)\right) \\
Y_{i \neq \mathrm{C}_{24} \mathrm{H}_{12}, \neq \mathrm{H}_{2}}^{M 2 H}(j) & =Y_{i}^{*}(j) \\
Y_{\mathrm{H}_{2}}^{M 2 H}(j) & =Y_{\mathrm{H}_{2}}^{*}(j)+6 \frac{W_{\mathrm{H}_{2}}}{W_{\mathrm{C}_{24} \mathrm{H}_{12}}} Y_{\mathrm{C}_{24} \mathrm{H}_{12}}^{*}(j) \\
Y_{\mathrm{C}_{24} \mathrm{H}_{12}}^{M 2 H}(j) & =0 \\
h^{M 2 H}(j) & =\sum_{i=1}^{n s} h_{i}(T(j)) Y_{i}^{M 2 H *}(j),
\end{aligned}
$$

where Eq. 25 corresponds to a thermodynamic equilibrium calculation at the specified temperature and pressure, based on the elemental composition from the previous iteration. The mass fractions, $\mathbf{Y}^{\mathbf{M} 2 \mathbf{H}}(j)$, are again normalized before Eq. 29 so that $\sum_{i=1}^{n s} Y_{i}^{M 2 H *}(j)=1$

\section{V.C. Results}

The enthalpy of the mixtures are plotted in Fig. 14, Fig. 15 and Fig. 16, for original elemental compositions $\left(\mathbf{Y}_{\circ}\right)$ of $0 \%, 35 \%$, and $60 \%$ char yield, respectively. The enthalpy of the mixture calculated with a standard thermodynamic equilibrium calculation at constant temperature and pressure (no removal of carbon) is also shown.

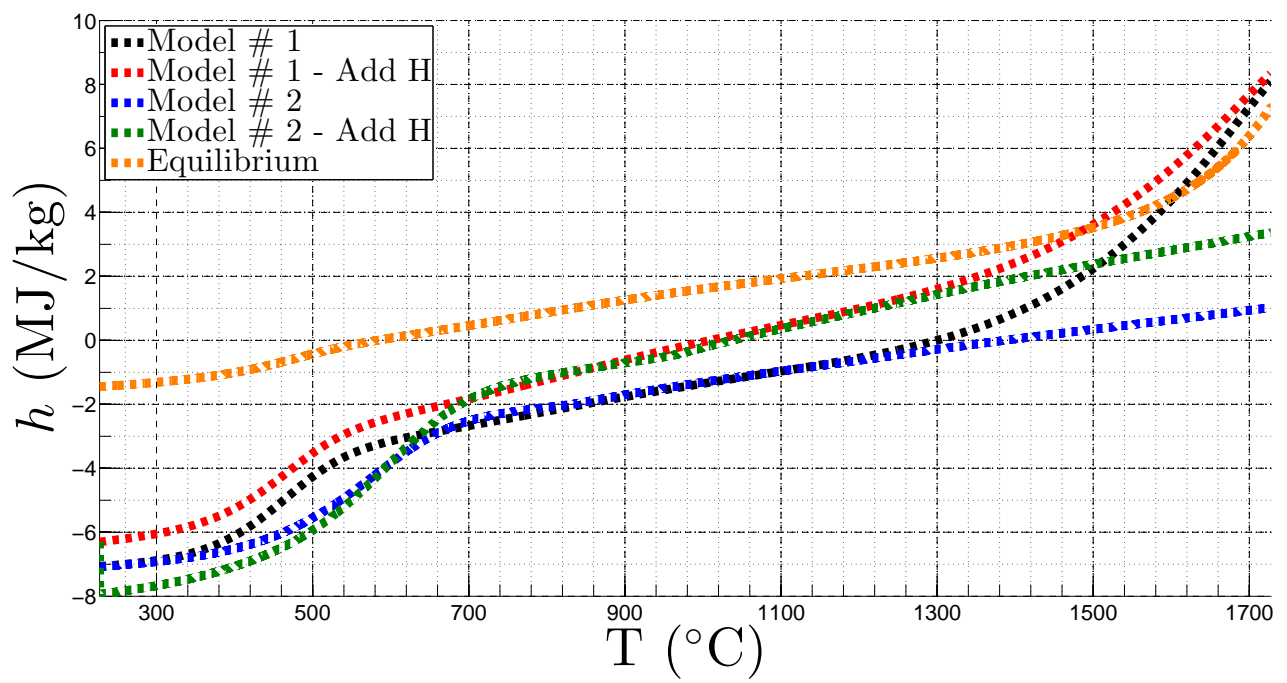

Figure 14: Enthalpy comparison using different models to account for solid char deposition. The original elemental composition corresponds to a $0 \%$ char yield.

As expected, a larger discrepancy is seen between the carbon deposition models and the thermodynamic equilibrium calculations for the compositions that initially include more carbon ( $0 \%$ char yield). This is because the high carbon content in these mixtures favors the formation of coronene. The main discrepancy between Model \# 1 and Model \# 2 is seen at higher temperatures. This is due to the constant removal of carbon from the mixture as the temperature is increased for Model \#2. Once a significant quantity of carbon is removed from the gas mixture, the formation of PAH molecules is no longer encouraged, and a relatively linear increase in enthalpy is seen as temperature increases. This is attributed to a relatively constant $c_{p}$ value in this temperature range. These plots indicate that for regions in the pyrolysis layer where there is a high concentration of carbon present in the gaseous phase, solid carbon deposition will greatly influence the enthalpy of the mixture. Finally, the differences between Model \#1 and Model \#2 at higher temperatures indicate that taking into account the history of the pyrolysis gas flow is important. Where soot formation, or solid carbon deposition occurs in the heat shield will effect where the elemental composition of the pyrolysis gas changes. The species composition and elemental composition of the pyrolysis gas will continue to change 


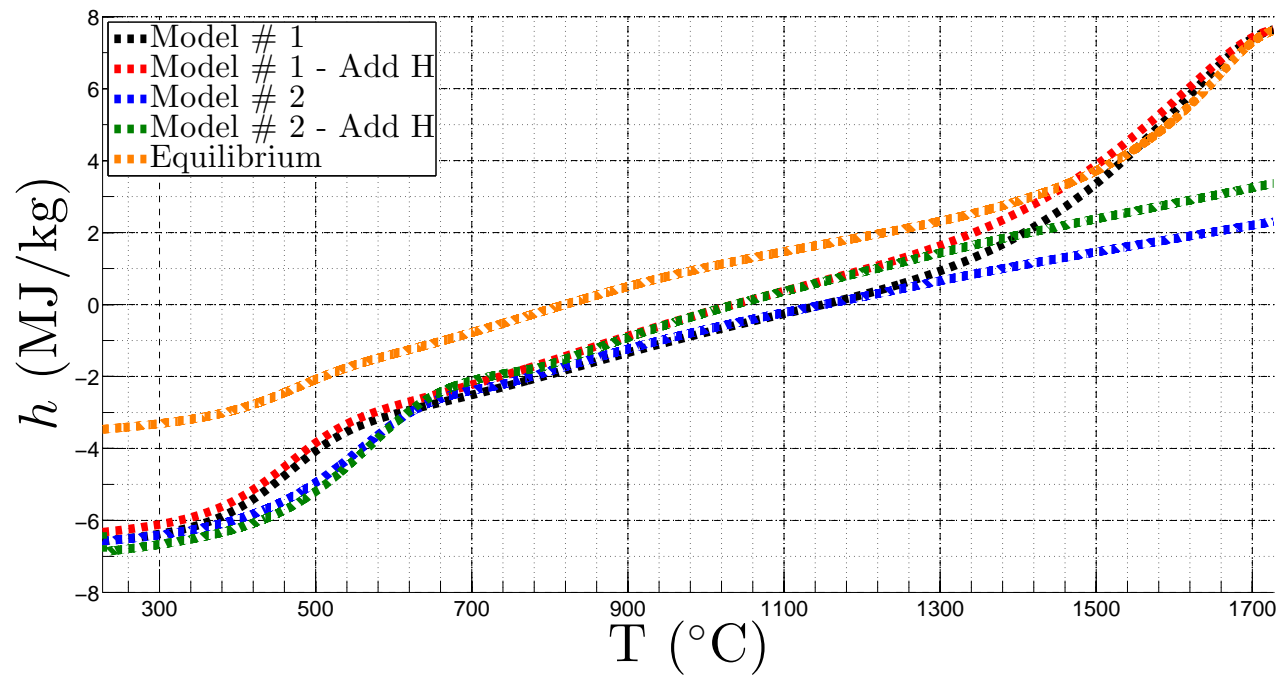

Figure 15: Enthalpy comparison using different models to account for solid char deposition. The original elemental composition corresponds to a $35 \%$ char yield.

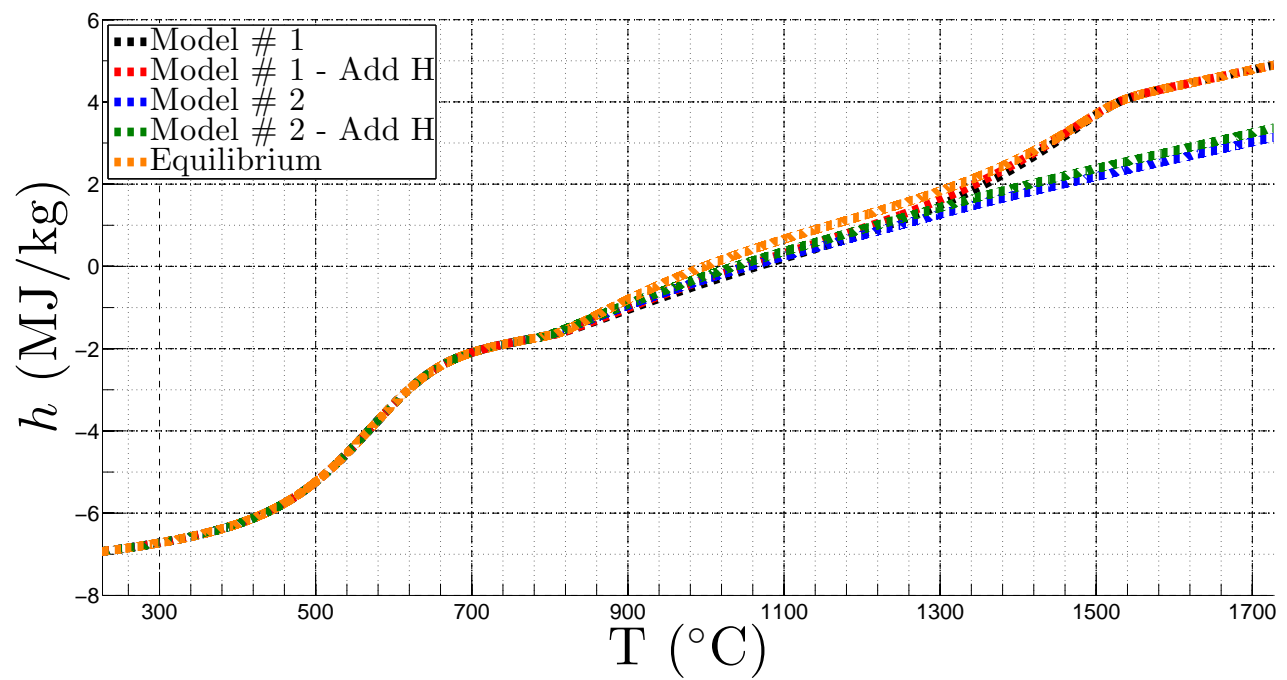

Figure 16: Enthalpy comparison using different models to account for solid char deposition. The original elemental composition corresponds to a $60 \%$ char yield. 
as the gas flows from the pyrolysis layer, through the char layer, and into the boundary layer, and should be accounted for in material response models.

\section{Analysis of Experimental Results}

All of the previous sections have quantitatively shown the effect that different modeling assumptions (i.e., equilibrium vs. finite-rate kinetics) have on the pyrolysis gas mixture. In order to investigate the validity of some the assumptions previously made, a detailed analysis of available experimental data is performed in order to determine whether or not experimentally measured pyrolysis gases are in a state of thermodynamic equilibrium, and to investigate the range of elemental compositions observed in previous studies.

In 1967, Sykes [16] produced the first detailed report in the aerospace community on the composition of the pyrolysis gases produced by the thermal decomposition of a phenolic resin. A commercially available novolac-type resin (Union Carbide Corporation - BRP 5549) premixed with hexamethylenetetramine was used in this study. The resin was cured, and $\sim 7 \mathrm{mg}$ samples were tested. These specimens were placed in a pyrolyzer attached to a gas chromatograph [69]. The samples were heated to a desired temperature for 10 seconds, and then the temperature was quenched. Temperatures from $100^{\circ} \mathrm{C}$ to $1000^{\circ} \mathrm{C}$ were analyzed at $50^{\circ} \mathrm{C}$ intervals. A detailed explanation of the experimental set-up can be found in [70].

The experimental data collected by Sykes [16] are shown in Fig. 17 and are compared to equilibrium calculations with the same H:C:O composition. The elemental composition of the pyrolysis gas measured by Sykes [16] varies at each temperature (Table 3), and was used in the equilibrium calculations shown in Fig. 17. The gas mixture contains the same 55 species used throughout this paper, and includes additional species measured by Sykes (toluene $-\mathrm{C}_{7} \mathrm{H}_{8}$, phenol $-\mathrm{C}_{6} \mathrm{H}_{5} \mathrm{OH}$ and xylenol - $\left(\mathrm{CH}_{3}\right)_{2} \mathrm{C}_{6} \mathrm{H}_{3} \mathrm{OH}$ ). References for the thermodynamic data for the added species can be found in Appendix C. Results comparing the experimental measurements and numerical calculations are shown in Fig. 17. It is clear that the experimentally-measured gas mixture is not in thermodynamic equilibrium, and the greatest relative discrepancy is seen in the amount of $\mathrm{C}_{7} \mathrm{H}_{8}, \mathrm{C}_{6} \mathrm{H}_{5} \mathrm{OH}$ and $\left(\mathrm{CH}_{3}\right)_{2} \mathrm{C}_{6} \mathrm{H}_{3} \mathrm{OH}$ present around $500^{\circ} \mathrm{C}$. At $500^{\circ} \mathrm{C}$ and $550^{\circ} \mathrm{C}$, the equilibrium calculations predict $X_{\mathrm{C}_{24} \mathrm{H}_{12}} \approx 0.04$ and $X_{\mathrm{C}_{24} \mathrm{H}_{12}} \approx 0.02$ at the two temperatures, respectively. This corresponds to $Y_{\mathrm{C}_{24} \mathrm{H}_{12}} \approx 0.4$ at $500^{\circ} \mathrm{C}$ and $Y_{\mathrm{C}_{24} \mathrm{H}_{12}} \approx 0.2$ at $550^{\circ} \mathrm{C}$. Again, the species with the largest $\mathrm{C} / \mathrm{H}$ ratio is favored from a thermodynamic standpoint. As discussed in Sec. III.A.5, at these relatively low temperatures, not accounting for gas condensation/solidification may effect the thermodynamic equilibrium calculations performed.

Under these experimental conditions, the kinetics of the decomposition of the resin, specifically the finite time needed for the observed large hydrocarbon molecules to break down, plays a large role in accurately predicting the composition of the pyrolysis gases. In summary, an equilibrium assumption does not accurately predict the composition of the gas mixture (Fig. 17).

Trick et al. [26] performed a similar experiment to Sykes [16], except that a composite material (fibers and resin) was used, unlike the neat resin analyzed previously. A Fiberite Inc. commercially available carbon phenolic composite material was used, designated SC1008/T300. This material has Amoco heat-treated T300 carbon fibers impregnated with a resole resin [46]. The samples were pyrolyzed in a thermogravimetric balance, and a constant heating rate of $1^{\circ} \mathrm{C} / \mathrm{min}$ was used. Fourier transform infrared spectroscopy (FTIR) was used to analyze the experiments. These measurements were combined with pyrolysis gas composition measurements performed in other studies [71,72], and this data has been converted to elemental mole fractions in Table 4. The experiments did not distinguish between phenol $\mathrm{C}_{6} \mathrm{H}_{6} \mathrm{O}$ and cresol $\left(\mathrm{C}_{7} \mathrm{H}_{8} \mathrm{O}\right.$, and referred to the combination of the two as "low molecular weight substances (LMS)". They also provided different compositions over three different characteristic temperature ranges. In Table 4, the first two lines represent the same experimental measurement, with the first line assuming that all of the LMS observed can be attributed to phenol, and the second line assumes that all of the LMS observed can be attributed to cresol. The results are similar for each assumption, and bound the possible composition range. The results show a large change in the elemental composition of the pyrolysis gases over the different temperature ranges (consistent with the results from Sykes [16]).

Combining the previous experimental data for the elemental composition of the pyrolysis gases produced from a phenolic resin, over a large range of temperatures, results in a large range of values, as shown in Fig. 18. This plot contains values for temperatures above $300^{\circ} \mathrm{C}$ so that the results are not affected by the resin cure time [16]. The shading for Trick et al.'s [46] data at low temperatures represents the range previously described due to measuring a combined fraction of cresol and phenol. It is hard to quantitatively 
Table 3: Calculated elemental composition of measured pyrolysis gases over a large temperature range measured by Sykes [16].

\begin{tabular}{cccc} 
Temperature $\left({ }^{\circ} \mathrm{C}\right)$ & $\mathrm{C}$ (molar) & $\mathrm{H}$ (molar) & $\mathrm{O}$ (molar) \\
\hline 100 & 0.000 & 0.667 & 0.333 \\
150 & 0.000 & 0.667 & 0.333 \\
200 & 0.000 & 0.667 & 0.333 \\
250 & 0.000 & 0.667 & 0.333 \\
300 & 0.000 & 0.667 & 0.333 \\
350 & 0.000 & 0.667 & 0.333 \\
400 & 0.202 & 0.586 & 0.212 \\
450 & 0.211 & 0.594 & 0.195 \\
500 & 0.368 & 0.534 & 0.098 \\
550 & 0.319 & 0.573 & 0.108 \\
600 & 0.273 & 0.644 & 0.083 \\
650 & 0.225 & 0.690 & 0.085 \\
700 & 0.164 & 0.769 & 0.067 \\
750 & 0.103 & 0.849 & 0.048 \\
800 & 0.044 & 0.929 & 0.027 \\
850 & 0.030 & 0.954 & 0.015 \\
900 & 0.009 & 0.991 & 0.000 \\
950 & 0.000 & 1.00 & 0.000 \\
1000 & 0.000 & 1.00 & 0.000
\end{tabular}

Table 4: Calculated molar elemental composition of the pyrolysis gases reported by Trick et al. (Table 2 in $[26])$.

\begin{tabular}{cccc} 
Temperature Range $\left({ }^{\circ} \mathrm{C}\right)$ & $\mathrm{C}($ molar $)$ & $\mathrm{H}$ (molar) & $\mathrm{O}$ (molar) \\
\hline $300-550(100 \%$ Phenol) & 0.400 & 0.466 & 0.133 \\
$300-550(100 \%$ Cresol $)$ & 0.389 & 0.500 & 0.111 \\
$400-800$ & 0.108 & 0.792 & 0.010 \\
$560-900$ & 0.071 & 0.788 & 0.141
\end{tabular}

estimate the error associated with the experimental measurements, as there is a contribution both from experimental error, and errors associated with not all mass of gaseous species being accounted for. Ongoing work by Wong et al. [33] should rectify potential conservation of mass issues. In addition, as outlined in Sec. II.C, a range of char compositions has been observed experimentally. Figure 18 shows that the constant gas compositions used in previous numerical studies represents a simple average composition over a large temperature range. As shown in the previous sections, this over-simplification of the pyrolysis gas elemental composition has significant effects on the pyrolysis gas composition and properties.

When comparing data reported by Trick et al. [46] to the data reported by Sykes [16], the effect of measuring gas species over a large temperature range must be accounted for. The data reported by Trick et al. [46] represents an integration of the pyrolysis gas products over a temperature range. However, neither the elemental composition nor the volume of pyrolysis gas evolved is constant with temperature. For proper comparison, the data set reported by Sykes [16] must be integrated over temperature in a manner similar to the data set reported by Trick et al. [46]. Figure 19 shows the resulting comparison with Sykes' [16] data. Discrepancies are still observed between the two studies, and further experimental investigations are required to describe the observed differences. 

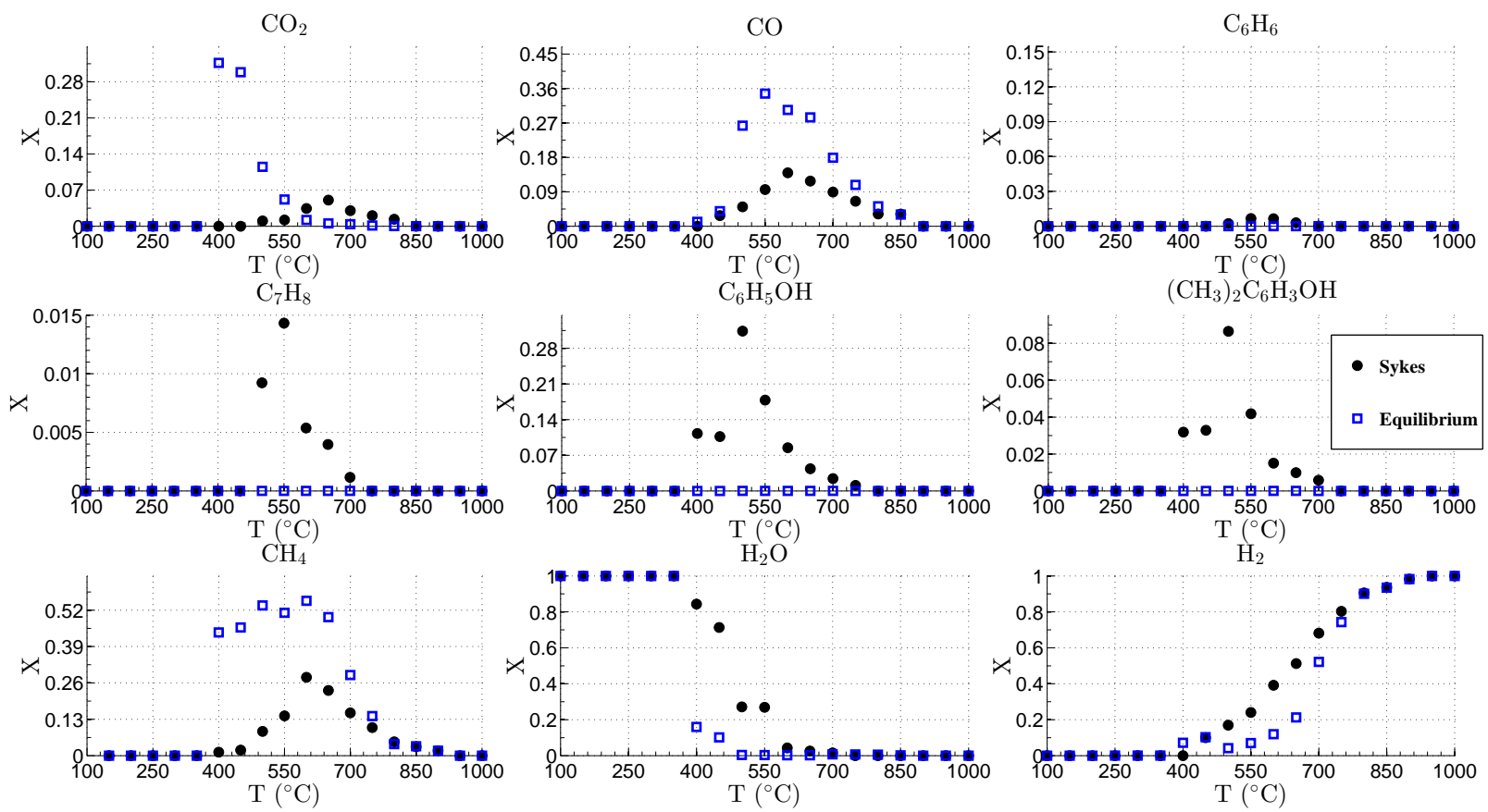

Figure 17: Experimental data reported in Table 1 of [16] compared to thermodynamic equilibrium calculations.

\section{Constrained Equilibrium Calculations}

A constrained equilibrium calculation allows one to apply different linear constraints to a chemical mixture, and then perform an equilibrium calculation calculation keeping the specified constraint(s) constant. Simple examples of constraints include the mass fraction of an individual species, and the sum of the mass fractions of two different species. While the pyrolysis gas mixture measured by Sykes [16] is not in thermodynamic equilibrium (as shown in Sec. VI), it may still be possible for the pyrolysis gases to be in a state of constrained thermodynamic equilibrium. This section is geared towards investigating the feasibility of using constrained equilibrium calculations to represent the pyrolysis gas mixture.

All constrained equilibrium calculations are performed using the CEQ code developed by Professor Stephen B. Pope at Cornell University [73-75]. Constrained equilibrium calculations are performed based on mass fractions, and include 58 total species (55 species model +3 additional species measured experimentally by Sykes [16]). Many constraints were experimented with, including general linear constraints (summation of mass fractions of multiple species) and individual species constraints. As is shown in Fig. 20, it was found that the experimental data could be well represented if individual species constraints were put on $\mathrm{CO}_{2}, \mathrm{C}_{7} \mathrm{H}_{8}, \mathrm{C}_{6} \mathrm{H}_{5} \mathrm{OH}$ and $\left(\mathrm{CH}_{3}\right)_{2} \mathrm{C}_{6} \mathrm{H}_{3} \mathrm{OH}$.

From Fig. 20 several conclusions can be drawn. While the measured gases are not in thermodynamic equilibrium at each temperature, the mixture composition is well-represented by a constrained equilibrium calculation. The aromatic species measured are only present in a temperature range from $\sim 400{ }^{\circ} \mathrm{C}$ to $\sim 700^{\circ} \mathrm{C}$. Above this temperature, these species are no longer pyrolysis gas products. Below this temperature these species have not yet been formed (i.e. they have not yet been liberated from the resin). A more detailed explanation of the resin decomposition is given in Sec. A.B. $\mathrm{C}_{7} \mathrm{H}_{8}, \mathrm{C}_{6} \mathrm{H}_{5} \mathrm{OH}$ and $\left(\mathrm{CH}_{3}\right)_{2} \mathrm{C}_{6} \mathrm{H}_{3} \mathrm{OH}$ represent direct products from the decomposition of the resin, and this is why they are observed experimentally.

A comparison of mass specific mixture enthalpy is shown in Fig. 21 for the three different gas compositions discussed (Sykes' [16] data, an equilibrium mixture, and a constrained equilibrium mixture). While the mixture composition changes drastically, the calculated enthalpies are still surprisingly similar. The largest (albeit small) discrepancies are observed when there is a strong concentration of aromatic species (midtemperature range). These results are consistent with the computational results previously shown in Fig. 7. This figure shows that for temperatures between $\sim 500^{\circ} \mathrm{C}$ and $\sim 800^{\circ} \mathrm{C}$, the mixture enthalpy is fairly independent of the gas species model used; but it is largely dependent on the elemental composition of the gas considered. This is the same effect that is shown in Fig. 21 . For temperatures $\sim 500^{\circ} \mathrm{C}$, the equilibrium 
× Data Reported by Trick (neat resole)

- Sykes Data (neat novolac)

-.-Park Composition

---Milos Composition

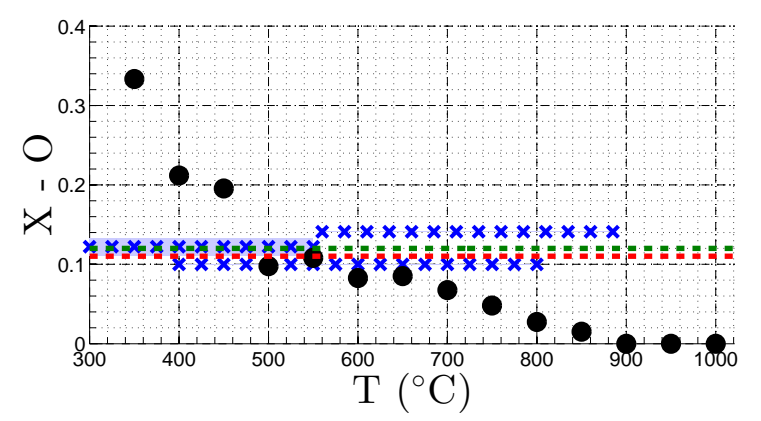

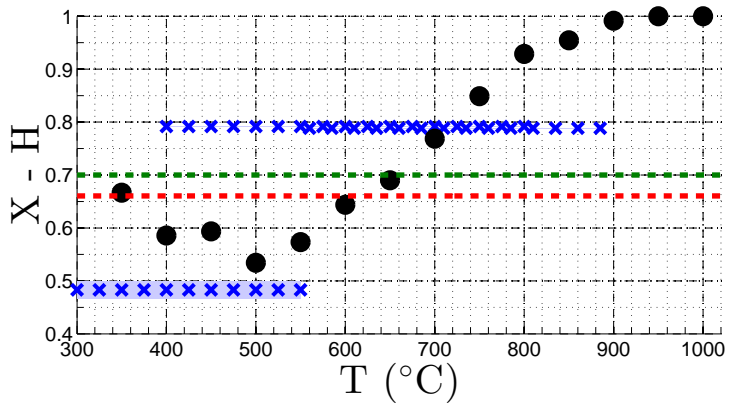

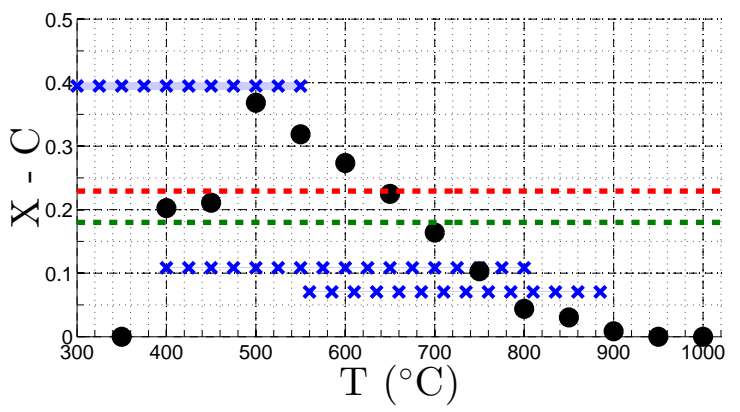

Figure 18: Comparison of pyrolysis gas elemental compositions from experimental studies and computational studies. Shaded areas represent the range in Trick et al.'s [46] data from the phenol/cresol combination. Values taken from Milos and Chen [24] are approximate, as the original composition also includes some N and Si. Values taken from Park et. al. [25] correspond to a pyrolysis gas mixture for a PICA heatshield.

calculations do not predict the mixture composition well, but the enthalpy is well re-produced. At higher temperatures, the mixture composition measured by Sykes [16] is mainly hydrogen, so it is not surprising that the mixture compositions and enthalpies are matched in this regime.

The same constrained thermodynamic equilibrium method is applied to the more complicated mixture described in Sec. III.B. Constraints placed on individual species perform better, and two sample plots showing the mixture reconstruction are shown in Fig. 22 and Fig. 23. A constraint is always placed on phenol $\left(\mathrm{A}_{1} \mathrm{OH}\right)$, as the simulations performed in Sec. III.B assumed an initial composition of $100 \%$ phenol. The kinetic decomposition of phenol therefore plays a very important role in the evolution of the gas mixture, and is a logical choice for a species constraint. In addition, due to the important role that PAH molecules play in pyrolysis gas mixtures, constraints are also placed on the PAH species present. As illustrated in Fig. 22 and Fig. 23, when more constraints are used, the mixture composition is more accurately represented. The order of species constrained is: $\mathrm{A}_{1} \mathrm{OH}, \mathrm{A}_{1} \mathrm{C}_{2} \mathrm{H}, \mathrm{A} 1, \mathrm{~A}_{2} \mathrm{R} 5, \mathrm{~A}_{2} \mathrm{C}_{2} \mathrm{HB}, \mathrm{A}_{2} \mathrm{R} 5 \mathrm{C}_{2} \mathrm{H}, \mathrm{A} 2$, and FLTN, which is based on the predicted mass fractions present of these species at $t=1000 \mu \mathrm{s}$. In Fig. 22, Fig. 23, and Fig. 24, the molecule $\mathrm{CO}$ is reconstructed accurately, even though it is not a constrained species. This is important as it has been previously identified as a strong radiator (Sec. I).

Alternatively, a sum of the mass fractions of $\mathrm{A}_{1} \mathrm{C}_{2} \mathrm{H}, \mathrm{A}_{1}, \mathrm{~A}_{2} \mathrm{R} 5, \mathrm{~A}_{2} \mathrm{C}_{2} \mathrm{HB}, \mathrm{A}_{2} \mathrm{R} 5 \mathrm{C}_{2} \mathrm{H}, \mathrm{A}_{2}$, and FLTN, is used as a constraint, in conjunction with a species constraint placed on $\mathrm{A}_{1} \mathrm{OH}$. These results are shown in Fig. 24. While visually it appears as this constraint does not do a good job at representing the mixture composition, the enthalpy plot shown in Fig. 25 illustrates how the mass specific enthalpy of the mixture is well-represented with this constraint. Unsurprisingly, as this idealized mixture starts entirely as phenol, Fig. 25 shows that a large benefit is initially gained by constraining the mass fraction of phenol. At times $\gtrsim 700 \mu \mathrm{s}$, when significant amounts of the original phenol start to react, discrepancies are seen between the different constraint selections. In general, the more constraints that are used, the closer the enthalpy is to that of the mixture calculated using finite-rate kinetics. However, the constraint based on the sum of the aforementioned $\mathrm{PAH}$ species, while over predicting the concentration of the largest PAH species included (FLTN, Fig. 24), the enthalpy of the mixture is better represented than constraining on 7 other species individually. This highlights the importance of PAH species in these types of gas mixtures, and shows that choosing the appropriate constraint when performing constrained equilibrium calculations can yield 
× Data Reported by Trick (neat resole)

- Sykes Data Integrated (neat novolac)
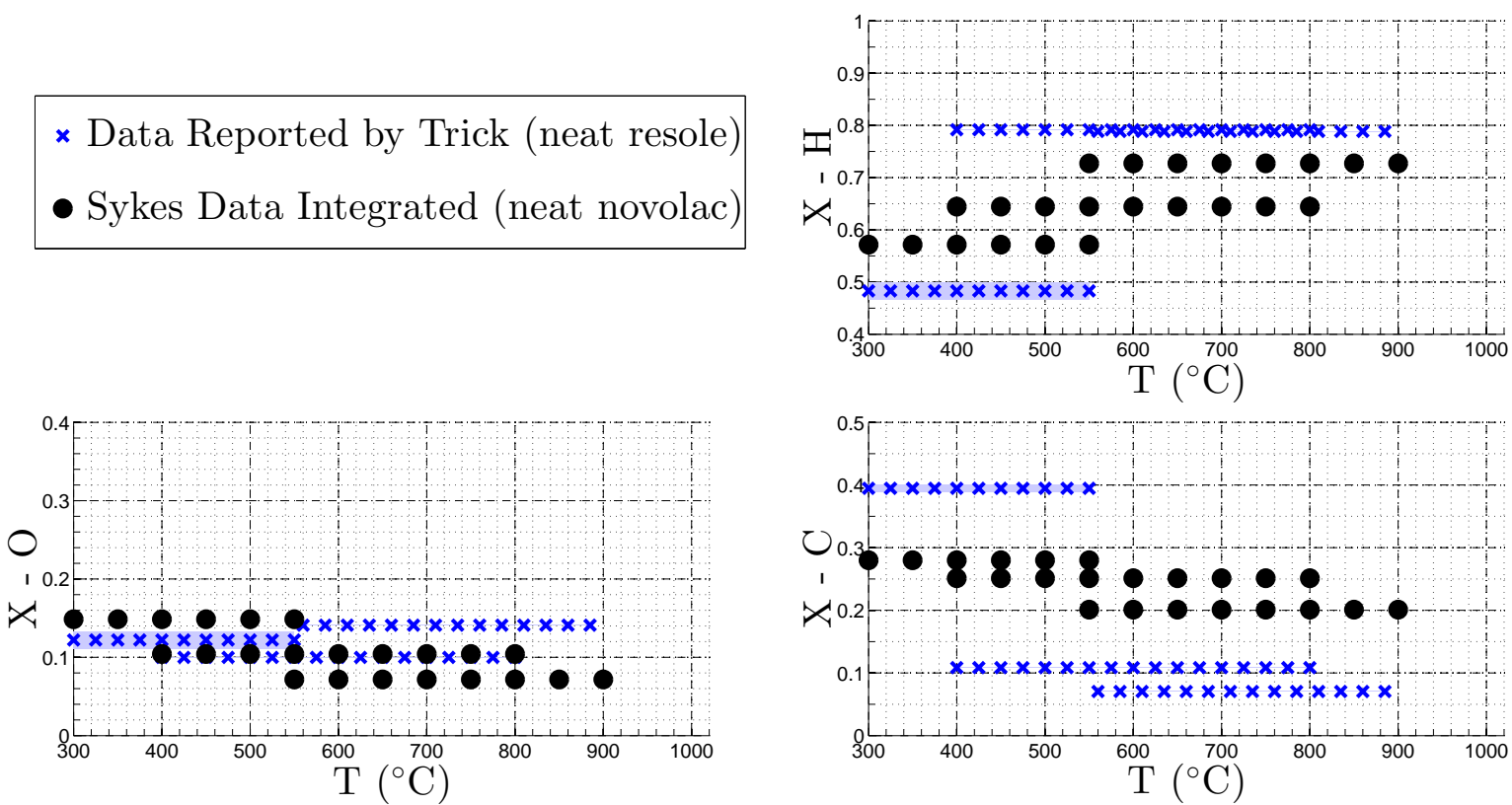

Figure 19: Comparison of pyrolysis gas elemental composition from the work of Trick et al. [46] and Sykes [16]. Shaded areas represent the range in Trick et al.'s [46] data from the phenol/cresol combination. Data from Sykes has been integrated over the temperature ranges that Trick reports.

significant benefits. 

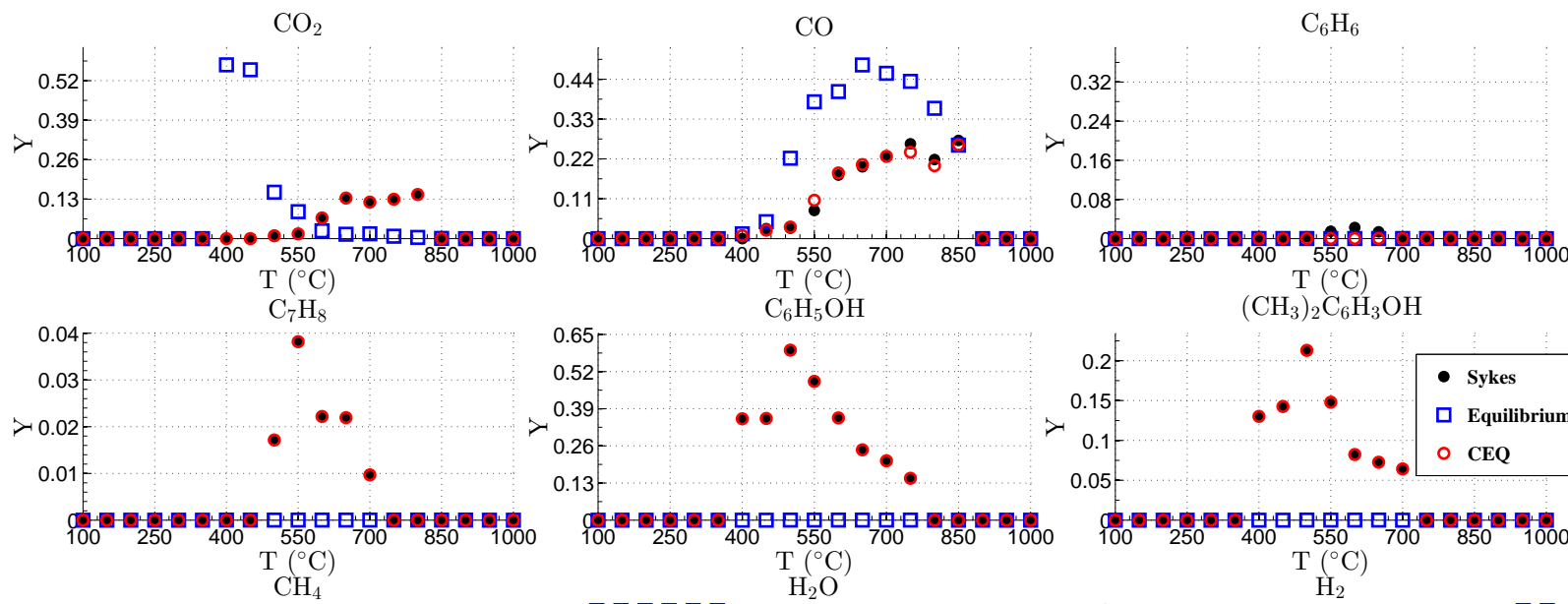

$\mathrm{T}\left({ }^{\circ} \mathrm{C}\right)$

$\left(\mathrm{CH}_{3}\right)_{2} \mathrm{C}_{6} \mathrm{H}_{3} \mathrm{OH}$

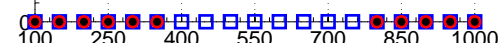
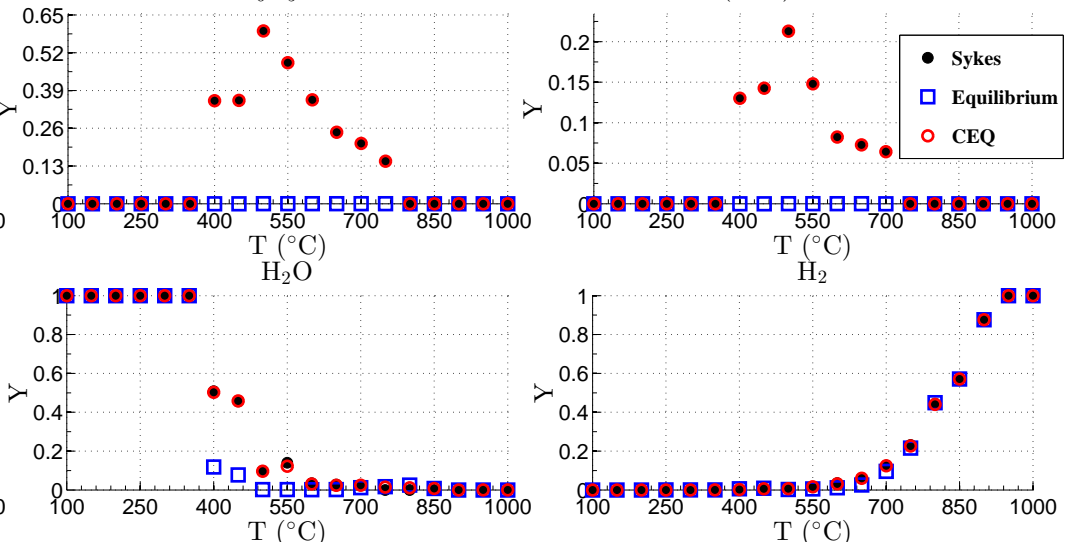

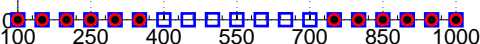
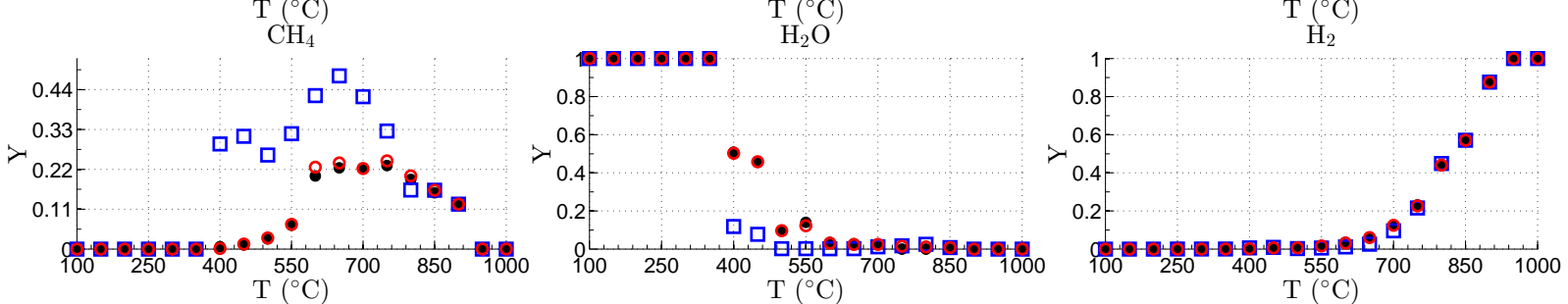

Figure 20: Experimental data reported in Table 1 in [16], converted to mass fractions, and compared to constrained equilibrium calculations.

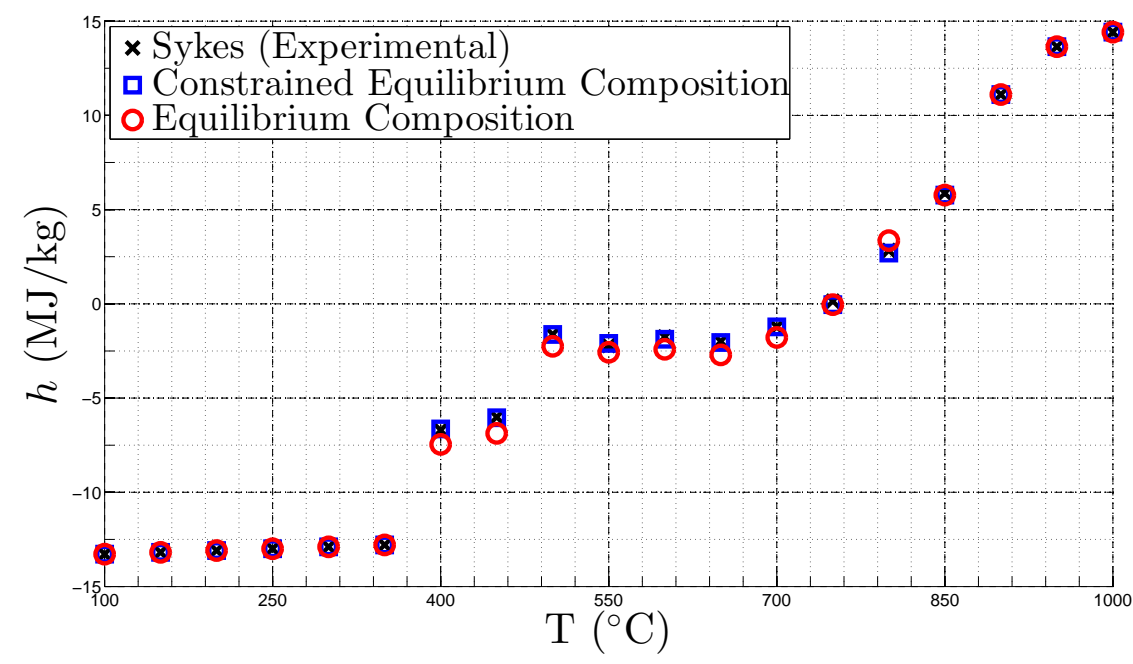

Figure 21: Comparison of mixture enthalpies based on experimental data reported in Table 1 in [16]. 


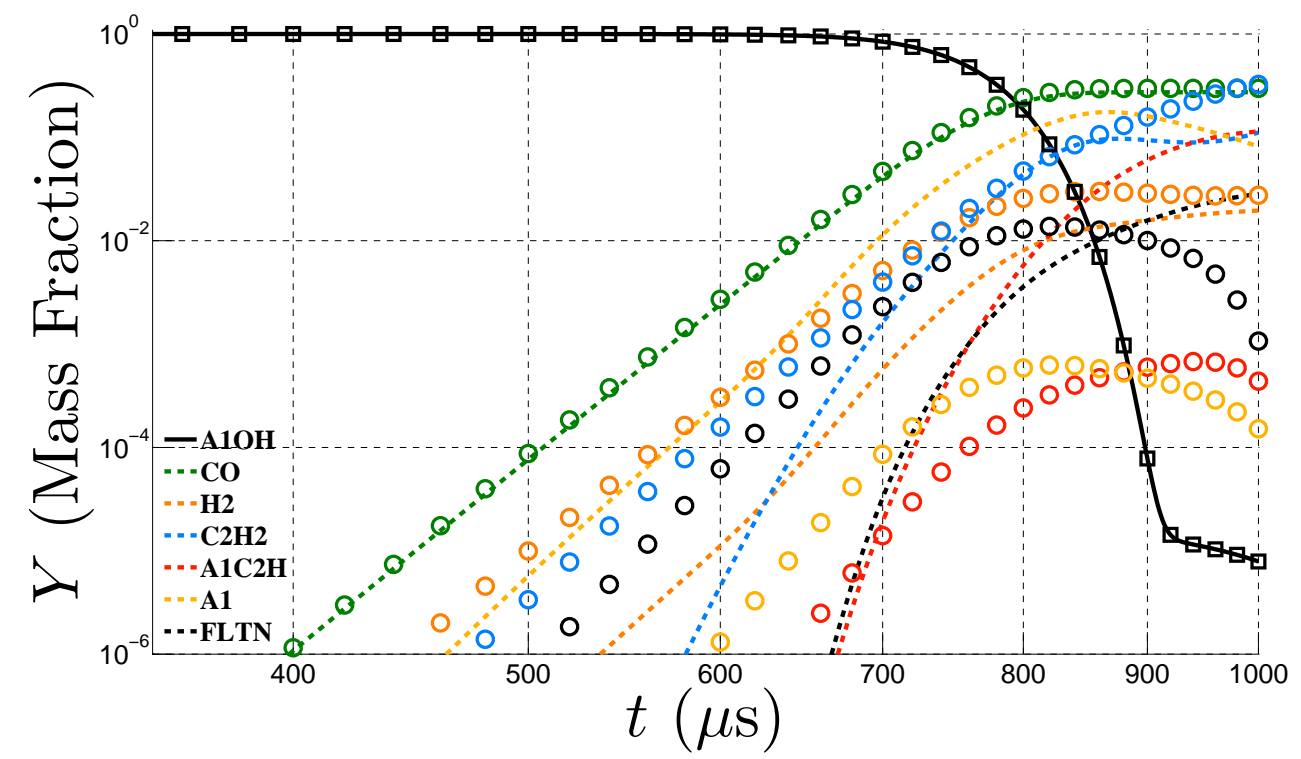

Figure 22: Comparison of mixture composition for finite-rate chemistry results and constrained equilibrium calculations constraining on $\mathrm{A}_{1} \mathrm{OH}$. Lines represent finite-rate chemistry results, and symbols represent constrained equilibrium calculations. $T=230^{\circ} \mathrm{C}+1.57^{\circ} \mathrm{C} \cdot t$, where $T$ is in ${ }^{\circ} \mathrm{C}$, and $t$ is in $\mu \mathrm{s} . P=50 \mathrm{kPa}$.

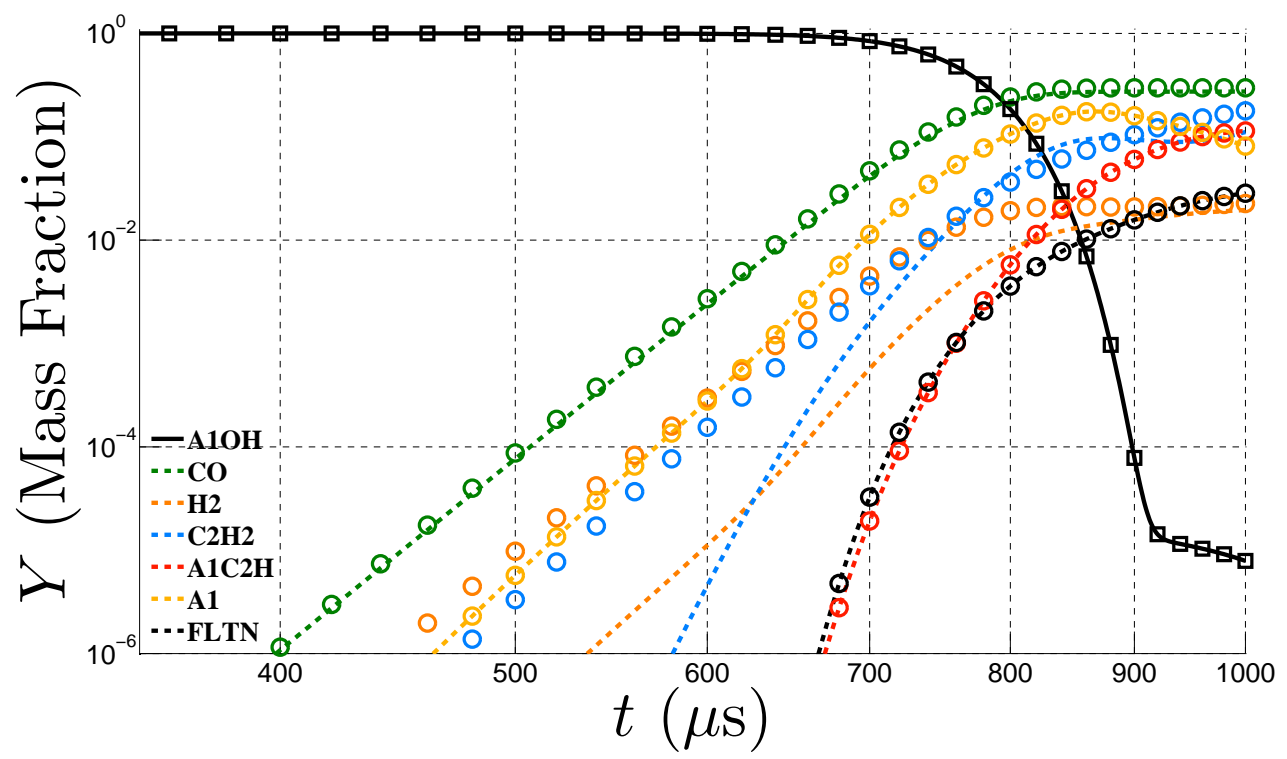

Figure 23: Comparison of mixture composition for finite-rate chemistry results and constrained equilibrium calculations constraining on 8 species. Lines represent finite-rate chemistry results, and symbols represent constrained equilibrium calculations. $T=230^{\circ} \mathrm{C}+1.57^{\circ} \mathrm{C} \cdot t$, where $T$ is in ${ }^{\circ} \mathrm{C}$, and $t$ is in $\mu$ s. $P=50 \mathrm{kPa}$. 


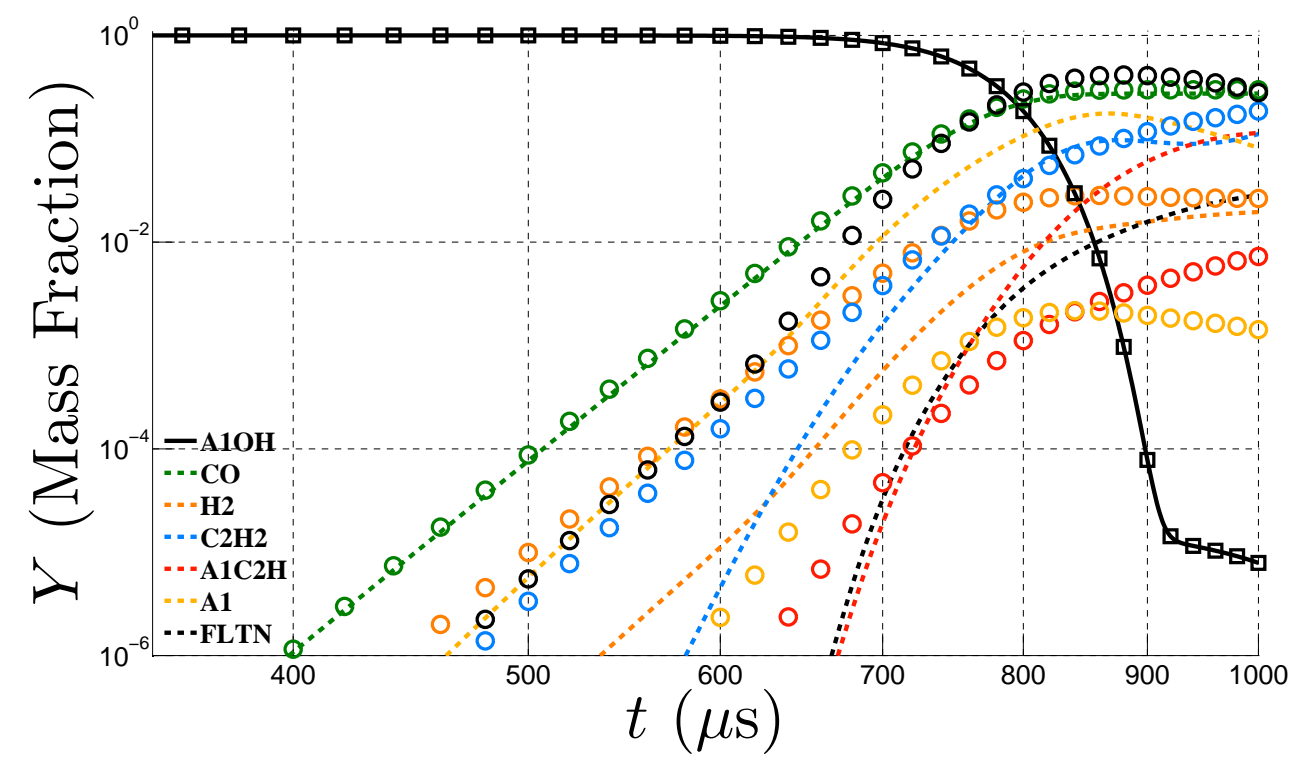

Figure 24: Comparison of mixture composition for finite-rate chemistry results and constrained equilibrium calculations constraining on $\mathrm{A} 1 \mathrm{OH}$ and the summation of mass fractions of $\mathrm{A}_{1} \mathrm{C}_{2} \mathrm{H}, \mathrm{A}_{1}, \mathrm{~A}_{2} \mathrm{R} 5, \mathrm{~A}_{2} \mathrm{C}_{2} \mathrm{HB}$, $\mathrm{A}_{2} \mathrm{R} 5 \mathrm{C}_{2} \mathrm{H}, \mathrm{A}_{2}$, and FLTN. Lines represent finite-rate chemistry results, and symbols represent constrained equilibrium calculations. $T=230^{\circ} \mathrm{C}+1.57^{\circ} \mathrm{C} \cdot t$, where $T$ is in ${ }^{\circ} \mathrm{C}$, and $t$ is in $\mu \mathrm{s} . P=50 \mathrm{kPa}$.

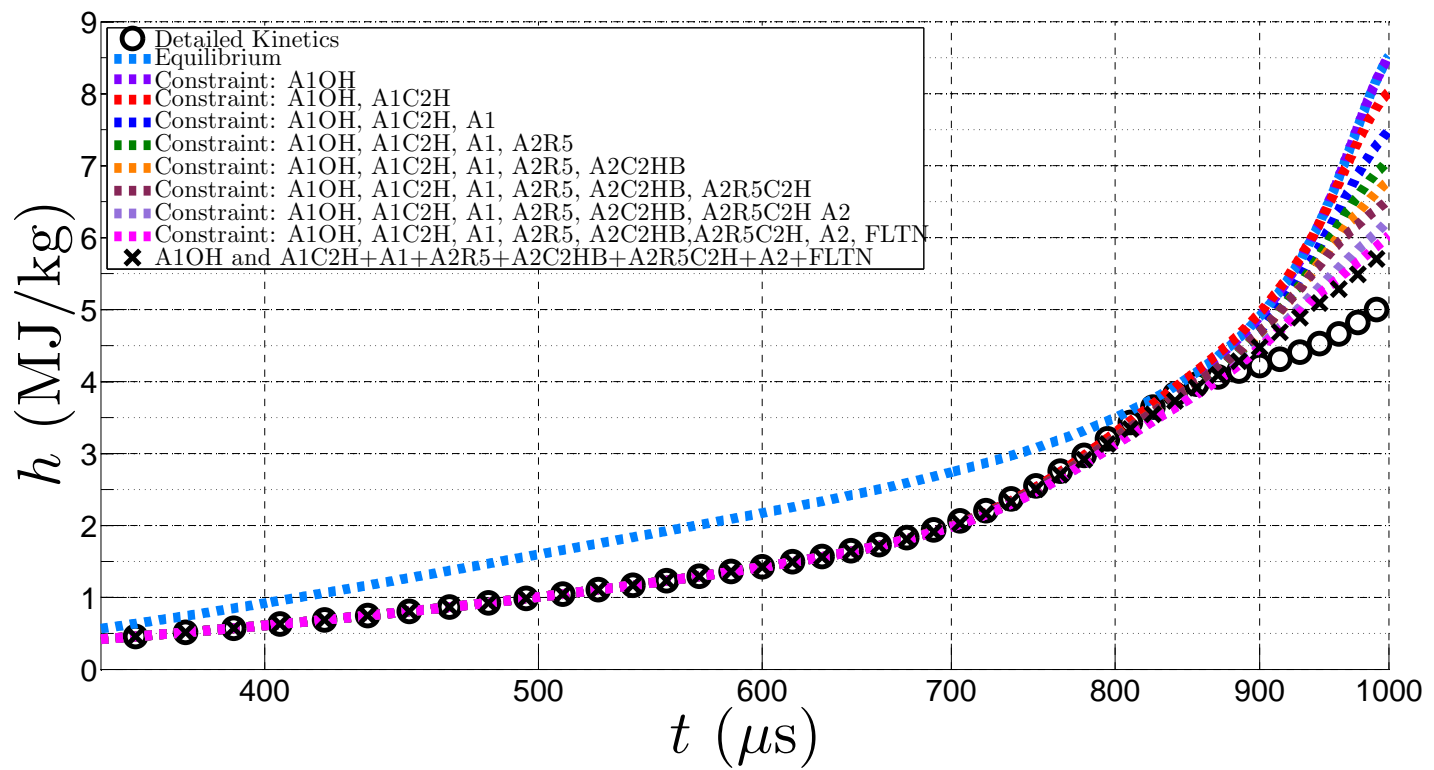

Figure 25: Evolution of mixture enthalpy for the different gas mixtures calculated through constrained equilibrium calculations. $T=230^{\circ} \mathrm{C}+1.57^{\circ} \mathrm{C} \cdot t$, where $T$ is in ${ }^{\circ} \mathrm{C}$, and $t$ is in $\mu \mathrm{s} . P=50 \mathrm{kPa}$. 


\section{Summary and Discussion}

Current kinetic models are not advanced enough to capture all aspects of the phenolic resin decomposition, including phase transition from solid to gaseous species, decomposition products, heterogeneous reactions, soot formation, etc. On a more basic level, despite the continued investigation of the decomposition of phenol (which is a major component of the resin), there is still a debate about the primary mechanism for this decomposition, and the primary products that are created [76-84]. A review of previous work on phenol decomposition can be found in [82], which illustrates a long debate over the primary reaction involved in the thermal decomposition of phenol. Due to the complicated nature of this system, it is clear that reduced "engineering" models are needed for design purposes.

Based on the detailed investigation performed in this work, it is now possible to create a fuller, more consistent description of many of the physical phenomena, and their implications, occurring in an ablative heatshield.

- The solid constituents of phenolic resin are known (see Sec. II.B and Appendix A). Any minor variations in resin composition, possibly due to cross-linking density or impurities, will not be a leading source of error for modeling efforts. An elemental composition of $\mathrm{C}: \mathrm{H}: \mathrm{O}=0.500: 0.429: 0.071$ by mole is believed to be a good choice for the resin composition.

- A mass-loss model used to determine the mass and composition of pyrolysis gas produced [30] currently appears (in the author's opinion) to be the most viable method to approach the initial decomposition of the solid resin, i.e., solid $\rightarrow$ gas phase transformation. The model is consistent with charring; not all of the solid resin undergoes a phase transformation, and some mass remains behind as char.

- The mass-loss model [30] does not assume that the pyrolysis gases produced have a constant elemental composition over time and temperature. The model was derived to be consistent with experimentally observed pyrolysis gas products (see Sec. VI). The temperature varies as a function of depth in the heatshield; therefore different pyrolysis products will be produced at different depths in the heatshield.

- The gaseous pyrolysis products must now be modeled. To predict the correct species composition of the gas mixture initially formed from the resin decomposition, constrained equilibrium calculations can be used. Constraints should be placed on the large aromatic species that are the direct products of the decomposition of the resin (Fig 20).

- As the pyrolysis gases continue to evolve, if the correct elemental composition is used for $500^{\circ} \mathrm{C} \lesssim$ $T \lesssim 800^{\circ} \mathrm{C}$, the mass specific enthalpy of the mixture can be well represented (Fig. 7 and Fig. 21) by a thermodynamic equilibrium calculation. For $T \gtrsim 1200^{\circ} \mathrm{C}$, the mass specific mixture enthalpy depends largely on the gas model used (Fig. 7). For a gas model to be accurate over a large range of temperatures, both the mixture elemental composition must be known, and an accurate gas species model must be used that includes PAH species (Fig. 4 and Fig. 6).

- The formation of PAH species at higher temperatures through gas phase reactions is supported both by thermodynamic equilibrium calculations (Fig. 4 and Fig. 6) and calculations based on finite-rate kinetics (Fig. 9).

- Once the PAH species are formed, they are expected to be deposited on the fibers; particle growth through vapor phase nucleation (see Sec. IV.B) and heterogeneous reactions with the carbon fibers (see Sec. IV.C) will remove carbon from the gas mixture.

- This solid carbon deposition changes the elemental composition (C:H:O) ratio of the gas mixture, therefore changing the bulk properties of the gas mixture (Fig. 14, Fig. 15, and Fig. 16).

- Due to the slow time scales involved with PAH formation, a thermodynamic equilibrium approach should not be used (Fig. 9 and Fig. 10).

- Preliminary constrained equilibrium calculations show that with an intelligent choice of constraint based on PAH species, the mixture properties can be well approximated if the slow time scale associated with PAH formation were to be known (Fig. 25). 
Further experiments and investigations are still needed to accurately measure/simulate the evolution of $\mathrm{PAH}$ species in conditions relevant to pyrolysis in ablative heatshields. Once these time scale are known with more certainty, it will be possible to model the pyrolysis gas mixture with more accuracy. In addition, the effects of diffusion have been neglected in this work. Mass diffusion will likely play a role internal to the heatshield itself, and near the surface of the heatshield in the char layer. Near the surface of the heatshield it is possible for atmospheric gas from the boundary layer to diffuse into the char layer. Some authors have investigated this effect [61], though this is still an open research topic. In addition, species diffusion will occur inside of pyrolysis layer, when porous flow is occurring. State of the art computations [30] have not been able to account for species diffusion with detailed kinetic models, and this is also a topic for future work.

\section{Conclusion}

A detailed investigation into the pyrolysis gases produced by a PICA heatshield was performed in this work. Published physical properties of PICA were compiled, and the fundamental processes that go into phenolic resin synthesis were explained, providing a needed link between the physical properties of solid PICA, and the pyrolysis gases that are created when PICA starts to undergo a thermal decomposition. The implications of including or excluding certain species in the gas model were illustrated, and an emphasis was specifically placed on the need to include PAH species in the gas mixture. The effect of solid carbon deposition, a phenomena associated with the presence of PAH species, was predicted to have an effect on the elemental composition of the gas mixture, and on the bulk properties of the mixture. The kinetic evolution of the pyrolysis gas mixture was also investigated, and the assumption of thermodynamic equilibrium vs. finite-rate kinetics was evaluated. In order to model the pyrolysis gas mixture in a consistent and accurate way, an equilibrium approach is inadequate, and a method to account for the finite time scale associated with PAH formation should be used. Constrained equilibrium calculations were shown to reproduce the mass specific mixture enthalpy of the pyrolysis gases well, if a time scale associated with $\mathrm{PAH}$ formation were to be known.

Future work should focus on two of the unknowns identified in this work; the rate of solid carbon deposition, and a timescale associated with PAH formation under conditions relevant to pyrolysis. Once an accurate timescale for PAH formation can be determined, combined with the RCCE method, it is believed that an engineering model could be developed to accurately track the kinetic evolution of the pyrolysis gases inside of the heatshield. Additionally, experimentally quantifying the effects of solid carbon deposition could validate the previously proposed sooting and collision models accounting for this effect. Finally, effect of mass diffusion inside of the heatshield could be investigated in the future as well.

The detailed investigation into the reacting pyrolysis gas mixture in this paper allowed a consistent, and more detailed description of many of the physical phenomena occurring in a PICA heatshield, and their implications, to be created.

\section{Acknowledgments}

The authors gratefully acknowledge funding from the Air Force Office of Scientific Research (Award FA9550-12-1-0472) under the supervision of Dr. Chiping Li. The views and conclusions contained herein are those of the authors and should not be interpreted as necessarily representing the official policies or endorsements, either expressed or implied, of the Air Force Office of Scientific Research or the U.S. Government. Financial support was also provided by the NSERC of Canada (postdoctoral fellowship to VMM).

\section{A. Resin Synthesis}

This section provides an overview of some of the possible synthesis processes used for making phenolic resins. All mechanisms and properties are adapted from [16], [35], [39], and [26], and the references mentioned therein. 


\section{A.A. General}

Novolac and resole resins are synthetic polymers $(\mathbf{3})$, generated via the co-polymerization of phenol (1) and formaldehyde (2), in the presence of an acid or base catalyst respectively (Fig. 26). Although the polymers generated using an acid catalyst (novolac resins) are structurally similar to those generated using a base catalyst (resole resins), their structure and composition often differ. With respect to the simplified polymer structure $(\mathbf{3})$ shown in Fig. 26, these differences include variations in cross-linking density $(n)$, amount of 2,2'-methylene $\left(\mathrm{CH}_{2}\right)$ linkages $(m)$ vs. 2,4'-methylene linkages $(q)$, ether linkages $\left(\mathrm{CH}_{2} \mathrm{OCH}_{2}\right)$ $(p)$, and nitrogen incorporation $\left(\mathrm{CH}_{2} \mathrm{NHCH}_{2}\right)(o)$. A more detailed discussion regarding the synthesis, and subsequent compositional differences of novolac and resole resins is given in Sec. A.C.

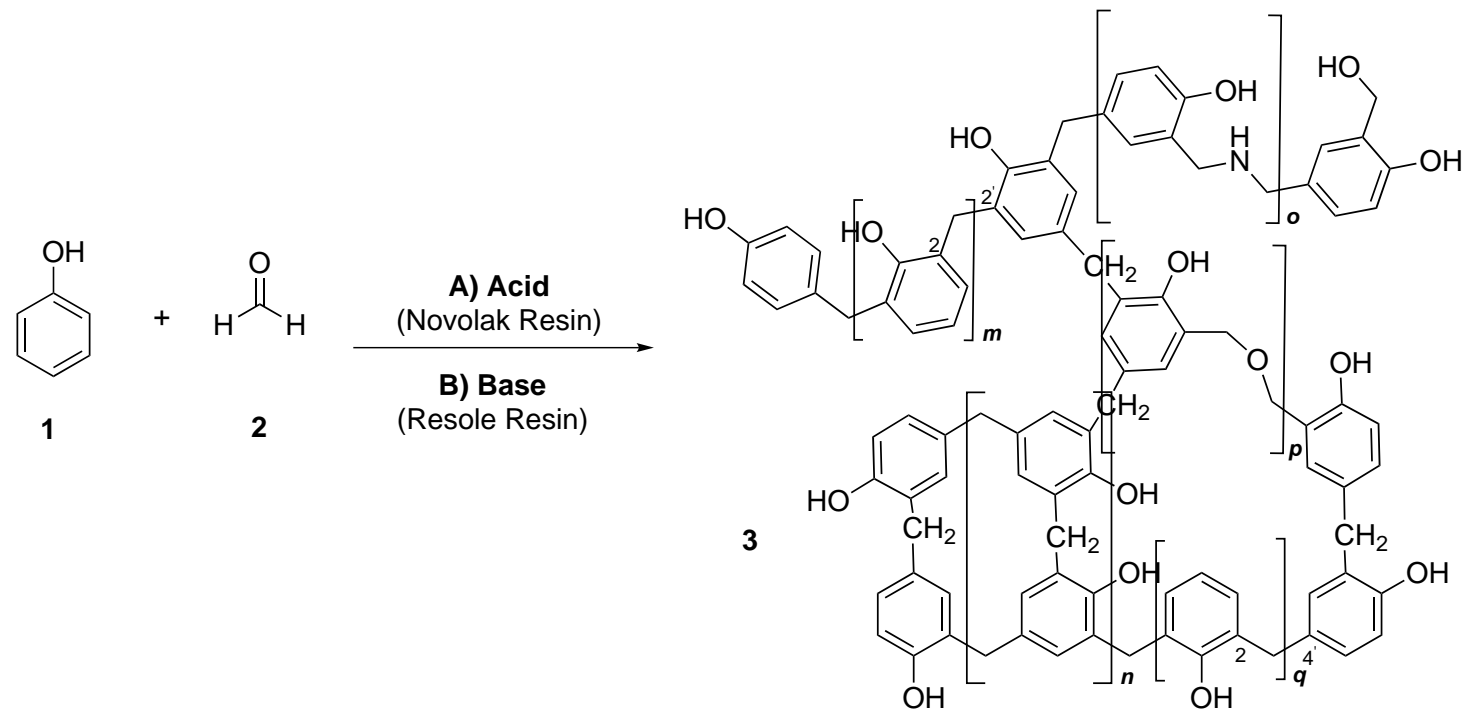

Figure 26: Synthesis of a phenolic resin by co-polymerization of phenol and formaldehyde under acidic conditions (i.e. novolac resins) or basic conditions (i.e. resole resins).

The method employed to synthesize the resin results in compositional differences such as the cross-linking density, as well as the number of nitrogen and oxygen linkages present. This will affect the resulting physical properties of the resin, including hardness as well as chemical and thermal stability. Generally, resins synthesized by acid catalysis (novolacs) comprise a more limited structural range then those synthesized by base catalysis (resoles), and thus resole resins generally result in products with more diverse properties. It is worthy to note that cure times, as well as temperatures, are dependent upon the structure of the uncured resin following polymerization. Furthermore, the presence of impurities such as residual water, phenol, and acid or base catalysts can also affect the extent of the cure.

\section{A.B. Curing and Decomposition Characteristics}

The composition of a resin can also be modified post-polymerization by application of a subsequent curing step. In the curing step, excess formaldehyde (or a formaldehyde source), sufficient heat (typically $\sim 150^{\circ} \mathrm{C}$ ), and/or an acid or base catalyst is applied in order to promote the cross-linking of any remaining unjoined or open sites. The high temperatures employed can also result in elimination of the ether and amine linkages ( $o$ and $p$ in 3) to give methylene linkages (Fig. 27). For example, pre-cured novolacs containing an increased amount of 2,2'-methylene linkages (e.g. high ortho novolacs, see Sec. A.C.2) cross-link more easily, and cure faster than those predominantly comprised of $2,4^{\prime}$-linkages.

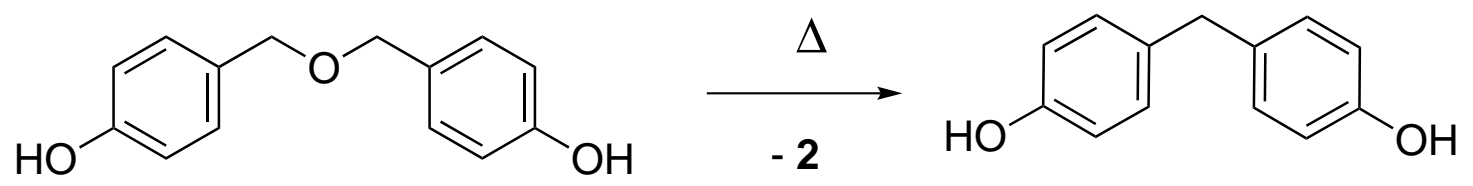

Figure 27: Conversion of ether to methylene linkages upon curing. 
The extent of curing is important as this will also affect the resulting composition and properties of the resin, as well as the pyrolysis gases evolved. At approximately $300^{\circ} \mathrm{C}$, any remaining ether $(p$ in $\mathbf{3})$ and nitrogen ( $o$ in 3) linkages will begin to break forming aldehydes, cresols, and azomethines (which can also cause coloring). Furthermore, at this stage any small molecules that were trapped from the manufacturing process will be released, such as excess phenol, water, formaldehyde, ammonia etc. Substantial decomposition of the resin occurs at approximately $400^{\circ} \mathrm{C}$, due to cleavage of the phenolic hydroxyl groups as well as the methylene linkages. These processes generate reactive oxygen species, which can further accelerate the breakdown of the methylene linkages via oxidation to hydroperoxide, ketone, and alcohol intermediates, which rapidly decompose. Volatile byproducts are formed such as water, hydrogen, methane $\left(\mathrm{CH}_{4}\right)$, carbon monoxide $(\mathrm{CO})$, carbon dioxide $\left(\mathrm{CO}_{2}\right)$, and phenols. Little shrinkage of the resin occurs, because many of the methylene cross-linkages are replaced by carbon-carbon bonds that form between two aromatic rings directly. At approximately $600^{\circ} \mathrm{C}$, substantial shrinkage occurs as a result of the formation of additional carbon-carbon bonds between aromatic rings, resulting in a polyaromatic char (typically, approximately $60 \%$ of the original resin). Substantial quantities of pyrolysis gases are liberated, composed mainly of hydrogen, but also methane, volatile aromatic compounds (such as phenol or benzene), water, carbon monoxide, and carbon dioxide. Finally, although the char ignites at $900^{\circ} \mathrm{C}$, controlled decomposition of phenolic resins in an inert atmosphere in the presence of other forms of carbon (e.g. carbon fibers, coke, synthetic graphite) can be used to yield stable, glassy composites.

\section{A.C. Synthesis of Novolac Resins}

Novolac resins are synthesized by acid-catalyzed polymerization of phenol and formaldehyde (Fig. 28). Typically $0.1 \%-2 \%$ (by mole) of acid catalyst is used. An acidic medium favors the production of linear polymers (in which repeat units are comprised of di-substituted phenol units). As substitution on phenol (1) increases, its reactivity towards formaldehyde decreases. As a result, excess phenol is added in order to achieve a controlled polymerization. This is effective up to molecular weights of $\sim 1000 \mathrm{~g} / \mathrm{mol}$, beyond which the concentration of end groups and unreacted phenol becomes too low, and polymer branching (in which repeat units are comprised of tri-substituted phenol units) becomes competitive with linear chain growth. With the addition of a cross-linking agent, the polymer is then cross-linked in a second, subsequent step in which the polymer chains are joined via additional $2,2^{\prime}$ - or $2,4^{\prime}$-methylene linkages between open sites (highlighted in Fig. 28).

In terms of resin composition, it is worth mentioning that because benzylic alcohols (10) are unstable in the presence of strong acids, and resins synthesized using strong acid catalysts are generally devoid of ether linkages. However, ether linkages may be produced in small amounts when weak acid catalysts (such as oxalic acid) are employed (see Sec. B for a more detailed explanation). In the curing step for these resins, nitrogen-containing compounds, such as hexamethylenetetramine (4), are often employed as a source of formaldehyde (2). Figure 29 outlines how $\mathbf{4}$ serves as a source of $\mathbf{2}$. Typically $5 \%-15 \%$ (by mole) of $\mathbf{4}$ is utilized; as a result, varying amounts of nitrogen is often incorporated in novolac resins due to competing reactions of phenol (1) with imine (5).

\section{A.C.1. Brønsted Acid Catalysts - Novolac Resins}

Figure 30 gives a generalized mechanism for polymerization under Brønsted acidic conditions. In water, formaldehyde (2) exists primarily in its hydrate form (7), which is a commercially available as formalin. Compound $\mathbf{7}$ is protonated in the presence of a Brønsted acid, such as sulfuric acid (6), a representative strong acid, generating $\mathbf{8}$ which expels water to provide protonated formaldehyde $\mathbf{9}$. Compound $\mathbf{9}$ then engages in electrophilic aromatic substitution with phenol (1). Although either $\mathrm{C} 2$ or $\mathrm{C} 4$ of phenol can react, a reaction at $\mathrm{C} 4$ is favored. In strong acid, the resulting benzylic alcohol (10) has a very short lifetime, and rapidly undergoes proton transfer providing 11. In weak acid, $\mathbf{1 1}$ is in an equilibrium with its unprotonated form (which can yield additional byproducts, discussed in Sec. B). Compound $\mathbf{1 1}$ then reacts with a second equivalent of phenol (1). Again, the reaction preferentially takes place at the C4 position, generating $\mathbf{1 2}$ which leads to $\mathbf{1 3}$ as the major product (bearing a 4,4'-methylene linkage). Compounds $\mathbf{1 5}$ and $\mathbf{1 9}$ are generated in an analogous manner as shown.

The major product $\mathbf{1 3}$ only has open sites at the $\mathrm{C} 2$ position, so formaldehyde $(\mathbf{2})$ will next add at the $\mathrm{C} 2$ position. The entire pathway described in Fig. 30 is then repeated with preferential substitution at C4 of phenol (1). In the end, this yields a polymer comprised of predominantly $2,4^{\prime}$-methylene linkages (typically 


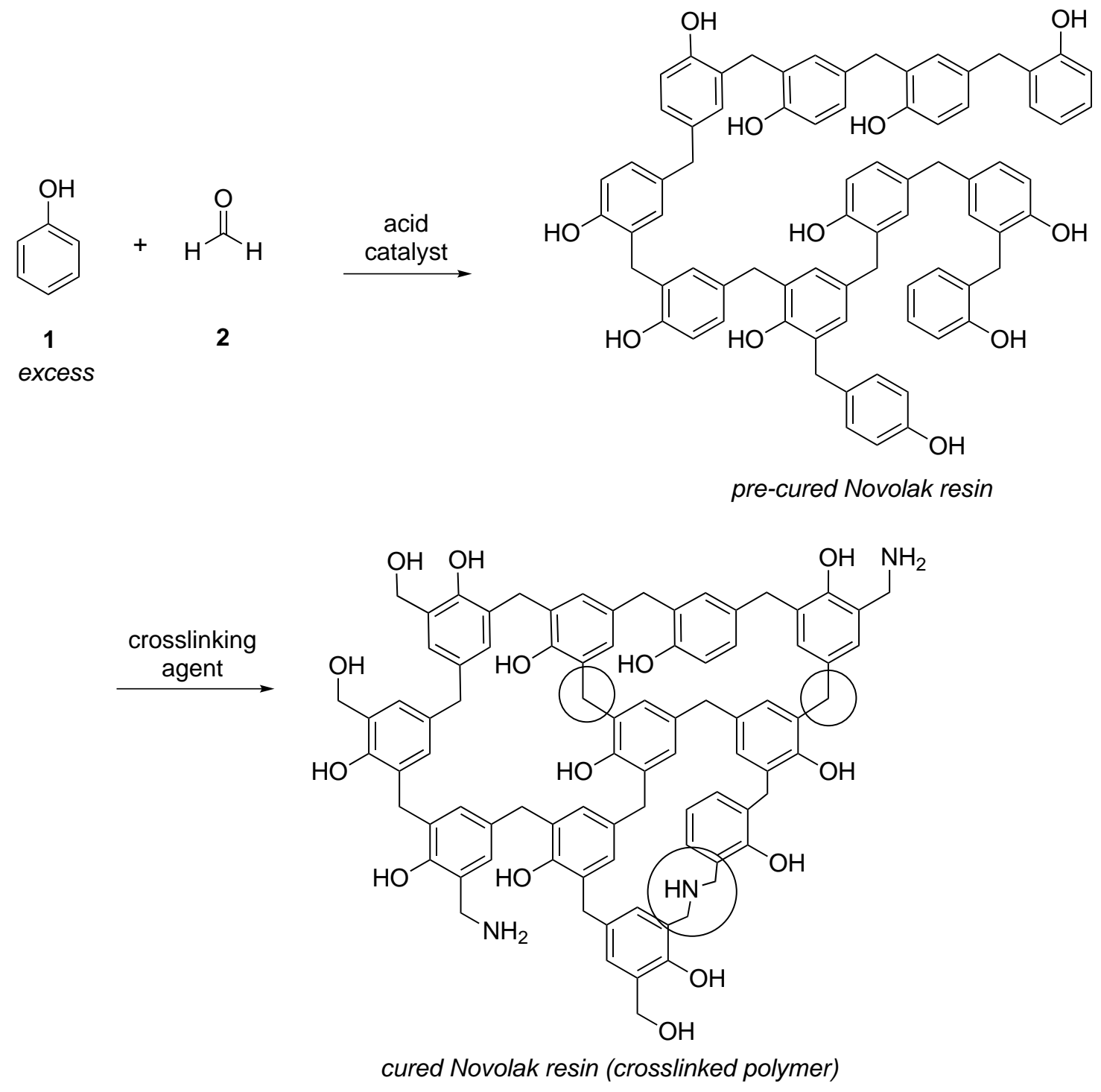

Figure 28: General synthetic scheme for the production of a novolac resin.

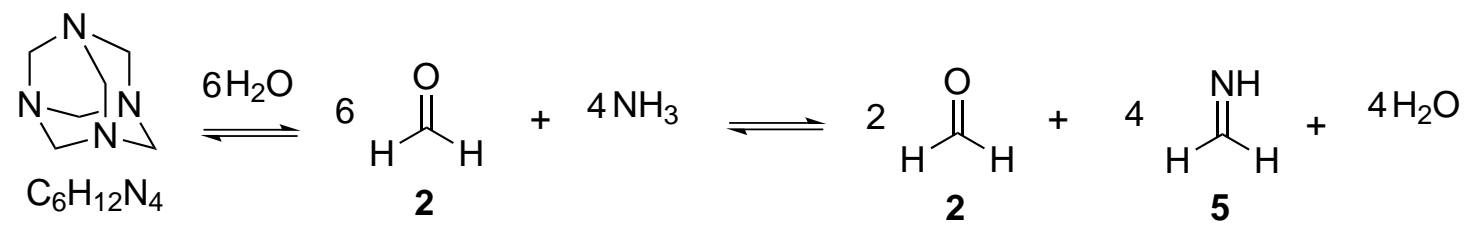

4

Figure 29: Hexamethylenetetramine (4) as a source of formaldehyde (2).

$\sim 50 \%-75 \%)$ : the remaining linkages are primarily $4,4^{\prime}$-methylene units $(\sim 20 \%)$, and only small amounts of $2,2^{\prime}$-methylene units are produced $(\sim 5 \%)$.

\section{A.C.2. Lewis (Neutral) Acid Catalysts - High Ortho Novolac Resins}

Figure 31 gives a plausible mechanism for polymerization under Lewis acid conditions. Initially, phenol (1) forms a coordination complex (21) from reaction with a divalent metal precursor $(\mathbf{2 0})(\mathrm{M}=\mathrm{Zn}, \mathrm{Mg}, \mathrm{Mn}$, $\mathrm{Cd}, \mathrm{Co}, \mathrm{Pb}, \mathrm{Cu}$, or $\mathrm{Ni}$ ). Complex $\mathbf{2 1}$ can coordinate formalin (7), which directs the initial addition to $\mathrm{C} 2$, 


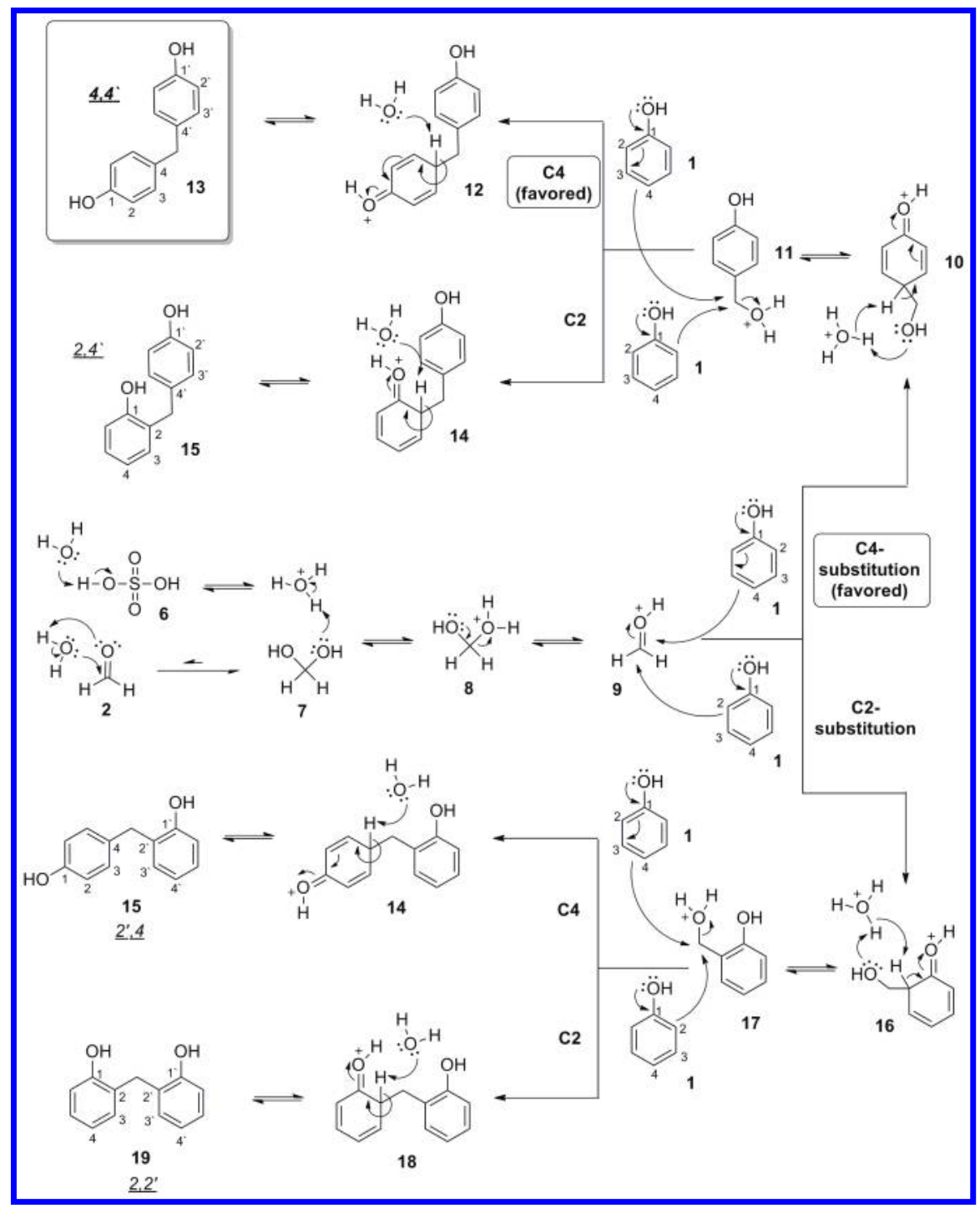

Figure 30: Brønsted acid-catalyzed reaction of phenol with formaldehyde.

generating 22. Compound $\mathbf{2 2}$ undergoes proton transfer yielding 23, which then unselectively reacts with phenol (1) at either C4 or C2 to form $\mathbf{1 5}$ and $\mathbf{1 9}$ respectively. This entire process is repeated as in Fig. 31, thus producing a polymer exhibiting a high content of $2,2^{\prime}$-linkages (typically $45 \%\left[2,2^{\prime}\right], 45 \%\left[2,4^{\prime}\right]$ ). In addition, as benzylic alcohol intermediates are present, ether linkages are also produced as minor byproducts $(\sim 10 \%)$ (see B).

\section{A.D. Synthesis of Resole Resins}

Resole resins are synthesized by base-catalyzed polymerization of phenol and formaldehyde (Fig. 32). Typically $\sim 1 \%-12 \%$ (by mole) of base catalyst is used. A basic medium favors the production of branched polymers, because substitution of phenolate ions (generated from 1 under basic conditions) increases reactivity towards formaldehyde. Similarly, these polymers often cross-link under the reaction conditions and thus generally do not require the addition of a cross-linking agent in the curing step. As a result of this polymethylolation of phenol, excess formaldehyde is added in order to achieve a controlled polymerization. Regardless, resole resins will still often contain a small amount of unreacted, "trapped" phenol ( $\sim 5 \%-15 \%$ by mole). As benzylic alcohols are stable in the presence of base, resins synthesized using base catalysts also generally contain a high amount of benzylic ether linkages (39) prior to curing (see Sec. B). However, these linkages can be converted to the stronger methylene linkages (Fig. 27) upon heating in the subsequent curing 


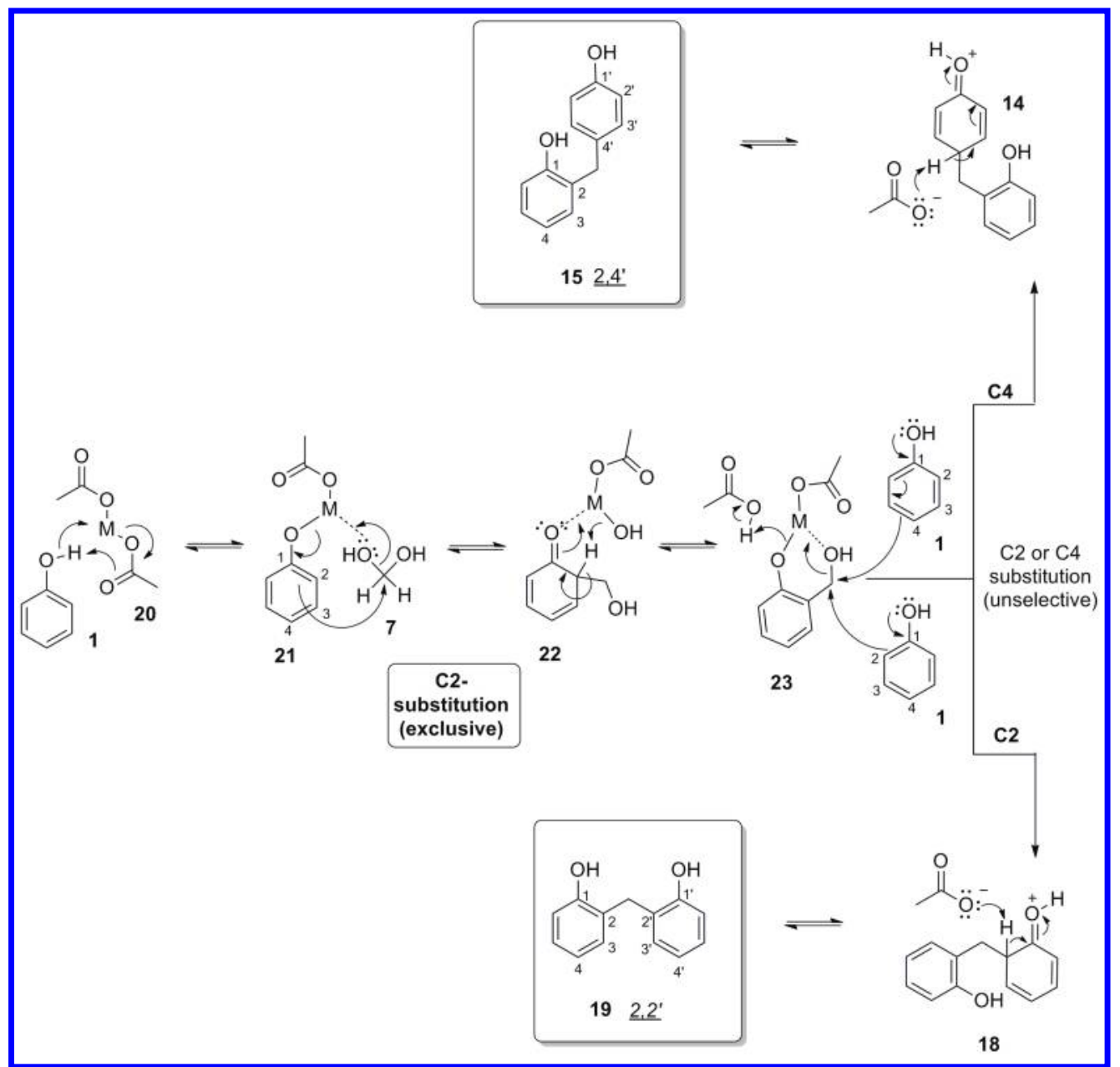

Figure 31: Lewis acid catalyzed reaction of phenol with formaldehyde.

step. Fewer ether linkages are produced if weaker bases such as amine bases are used as catalysts instead of sodium hydroxide $(\mathrm{NaOH})$. However, in these cases a significant amount of nitrogen is incorporated. This occurs as a result of reaction of phenolate ions with imines (5), which form from the reaction of formaldehyde (2) with the amine catalyst (Fig. 29). The use of amine bases also typically results in polymers with higher molecular weights, less free phenol, lower water solubility, and a higher glass transition temperature.

As a result of the spontaneous cross-linking of the polymethylol groups that occurs under the reaction conditions for resole resins, the polymerization and curing processes can be conducted in one step; this is in contrast to novolac resins in which polymerization and curing are always conducted in two separate steps.

Figure 33 gives a generalized mechanism for polymerization under basic conditions. Phenol (1) reacts with base to form phenolate ion $(\mathbf{2 4})$, which reacts with formaldehyde $(\mathbf{2})$ (generated from formalin $(\mathbf{7})$ in the presence of base) to yield 25. Proton transfer produces mono-substituted phenolate ion (26), which reacts with formaldehyde $(\mathbf{2})$ analogously to $\mathbf{2 4}$, yielding phenolate $(\mathbf{2 7})$. Substitution increases the reactivity of phenolate ions: thus, reactivity increases in the order of $\mathbf{2 4}<\mathbf{2 6}<\mathbf{2 7}$. Reaction of phenolate (27) with 2 produces compound $\mathbf{2 8}$, which can eliminate hydroxide ion yielding $\mathbf{2 9}$. Reaction of $\mathbf{2 9}$ with phenolate ion (24) produces 30. Proton transfer reactions result in $\mathbf{3 1}$ and then 32, which can continue to react with $\mathbf{2 4}$ in an analogous fashion to $\mathbf{2 9}$, producing $\mathbf{3 3}, \mathbf{3 4}$, and finally fully branched phenol (35). Polymerization proceeds via further reaction of $\mathbf{3 5}$ and its intermediates until all of the formaldehyde is consumed, generating highly branched polymers. Furthermore, these polymethylolated repeat units can also react with each other, generating a highly cross-linked polymer network. 


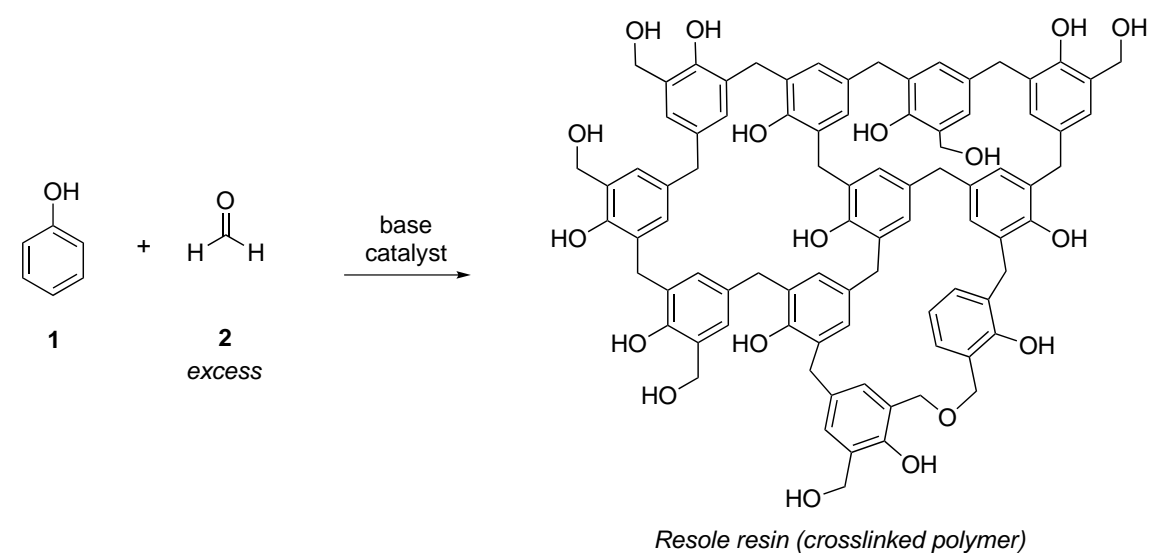

Figure 32: General synthetic scheme for the production of a resole resin.
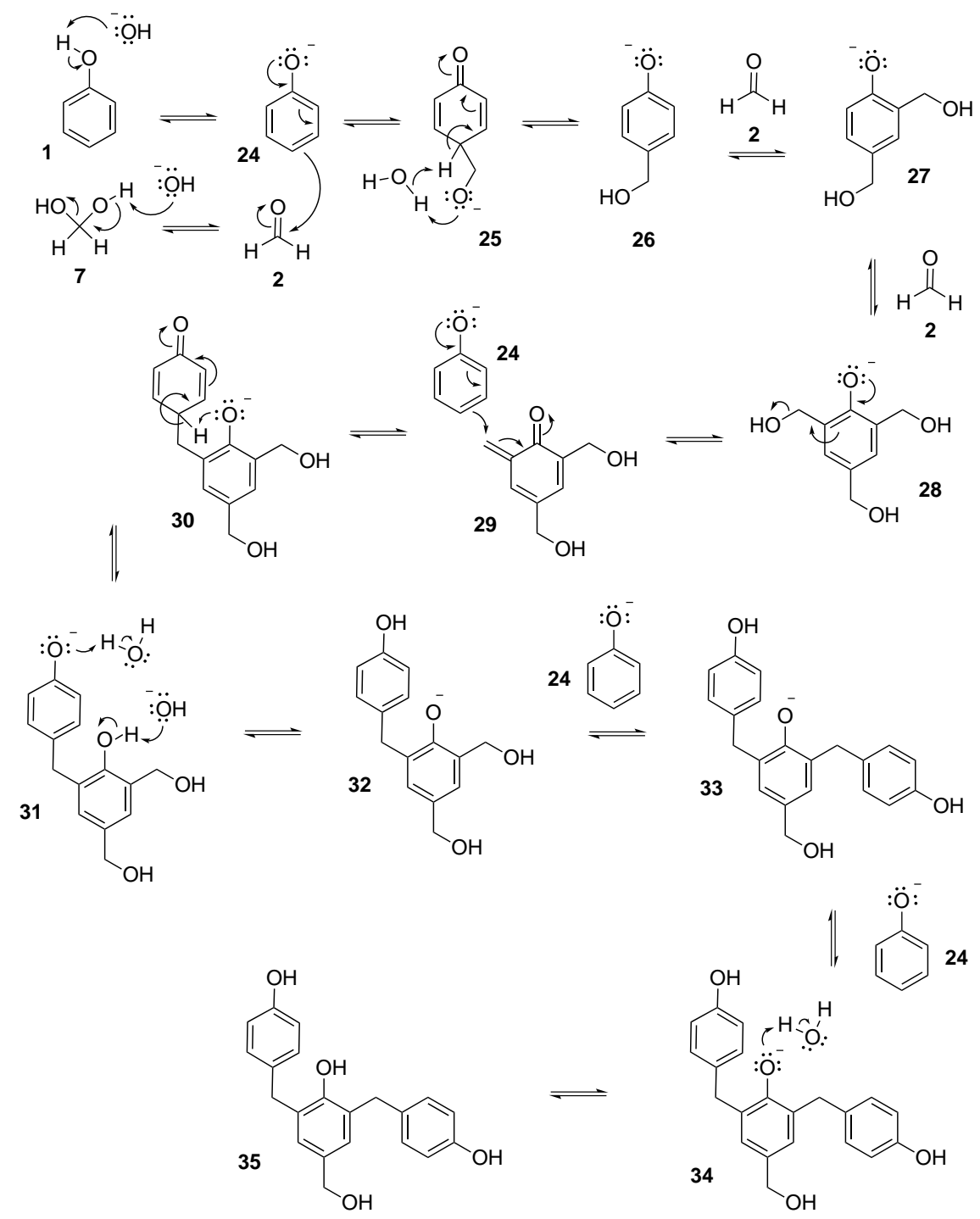

Figure 33: Base-catalyzed reaction of phenol with formaldehyde.

\section{B. Byproducts formed in synthesis of resins}

Figure 34 illustrates representative examples of various byproducts that can be formed in the synthesis of resins. Small ( $\sim 1 \%-2 \%$ by mole) benzodioxane (37) impurities are found when weak acids (such as oxalic 
or phosphoric acid) are used, due to the small amounts of benzylic alcohols (36) that are produced and react with protonated formaldehyde (9). This is not seen when sulfonic or sulfuric acid is used, as benzylic alcohols rapidly decompose under strongly acidic conditions; instead, they remain fully protonated as $\mathbf{1 7 .}$ However, 37 can liberate formaldehyde upon curing and can be subsequently reincorporated and cross-linked as methylene bridges. Formation of benzylic alcohols (36) under weak or neutral acidic conditions, as well as basic conditions, can also result in the production of varying amounts of benzylic ethers (38). However, these also generally decompose to formaldehyde and methylene linkages upon curing (Fig. 27). Formation of 39 can occur under any of the reaction conditions, and $\mathbf{3 9}$ can dimerize to produce $\mathbf{4 0}$. It is unlikely that this byproduct will decompose under the curing conditions. Hence, it might remain trapped in the resin and liberated as a pyrolysis gas at higher temperatures.

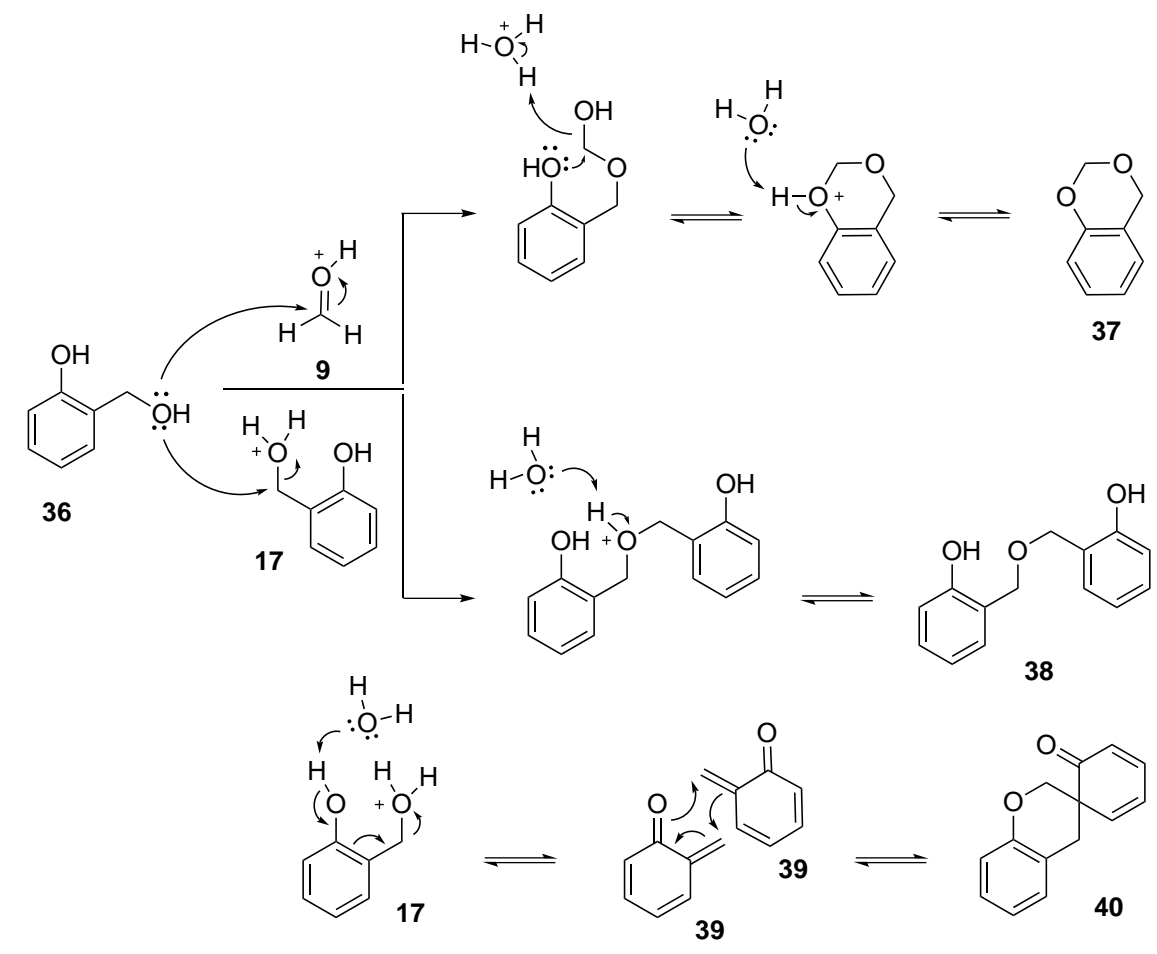

Figure 34: Byproducts formed in resin synthesis.

\section{Pyrolysis Gas Model}

The 55 species used for the pyrolysis gas mixture model are listed in Table 5. Even though no nitrogen content is assumed in this work, the entire model is included for generality. Only 8 species $\left(\mathrm{C}_{24} \mathrm{H}_{12}\right.$, $\mathrm{C}_{3} \mathrm{H}, \mathrm{C}_{3} \mathrm{H}_{2}$-triplet, $\mathrm{C}_{4}, \mathrm{C}_{4} \mathrm{H}, \mathrm{C}_{5}, \mathrm{C}_{5} \mathrm{H}$, and $\mathrm{C}_{3} \mathrm{H}_{2}$-singlet) do not use the standard CEA data. The three additional species used to model the work by Sykes [16] are shown in Table 6.

Table 5: 55 gas species model used to model the pyrolysis gas mixture.

\begin{tabular}{|c|c|c|}
\hline Species & Reference & Name (if different) in Paper Figures \\
\hline $\mathrm{C}$ & Ref. $\mid 85]$ & \\
\hline $\mathrm{C}^{+}$ & Ref. $[85]$ & \\
\hline $\mathrm{C}_{2}$ & Ref. 85 & \\
\hline $\mathrm{C}_{24} \stackrel{\mathrm{H}}{\mathrm{H}}_{12}$ & Ref. 53 & \\
\hline $\mathrm{C}_{2} \mathrm{H}$ & Ref. 85$]$ & \\
\hline $\mathrm{C}_{2} \mathrm{H}_{2}$, acetylene & Ref. 85 & $\mathrm{C}_{2} \mathrm{H}_{2}$ \\
\hline $\mathrm{C}_{2} \mathrm{H}_{2}$, vinylidene & Ref. 85 & \\
\hline $\mathrm{C}_{2} \mathrm{H}_{4}$ & Ref. 85$]$ & \\
\hline $\mathrm{C}_{2}^{-} \mathrm{H}_{6}$ & Ref. $[85]$ & \\
\hline $\mathrm{C}_{2}^{2} \mathrm{~N}_{2}^{0}$ & Ref. 85 & \\
\hline $\mathrm{C}_{2} \mathrm{O}$ & Ref. [85] & \\
\hline
\end{tabular}




\begin{tabular}{|c|c|c|}
\hline $\mathrm{C}_{3}$ & Ref $[85]$ & \\
\hline $\mathrm{C}_{3} \mathrm{H}^{3}$ & Ref. 53 & \\
\hline $\mathrm{C}_{3} \mathrm{H}_{2}$, triplet & Ref. 53 & $\mathrm{C}_{3} \mathrm{H}_{2}$ \\
\hline $\mathrm{C}_{3} \mathrm{H}_{3}, 2$-propynl & Ref. 85. & $3^{\Pi_{1}}$ \\
\hline $\mathrm{C}_{3} \mathrm{H}_{4}$, allene & Ref. 85. & \\
\hline $\mathrm{C}_{3} \mathrm{H}_{4}$, propyne & Ref. 85. & \\
\hline $\mathrm{C}_{3} \mathrm{O}_{2}$ & Ref. [85] & \\
\hline $\mathrm{C}_{4} \mathrm{H}$ & Ref. 53 & \\
\hline $\mathrm{C}_{4} \mathrm{H}_{2}$, butadiyne & Ref. 85. & $\mathrm{C}_{4} \mathrm{H}_{2}$ \\
\hline $\mathrm{C}_{4} \mathrm{~N}_{2}$ & Ref. 85$]$ & \\
\hline $\mathrm{C}_{5}{ }_{5} \mathrm{H}$ & Ref. 53 & \\
\hline $\mathrm{C}_{6} \mathrm{H}_{2}$ & Ref. [85] & \\
\hline $\mathrm{C}_{6}^{0} \mathrm{H}_{6}^{2}$ & Ref. 85$]$ & \\
\hline $\mathrm{CCN}$ & Ref. [85] & \\
\hline $\mathrm{CH}$ & Ref. ${ }^{8} 85^{\circ}$ & \\
\hline $\mathrm{CH}_{2}$ & Ref. [85] & \\
\hline $\mathrm{CH}_{3}^{2}$ & Ref. $85^{\circ}$ & \\
\hline $\mathrm{CH}_{3} \mathrm{CN}$ & Ref. [85] & \\
\hline $\mathrm{CH}_{4}$ & Ref. [85] & \\
\hline $\mathrm{CN}^{*}$ & Ref. [85] & \\
\hline $\mathrm{CNC}$ & Ref. [85] & \\
\hline $\mathrm{CO}$ & Ref. [85] & \\
\hline $\mathrm{CO}_{2}$ & Ref. [85] & \\
\hline $\mathrm{e}^{-}$ & Ref. [85] & \\
\hline $\mathrm{H}$ & Ref. [85] & \\
\hline $\mathrm{H}^{+}$ & Ref. [85] & \\
\hline $\mathrm{H}_{2}$ & Ref. [85] & \\
\hline $\mathrm{H}_{2}{ }^{2} \mathrm{O}$ & Ref. [85] & \\
\hline $\mathrm{C}_{3} \mathrm{H}_{2}$, singlet & Ref. [53] & $\mathrm{HCCCH}$ \\
\hline $\mathrm{HCN}$ & Ref. 85$]$ & \\
\hline $\mathrm{HNC}$ & Ref. 85$]$ & \\
\hline $\mathrm{HO}_{2}$ & Ref. [85] & \\
\hline $\mathrm{N}^{2}$ & Ref. [85] & \\
\hline $\mathrm{N}_{2}$ & Ref. [85] & \\
\hline $\mathrm{NH}$ & Ref. [85] & \\
\hline $\mathrm{NH}_{3}$ & Ref. [85] & \\
\hline NO & Ref. [85] & \\
\hline $\mathrm{NO}^{+}$ & Ref. [85] & \\
\hline $\mathrm{O}$ & Ref. [85] & \\
\hline $\mathrm{O}^{+}$ & Ref. [85] & \\
\hline $\mathrm{O}_{2}$ & Ref. [85] & \\
\hline $\mathrm{OH}$ & Ref. [85] & \\
\hline
\end{tabular}

Table 6: References for additional 3 species used to model Sykes' data [16].

\begin{tabular}{c|c|c} 
Species & Reference & Name (if different) in Paper Figures \\
\hline $\mathrm{C}_{7} \mathrm{H}_{8}$ & Ref. 85 & \\
$\mathrm{C}_{6} \mathrm{H}_{5} \mathrm{OH}$ & Ref. & $85]$ \\
$\left(\mathrm{CH}_{3}\right)_{2} \mathrm{C}_{6} \mathrm{H}_{3} \mathrm{OH}$ & Personal calculations [57,58] &
\end{tabular}

Thermodynamic data used in this thesis that is not available from the CEA [52 database in presented below, using constant NASA polynomial fits [86], and shown in the input format for Cantera [54].

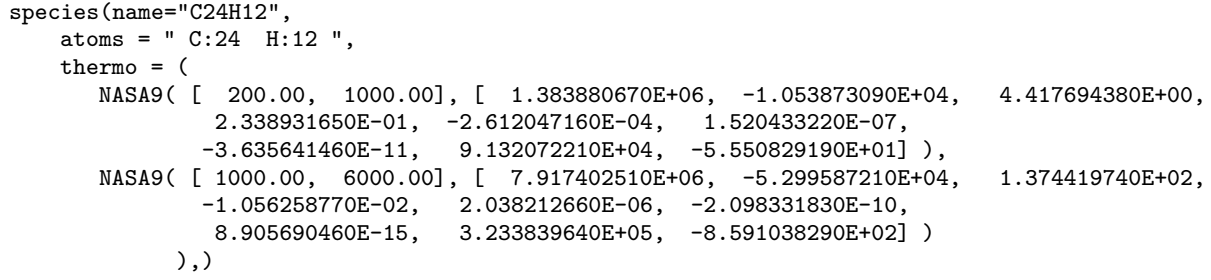




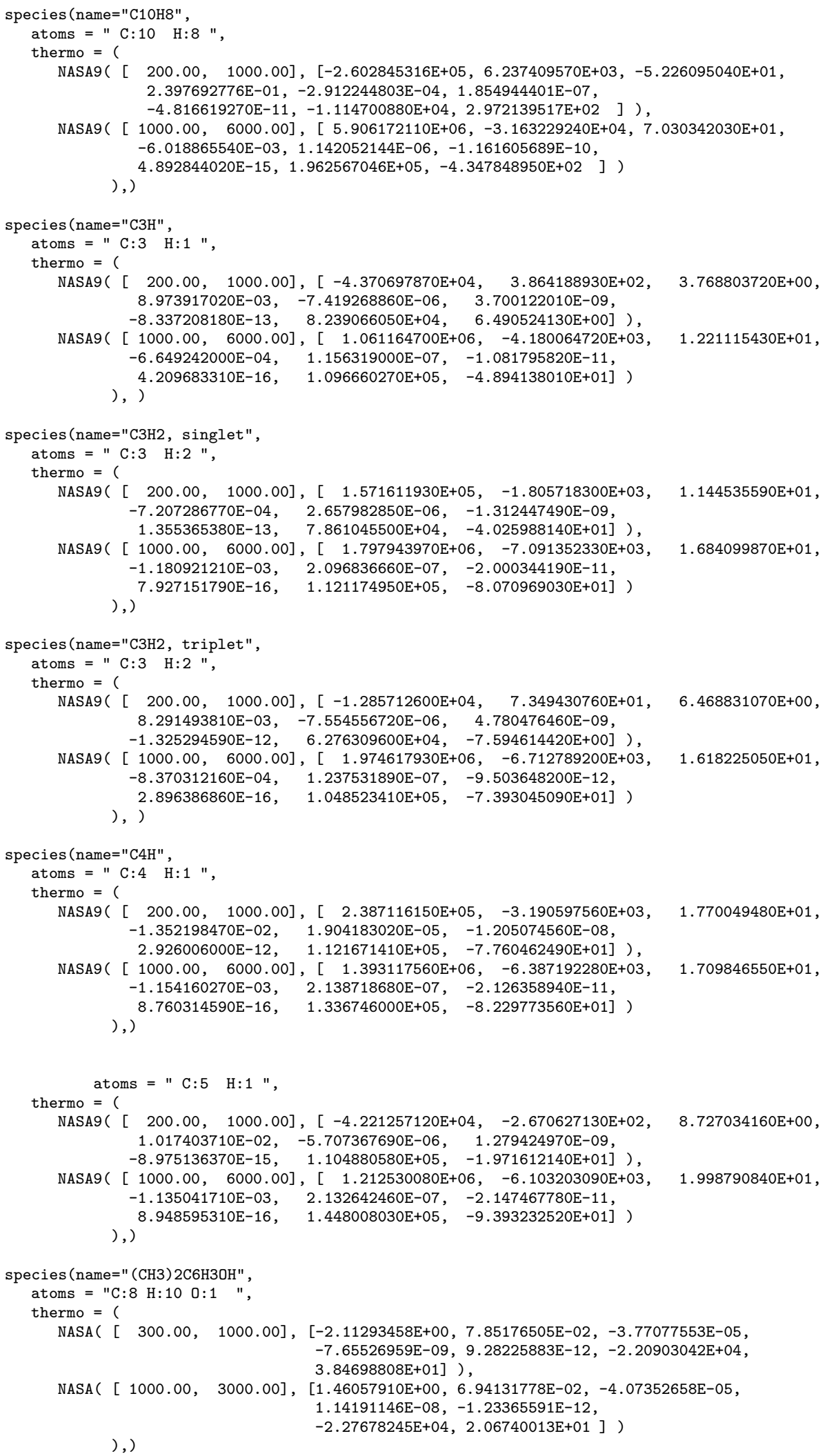

NASA9 ( $[1000.00,6000.00],[5.906172110 \mathrm{E}+06,-3.163229240 \mathrm{E}+04,7.030342030 \mathrm{E}+01$ $-6.018865540 \mathrm{E}-03,1.142052144 \mathrm{E}-06,-1.161605689 \mathrm{E}-10$,

$\operatorname{NASA9}([1000.00,6000.00],[1.061164700 \mathrm{E}+06,-4.180064720 \mathrm{E}+03,1.221115430 \mathrm{E}+01$, $-6.649242000 \mathrm{E}-04, \quad 1.156319000 \mathrm{E}-07, \quad-1.081795820 \mathrm{E}-11$,

NASA9 ( $[1000.00,6000.00],[1.974617930 \mathrm{E}+06,-6.712789200 \mathrm{E}+03,1.618225050 \mathrm{E}+01$, $-8.370312160 \mathrm{E}-04, \quad 1.237531890 \mathrm{E}-07, \quad-9.503648200 \mathrm{E}-12$,

\section{References}

${ }^{1}$ Olynick, D., Chen, Y.-K., and Tauber, M. E., "Aerothermodynamics of the Stardust sample return capsule," Journal of Spacecraft and Rockets, Vol. 36, No. 3, 1999, pp. 442-462. 1, 2 
${ }^{2}$ Tran, H. K., "Development of Lightweight Ceramic Ablators and Arc-Jet Test Results," NASA TM-108798, 1994.1

${ }^{3}$ Tran, H. K., Johnson, C. E., Rasky, D. J., Hui, F. C. L., Hsu, M.-T., Chen, T., Chen, Y. K., Paragas, D., and Kobayashi, L., "Phenolic Impregnated Carbon Ablators (PICA) as Thermal Protection Systems for Discovery Missions," NASA TM-110440, 1997. 1, 4, 5, 7, 8, 9

${ }^{4}$ Ritter, H., Bayle, O., Mignot, Y., Boulier, E., Portela, P., Bouilly, J.-M., and Sharda, R., "Ongoing European Developments on Entry Heatshields and TPS Materials," 8th International Planetary Probe Workshop, Portsmouth, Virginia, 2011. 1

${ }^{5}$ Ritter, H., Portela, P., Keller, K., Bouilly, J.-M., and Burnage, S., "Development of a European Ablative Material for Heatshields of Sample Return Missions," 6th European Workshop on Thermal Protection Systems and Hot Structures, Stuttgart, Germany, 2009. 1

${ }^{6}$ Sharpe, R. J. and Wright, M. D., "NASA Materials Research for Extreme Conditions," NASA TM-2009-215901, 2009. 2, 5

${ }^{7}$ Chung, B. T. F. and Hsiao, J., "Heat Transfer with Ablation in a Finite Slab Subjected to Time-Variant Heat Fluxes," AIAA Journal, Vol. 23, No. 1, 1985, pp. 145-150. 2

${ }^{8}$ Goodman, T. R., "Application of Integral Methods to Transient Nonlinear Heat," Advances in Heat Transfer, Vol. 1, 1964, pp. 51-122. 2

2

${ }^{9}$ Kendall, R. M., Rindal, R. A., and Bartlett, E. P., "Thermochemical Ablation," AIAA Paper, Vol. 642, 1965, pp. 13-15.

${ }^{10}$ Leone, S. A., Potts, R. L., and Laganelli, A. L., "Enhancements to integral solutions to ablation and charring," Journal of Spacecraft and Rockets, Vol. 32, No. 2, 1995, pp. 210-216. 2

${ }^{11}$ Maruyama, S., Viskanta, R., and Aihara, T., "Active thermal protection system against intense irradiation," Journal of Thermophysics and Heat Transfer, Vol. 3, No. 4, 1989, pp. 389-394. 2

12Potts, R. L., "Hybrid integral/quasi-steady solution of charring ablation," 5th Joint Thermophysics and Heat Transfer Conference, AIAA, 1990. 2

${ }^{13}$ Potts, R. L., "An Integral Method Theorem for Heat Conduction," AIAA Journal, Vol. 21, No. 4, 1983, pp. 630-631. 2

$\checkmark{ }^{14}$ Potts, R. L., "Application of integral methods to ablation charring erosion - A review," Journal of Spacecraft and Rockets, Vol. 32, No. 2, 1995, pp. 200-209. 2

${ }^{15}$ Quan, V., "Integral solution for erosion heat transfer," AIAA Journal, Vol. 8, No. 8, 1970, pp. 1512-1514. 2

${ }^{16}$ Sykes Jr., G. F., "Decomposition Characteristics of a Char-Forming Phenolic Polymer Used for Ablative Composites,"

NASA TN D-3810, 1967. 2, 6, 7, 8, 9, 10, 26, 27, 28, 29, 30, 31, 35, 42, 43

${ }^{17}$ Bose, D., Brown, J. L., Prabhu, D. K., Gnoffo, P., Johnston, C. O., and Hollis, B., "Uncertainty Assessment of Hypersonic Aerothermodynamics Prediction Capability," Journal of Spacecraft and Rockets, Vol. 50, No. 1, 2013, pp. 12-18. 2

$\checkmark{ }^{18}$ Bose, D., White, T., Santos, J., Feldman, J., Mahzari, M., Olson, M., and Laub, B., "Initial Assessment of Mars Science Laboratory Heatshield Instrumentation and Flight Data," 51st AIAA Aerospace Sciences Meeting including the New Horizons Forum and Aerospace Exposition, AIAA, 2013. 2, 14, 18

${ }^{19}$ Hollis, B. R. and Prabhu, D. K., "Assessment of Laminar, Convective Aeroheating Prediction Uncertainties for MarsEntry Vehicles," Journal of Spacecraft and Rockets, Vol. 50, No. 1, 2013, pp. 56-68. 2

${ }^{20}$ Wright, M., Edquist, K., Tang, C., Hollis, B., Krasa, P., and Campbell, C., "A Review of Aerothermal Modeling for Mars Entry Missions," 48th AIAA Aerospace Sciences Meeting Including the New Horizons Forum and Aerospace Exposition, AIAA, 2010. 2

${ }^{21}$ Chen, Y.-K. and Milos, F. S., "Ablation and thermal response program for spacecraft heatshield analysis," Journal of Spacecraft and Rockets, Vol. 36, No. 3, 1999, pp. 475-483. 2

${ }^{22}$ Martin, A., Boyd, I. D., Cozmuta, I., and Wright, M. J., "Chemistry model for ablating carbon-phenolic material during atmospheric re-entry," 48th AIAA Aerospace Sciences Meeting and Exhibit, AIAA, 2010. 2

${ }^{23}$ Milos, F. S. and Chen, Y.-K., "Ablation and Thermal Response Property Model Validation for Phenolic Impregnated Carbon Ablator," Journal of Spacecraft and Rockets, Vol. 47, No. 5, 2010, pp. 786-805. 2, 3

${ }^{24}$ Milos, F. S. and Chen, Y.-K., "Ablation, Thermal Response, and Chemistry Program for Analysis of Thermal Protection Systems," Journal of Spacecraft and Rockets, Vol. 50, No. 1, 2013, pp. 137-149. 2, 3, 7, 8, 10, 12, 13, 29

${ }^{25}$ Park, C., Jaffe, R. L., and Partridge, H., "Chemical-Kinetic Parameters of Hyperbolic Earth Entry," Journal of Thermophysics and Heat Transfer, Vol. 15, No. 1, 2001, pp. 76-90. 2, 3, 7, 10, 13, 29

${ }^{26}$ Trick, K. A. and Saliba, T. E., "Mechanisms of the pyrolysis of phenolic resin in a carbon/phenolic composite," Carbon, Vol. 33, No. 11, 1995, pp. 1509 - 1515. 2, 6, 7, 26, 27, 35

27 Mahzari, M., White, T., Braun, R., and Bose, D., "Preliminary Analysis of the Mars Science Laboratory's Entry Aerothermodynamic Environment and Thermal Protection System Performance," 51st AIAA Aerospace Sciences Meeting including the New Horizons Forum and Aerospace Exposition, AIAA, 2013. 2, 14, 18

${ }^{28}$ Milos, F. S. and Chen, Y.-K., "Ablation Predictions for Carbonaceous Materials Using Two Databases for Species Thermodynamics," Journal of Spacecraft and Rockets, Vol. 50, No. 2, 2013, pp. 245-255. 2

${ }^{29}$ Milos, F. S. and Chen, Y.-K., "Comprehensive model for multicomponent ablation thermochemistry," 35th Aerospace Sciences Meeting and Exhibit, AIAA, 1997. 2, 3, 10, 12

${ }^{30}$ Lachaud, J. and Mansour, N. N., "Porous-Material Analysis Toolbox Based on OpenFOAM and Applications," Journal of Thermophysics and Heat Transfer, 2014, pp. 1-12. 2, 3, 8, 14, 18, 34, 35

${ }^{31}$ Park, C., "Review of Chemical-Kinetic Problems of Future NASA Missions, I: Earth Entries," Journal of Thermophysics and Heat Transfer, Vol. 7, No. 3, 1993, pp. 385-398. 3

$\$ 32$ Park, C., Howe, J. T., Jaffe, R. L., and Candler, G. V., "Review of Chemical-Kinetic Problems of Future NASA Missions, II: Mars Entries," Journal of Thermophysics and Heat Transfer, Vol. 8, No. 1, 1994, pp. 9-23. 3

$\checkmark{ }^{33}$ Wong, H.-W., Peck, J., Edwards, R., Reinisch, G., Lachaud, J., and Mansour, N. N., "Measurement of pyrolysis products from phenolic polymer thermal decomposition," 52nd Aerospace Sciences Meeting, AIAA, 2014. 3, 6, 8, 9, 18, 27 
${ }^{34}$ Qi, T., Bauschlicher, Jr., C. W., Lawson, J. W., Desai, T. G., and Reed, E. J., "Comparison of ReaxFF, DFTB, and DFT for Phenolic Pyrolysis. 1. Molecular Dynamics Simulations," The Journal of Physical Chemistry A, Vol. 117, No. 44, 2013, pp. 11115-11125. 4, 6

${ }^{35}$ Kopf, P. W., Phenolic Resins, Vol. 7, John Wiley \& Sons, Inc., 2002. 4, 5, 6, 7, 9, 35

${ }^{36}$ Helber, B., Chazot, O., Magin, T., and Hubin, A., "Ablation of Carbon Preform In the VKI Plasmatron," 43rd AIAA Thermophysics Conference, AIAA, 2012. 4, 5

${ }^{37}$ Stackpoole, M., Sepka, S., Cozmuta, I., and Kontinos, D., "Post-flight evaluation of Stardust Sample Return Capsule forebody heatshield material," 46th Aerospace Sciences Meeting and Exhibit, AIAA, 2008. 4

${ }^{38}$ Bottin, B., Chazot, O., Carbonaro, M., van der Haegen, V., and Paris, S., "The VKI Plasmatron characteristics and performance," DTIC Document, 2000. 5

${ }^{39}$ Pilato, L., Phenolic resins: a century of progress, Springer, 2010. 5, 6, 35

${ }^{40}$ Desai, T. G., Lawson, J. W., and Keblinski, P., "Modeling initial stage of phenolic pyrolysis: Graphitic precursor formation and interfacial effects," Polymer, Vol. 52, No. 2, 2011, pp. $577-585.6$

${ }^{41}$ Jiang, D.-e., van Duin, A. C. T., Goddard, W. A., and Dai, S., "Simulating the Initial Stage of Phenolic Resin Carbonization via the ReaxFF Reactive Force Field," The Journal of Physical Chemistry A, Vol. 113, No. 25, 2009, pp. 6891-6894. 6

${ }^{42}$ Movahed, F. S., Cheng, G., Venkatachari, B. S., and Cozmuta, I., "Atomistic simulation of thermal decomposition of crosslinked and non-crosslinked phenolic resin chains," 42nd AIAA Thermophysics Conference, AIAA, 2011. 6

$\checkmark 43$ Till, S., Heaton, A., Payne, D., Stone, C., and Swan, M., "Computational chemistry studies of phenolic resin," 51st AIAA Aerospace Sciences Meeting including the New Horizons Forum and Aerospace Exposition, AIAA, 2013. 6

${ }^{44}$ Crouch, R. K. and Walberg, G. D., "An Investigation of Ablation Behavior of Avcoat 5026/39M Over a Wide Range of Thermal Environments," NASA TM X-1778, 1969. 7

${ }^{45}$ Jenkins, G. M., Kawamura, K., and Ban, L. L., "Formation and Structure of Polymeric Carbons," Proceedings of the Royal Society of London. Series A, Mathematical and Physical Sciences, Vol. 327, No. 1571, 1972, pp. pp. 501-517. 7

${ }^{46}$ Trick, K., Saliba, T., and Sandhu, S., "A kinetic model of the pyrolysis of phenolic resin in a carbon/phenolic composite," Carbon, Vol. 35, No. 3, 1997, pp. 393 - 401. 7, 9, 26, 27, 29, 30

${ }^{47}$ Jensen, K. A., Suo-Anttila, J. M., and Blevins, L. G., "Measurement of soot morphology, chemistry, and optical properties in the visible and near-infrared spectrum in the flame zone and overfire region of large JP-8 pool fires," Combustion Science and Technology, Vol. 179, No. 12, 2007, pp. 2453-2487. 8, 22

${ }^{48}$ Russo, C., Alfè, M., Rouzaud, J.-N., Stanzione, F., Tregrossi, A., and Ciajolo, A., "Probing structures of soot formed in premixed flames of methane, ethylene and benzene," Proceedings of the Combustion Institute, Vol. 34, No. 1, 2013, pp. 1885 1892. 8,22

${ }^{49}$ Wakefield, M. and Pitts, W. C., "Analysis of the Heat-Shield Experiment on the Pioneer-Venus Entry Probes," AIAA 1980-1494, 1980. 8

${ }^{50}$ Lachaud, J., Magin, T. E., Cozmuta, I., and Mansour, N. N., "A Short Review of Ablative Material Response Models and Simulation Tools," 7th European Symposium on the Aerothermodynamics, 2011, pp. 9-12. 8

${ }^{51}$ Ahn, H. K., Park, C., and Sawada, K., "Dynamics of pyrolysis gas in charring materials ablation," 36th AIAA Aerospace Sciences Meeting and Exhibit, AIAA, 1998. 8, 14, 18

${ }^{52}$ McBride, B. J. and Gordon, S., "Chemical Equilibrium with Applications," http://www.grc.nasa.gov/WWW/CEAWeb/. 9, 43

${ }^{53}$ Barros-Fernandez, B., Scoggins, J. B., Rabinovitch, J., Blanquart, G., Martin, A., , Jaffe, R. L., Mansour, N. N., and Magin, T., "Thermodynamic properties in equilibrium composition of carbon phenolic mixtures," In Preparation. 9, 42, 43

${ }^{54}$ Goodwin, D. G., "An Open-Source, Extensible Software Suite for CVD Process Simulation," Electrochemical Society, 2003, pp. 155-162. 10, 43

${ }^{55}$ Blanquart, G. and Pepiot, P., "Detailed chemical mechanism and surrogate formulations for engine fuels," Proceedings of 7th US Combustion Meeting, Atlanta, Georgia, 2011, pp. 9-12. 14

$\checkmark{ }^{56}$ Blanquart, G., Pepiot-Desjardins, P., and Pitsch, H., "Chemical mechanism for high temperature combustion of engine relevant fuels with emphasis on soot precursors," Combustion and Flame, Vol. 156, No. 3, 2009, pp. 588-607. 14

${ }^{57}$ Blanquart, G. and Pitsch, H., "Thermochemical properties of polycyclic aromatic hydrocarbons (PAH) from G3MP2B3 calculations," The Journal of Physical Chemistry A, Vol. 111, No. 28, 2007, pp. 6510-6520. 14, 43

${ }^{58}$ Narayanaswamy, K., Blanquart, G., and Pitsch, H., "A consistent chemical mechanism for oxidation of substituted aromatic species," Combustion and Flame, Vol. 157, No. 10, 2010, pp. 1879-1898. 14, 43

${ }^{59}$ Robert, J., "Chemkin-II: A Fortran chemical kinetics package for the analysis of gas-phase chemical kinetics," Sandia National Laboratories Report SAND89-8009B, 1989. 15

${ }^{60}$ Little, A., Bose, D., Karlgaard, C., Munk, M., Kuhl, C., Schoenenberger, M., Antill, C., Verhappen, R., Kutty, P., and White, T., "The Mars Science Laboratory (MSL) Entry, Descent And Landing Instrumentation (MEDLI): Hardware Performance and Data Reconstruction," 36th AAS Guidance and Control Conference, Breckenridge, CO, 1-6 February 2013. 18

${ }^{61}$ Lachaud, J., Cozmuta, I., and Mansour, N. N., "Multiscale approach to ablation modeling of phenolic impregnated carbon ablators," Journal of Spacecraft and Rockets, Vol. 47, No. 6, 2010, pp. 910-921. 18, 21, 35

${ }^{62}$ Wang, H., "Formation of nascent soot and other condensed-phase materials in flames," Proceedings of the Combustion Institute, Vol. 33, No. 1, 2011, pp. 41-67. 19

${ }^{63}$ Mitchell, P. and Frenklach, M., "Particle aggregation with simultaneous surface growth," Phys. Rev. E, Vol. 67, Jun 2003, pp. 061407. 19

${ }^{64}$ Miller, J. H., "The kinetics of polynuclear aromatic hydrocarbon agglomeration in flames," Symposium (International) on Combustion, Vol. 23, Elsevier, 1991, pp. 91-98. 19, 20 
${ }^{65}$ Sinnokrot, M. O. and Sherrill, C. D., "Highly accurate coupled cluster potential energy curves for the benzene dimer: sandwich, T-shaped, and parallel-displaced configurations," The Journal of Physical Chemistry A, Vol. 108, No. 46, 2004, pp. 10200-10207. 19

${ }^{66}$ Vincenti, W. G. and Kruger, C. H., Introduction to physical gas dynamics, Vol. 1, Wiley: New York, 1965. 19, 20

${ }^{67}$ Frisch, M. J., Trucks, G. W., Schlegel, H. B., Scuseria, G. E., Robb, M. A., Cheeseman, J. R., Montgomery, Jr., J. A., Vreven, T., Kudin, K. N., Burant, J. C., Millam, J. M., Iyengar, S. S., Tomasi, J., Barone, V., Mennucci, B., Cossi, M., Scalmani, G., Rega, N., Petersson, G. A., Nakatsuji, H., Hada, M., Ehara, M., Toyota, K., Fukuda, R., Hasegawa, J., Ishida, M., Nakajima, T., Honda, Y., Kitao, O., Nakai, H., Klene, M., Li, X., Knox, J. E., Hratchian, H. P., Cross, J. B., Bakken, V., Adamo, C., Jaramillo, J., Gomperts, R., Stratmann, R. E., Yazyev, O., Austin, A. J., Cammi, R., Pomelli, C., Ochterski, J. W., Ayala, P. Y., Morokuma, K., Voth, G. A., Salvador, P., Dannenberg, J. J., Zakrzewski, V. G., Dapprich, S., Daniels, A. D., Strain, M. C., Farkas, O., Malick, D. K., Rabuck, A. D., Raghavachari, K., Foresman, J. B., Ortiz, J. V., Cui, Q., Baboul, A. G., Clifford, S., Cioslowski, J., Stefanov, B. B., Liu, G., Liashenko, A., Piskorz, P., Komaromi, I., Martin, R. L., Fox, D. J., Keith, T., Al-Laham, M. A., Peng, C. Y., Nanayakkara, A., Challacombe, M., Gill, P. M. W., Johnson, B., Chen, W., Wong, M. W., Gonzalez, C., and Pople, J. A., "Gaussian 03, Revision C.02," Gaussian, Inc., Wallingford, CT, 2004.19

${ }^{68}$ Panerai, F., Martin, A., Mansour, N. N., Sepka, S. A., and Lachaud, J., "Flow-Tube Oxidation Experiments on the Carbon Preform of a Phenolic-Impregnated Carbon Ablator," Journal of Thermophysics and Heat Transfer, 2014, pp. 1-10. 22 26

${ }^{69}$ N., S. D. and Juvet, Jr, R. S., Gas-Liquid Chromatography. Theory and practice, Interscience (Wiley), New York, 1962.

${ }^{70}$ Stone, R. L. and Rase, H. F., "Differential Thermal Analysis. New Technique for Testing Silica-Alumina Catalysts," Analytical Chemistry, Vol. 29, No. 9, 1957, pp. 1273-1277. 26

${ }^{71}$ Kobayashi, K., Sugawara, S., Toyoda, S., and Honda, H., "An X-ray diffraction study of phenol-formaldehyde resin carbons," Carbon, Vol. 6, No. 3, 1968, pp. 359-363. 26

${ }^{72}$ Ouchi, K. and Honda, H., "Pyrolysis of coal I: Thermal cracking of phenolformaldehyde resins taken as coal models," Fuel, Vol. 38, No. 4, 1959, pp. 429-443. 26

73Pope, S. B., "Gibbs function continuation for the stable computation of chemical equilibrium," Combustion and Flame, Vol. 139, No. 3, 2004, pp. 222 - 226. 28

${ }^{74}$ Pope, S., "CEQ: A Fortran library to compute equilibrium compositions using Gibbs function continuation," http://eccentric.mae.cornell.edu/ pope/ceq, 2003. 28

${ }^{75}$ Pope, S., "The Computation of Constrained and Unconstrained Equilibrium Compositions of Ideal Gas Mixtures using Gibbs Function Continuation," Cornell University Report FDA 03-02, 2003. 28

${ }^{76}$ Brezinsky, K., Pecullan, M., and Glassman, I., "Pyrolysis and Oxidation of Phenol," The Journal of Physical Chemistry $A$, Vol. 102, No. 44, 1998, pp. 8614-8619. 34

${ }^{77}$ Cypres, R. and Bettens, B., "Mecanismes de fragmentation pyrolytique du phenol et des cresols," Tetrahedron, Vol. 30, No. 10, 1974, pp. $1253-1260.34$

${ }^{78}$ Khachatryan, L., Adounkpe, J., and Dellinger, B., "Formation of Phenoxy and Cyclopentadienyl Radicals from the Gas-Phase Pyrolysis of Phenol," The Journal of Physical Chemistry A, Vol. 112, No. 3, 2008, pp. 481-487. 34

${ }^{79}$ Lovell, A. B., Brezinsky, K., and Glassman, I., "The gas phase pyrolysis of phenol," International Journal of Chemical Kinetics, Vol. 21, No. 7, 1989, pp. 547-560. 34

${ }^{80}$ Manion, J. A. and Louw, R., "Rates, products, and mechanisms in the gas-phase hydrogenolysis of phenol between 922 and 1175 K," The Journal of Physical Chemistry, Vol. 93, No. 9, 1989, pp. 3563-3574. 34

${ }^{81}$ Roy, K., Horn, C., Frank, P., Slutsky, V. G., and Just, T., "High-temperature investigations on the pyrolysis of cyclopentadiene," Symposium (International) on Combustion, Vol. 27, No. 1, 1998, pp. 329 - 336. 34

${ }^{82}$ Scheer, A. M., Mukarakate, C., Robichaud, D. J., Nimlos, M. R., Carstensen, H.-H., and Ellison, G. B., "Unimolecular thermal decomposition of phenol and d5-phenol: Direct observation of cyclopentadiene formation via cyclohexadienone," The Journal of Chemical Physics, Vol. 136, 2012, pp. 044309. 34

${ }^{83} \mathrm{Xu}$, Z. F. and Lin, M. C., "Ab Initio Kinetics for the Unimolecular Reaction $\mathrm{C}_{6} \mathrm{H}_{5} \mathrm{OH} \rightarrow \mathrm{CO}+\mathrm{C}_{5} \mathrm{H}_{6}$," The Journal of Physical Chemistry A, Vol. 110, No. 4, 2006, pp. 1672-1677. 34

${ }^{84} \mathrm{Zhu}$, L. and Bozzelli, J. W., "Kinetics and Thermochemistry for the Gas-Phase KetoEnol Tautomerism of Phenol $\leftrightarrow$ 2,4-Cyclohexadienone," The Journal of Physical Chemistry A, Vol. 107, No. 19, 2003, pp. 3696-3703. 34

${ }^{85}$ McBride, B. J., Zehe, M. J., and Gordon, S., "NASA Glenn Coefficients for Calculating Thermodynamic Properties of Individual Species," NASA TP-2002-211556, 2002. 42, 43

${ }^{86}$ Gordon, S. and McBride, B. J., "Computer program for calculation of complex chemical equilibrium compositions and applications. I. Analysis." NASA RP-1311, 1994. 43 